\title{
AVALIAÇÃO DA INGESTÃO DE FLÚOR ATRAVÉS DOS DIFERENTES COMPONENTES DA DIETA E DA ESCOVAÇÃO POR CRIANÇAS DE 2-3 ANOS RESIDENTES EM ÁREA FLUORETADA NO BRASIL: IMPACTO NOS NÍVEIS DE FLÚOR NAS UNHAS
}

\section{BEATRIZ SIMÕES DE ALMEIDA}

Dissertação apresentada à Faculdade de Odontologia de Bauru, da Universidade de São Paulo, como parte dos requisitos para obtenção do título de Mestre em Odontologia, área de Saúde Coletiva

(Edição Revisada) 


\section{AVALIAÇÃO DA INGESTÃO DE FLÚOR ATRAVÉS DOS DIFERENTES COMPONENTES DA DIETA E DA ESCOVAÇÃO POR CRIANÇAS DE 2-3 ANOS RESIDENTES EM ÁREA FLUORETADA NO BRASIL: IMPACTO NOS NÍVEIS DE FLÚOR NAS UNHAS}

\section{BEATRIZ SIMÕES DE ALMEIDA}

Dissertação apresentada à Faculdade de Odontologia de Bauru, da Universidade de São Paulo, como parte dos requisitos para obtenção do título de Mestre em Odontologia, área de Saúde Coletiva

(Edição Revisada)

Orientadora: Profa Dra Marília Afonso Rabelo Buzalaf 


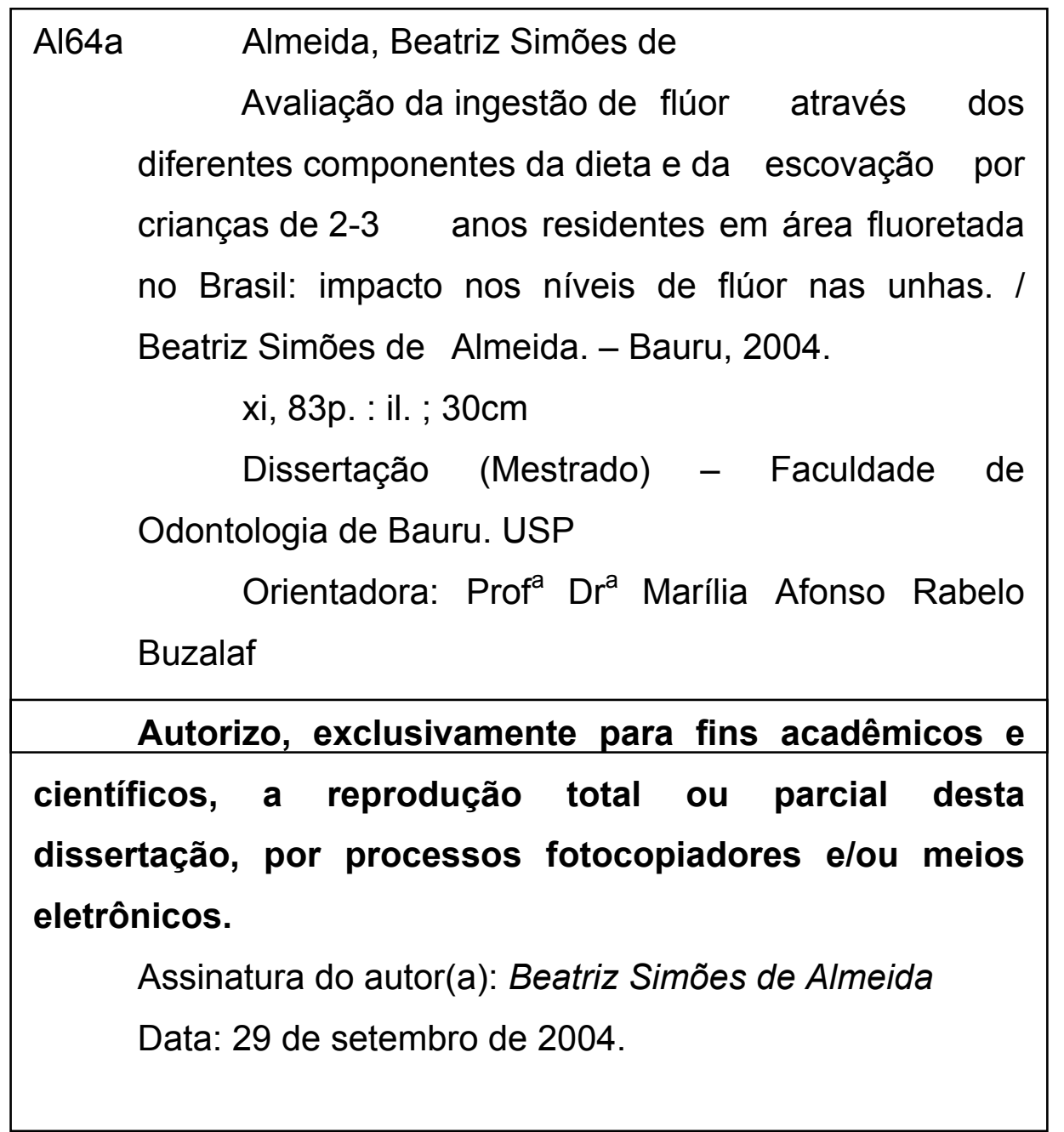




\section{BEATRIZ SIMÕES DE ALMEIDA}

$\begin{array}{ll}09 \text { de fevereiro de } 1978 \text { Nascimento - Tatuí - SP } \\ 1997 \text { - } 2000 & \text { Curso de Odontologia - } \\ & \text { Faculdade de Odontologia de } \\ & \text { Bauru - Universidade de São } \\ & \text { Paulo } \\ & \text { Curso de Aperfeiçoamento em } \\ & \text { Odontologia } \quad \text { Preventiva, } \\ & \text { ministrado na PREV/Assessoria } \\ & \text { e Consultoria S/C Ltda } \\ & \text { Curso de Especialização em } \\ & \text { Odontologia em Saúde Coletiva } \\ & - \text { Associação Paulista de } \\ & \text { Cirurgiões - Dentistas, regional } \\ & \text { Bauru. } \\ & \text { CROSP - Conselho Regional de } \\ \text { Odontologia de São Paulo } & \text { SBPqO - Sociedade Brasileira } \\ \text { Associações } & \text { de Pesquisa Odontológica }\end{array}$


A DEUS, que me deu o dom supremo da vida e me abençoou como sua filha muito amada;

AOS MEUS PAIS, Ângela e Saladino, pelo amor, carinho e apoio em todas as decisões difíceis tomadas em minha vida;

AOS MEUS IRMÃOS, Fabiana, Cristina e Rafael, CUNHADOS, Ronaldo e Marquinho, e SOBRINHOS, Natália, Mateus, Amanda, Gabriel e Isabela, obrigada por formarem esta família maravilhosa que somos. Vocês também me ajudaram muito nesta conquista;

AO BRUNO, que preencheu minha vida com seu amor, carinho, alegria e força, fazendo os momentos difíceis mais leves de serem enfretados;

\section{Dedico este trabalho.}

"Palavras de incentivo proferidas por pais e mães são como interruptores de luz. Dizer uma palavra de incentivo no momento certo na vida de uma criança é como acender a luz de um cômodo repleto de possibilidades."

Gary Smally e John Trent 


\section{Agradecimento Especial}

\section{À Profa Dra MArília AFONSO RABELO}

BUZALAF, pois você é mais que uma orientadora; é um exemplo de pessoa, tanto como profissional dedicada, como no convívio respeitoso com o próximo. Obrigada pelos ensinamentos e pela paciência, por estar sempre nos estimulando nos momentos difíceis e nos proporcionando acesso a tudo que está ao seu alcance. Que Deus a abençoe sempre!

"Um sorriso de incentivo, no momento certo, pode agir como a luz do Sol sobre uma flor em botão; pode ser o fator decisivo para transformar as lutas da vida." Autor desconhecido 


\section{Agradecimentos}

À FACUldADE DE Odontologia DE BAuRu, na pessoa de sua Excelentíssima Diretora, $\operatorname{Prof}^{\mathrm{a}}$. $\mathrm{Dr}^{\mathrm{a}}$. Maria Fidela de Lima Navarro.

Ao Prof. Dr. José Roberto de Magalhães Bastos, pelo apoio durante $\mathrm{o}$ início de meus estudos.

Ao Prof. Dr. José Roberto Pereira LaUris, por contribuir com as análises estatísticas de nossos trabalhos, sempre com muita prontidão.

Aos Professores do Departamento de Odontopediatria, Ortodontia e Saúde Coletiva, Profa. Dra. Nilce Emy Tomita, Prof. Dr. Arsenio Sales Peres e Profa. MS Sílyia Helena de Caryalho Sales Peres, pelo convívio durante esses anos.

Aos colegas de turma, Aline, haroldo, Hilton, IRENe, Kelly, LUCILENE, FABIANO, FAbíola, PRISCILA, RicARdo e Roberta, pelos momentos partilhados.

Aos amigos Helô, VANESSA E Rodrigo, que tanto me ajudaram no desenvolvimento laboratorial deste trabalho.

"Amigo é alguém que compreende seu passado, acredita em seu futuro e o aceita da maneira como vocêé." Autor desconhecido 
Aos funcionários da Saúde Coletiva, Helena, MARTA, Rosa e Silvia, pela ajuda e convívio amistoso.

Aos alunos e funcionários da Bioquímica, THELMA E OVíDIo, pela amizade e orientação nos trabalhos realizados no laboratório, sempre com muito boa vontade.

Aos PAIS, CRIANÇAS E FUNCIONÁRIAS DAS CRECHES que participaram deste estudo, pela valiosa e imprescindível colaboração.

Ao ACAssil José de Oliveira e CAMARgo JúNIOR, Diretor do Colégio Objetivo - Unidade Tatuí, por confiar em meu trabalho e abrir as portas de sua escola para mim.

"Plante uma palavra de amor bem no fundo do coração de uma pessoa. Regue-a com um sorriso e uma oração e veja o que acontece." Max Lucado 


\section{SUMÁRIO}

LISTA DE FIGURAS …...................................................................... vii

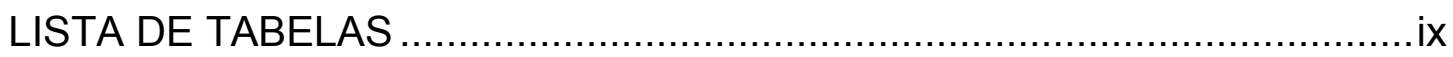

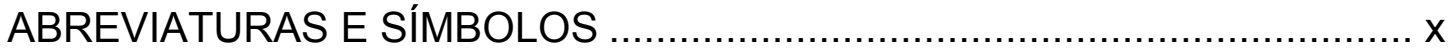

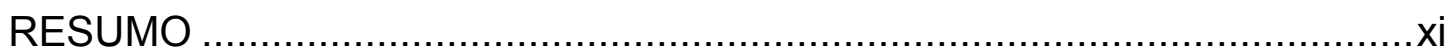

1 INTRODUÇÃO

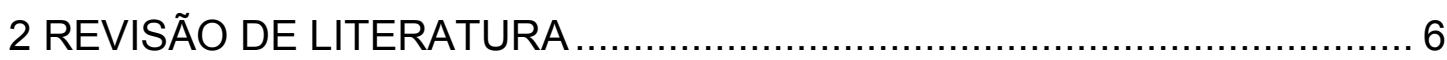

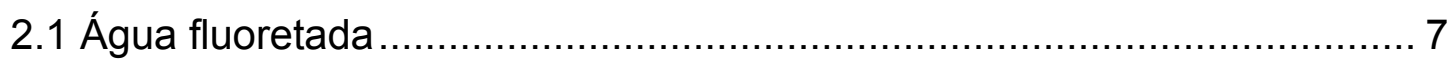

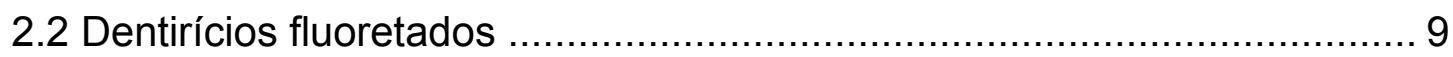

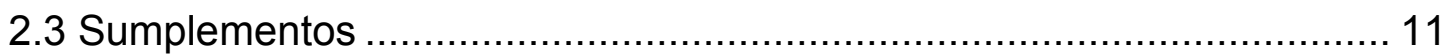

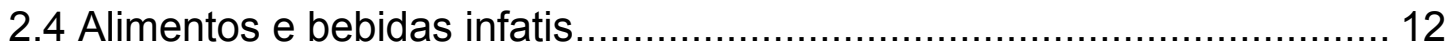

2.4 Unha como biomarcador de exposição crônica ao flúor ......................... 18

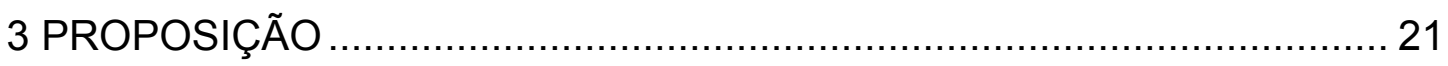

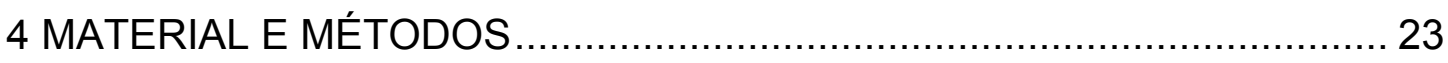

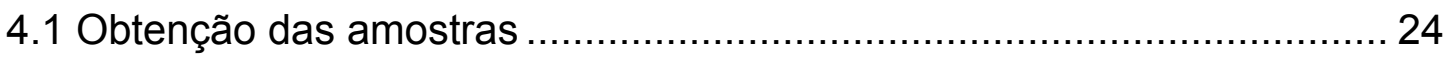

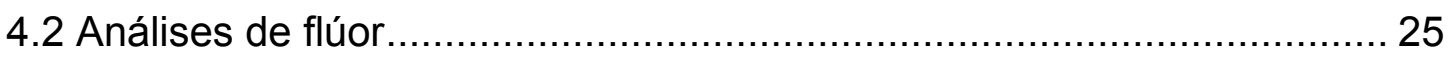

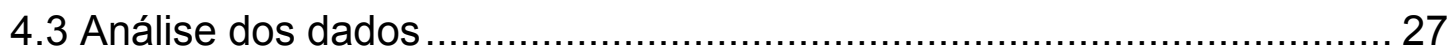

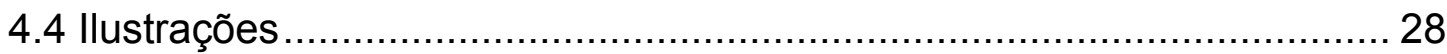

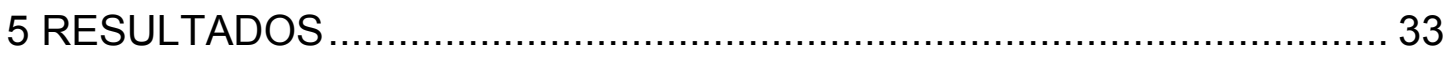

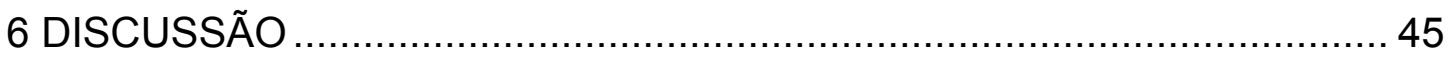

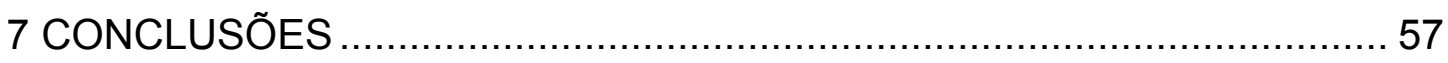

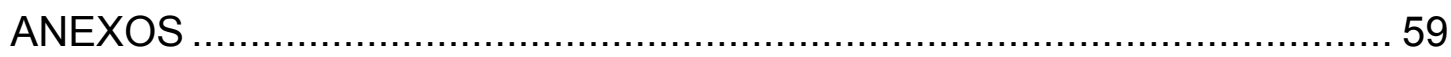

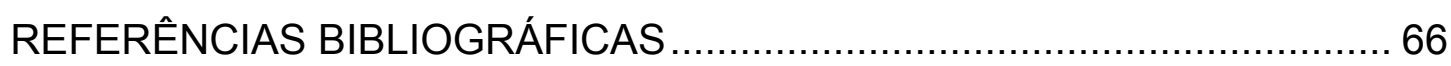

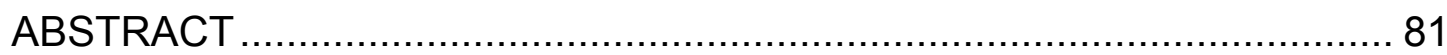

Apêndices 


\section{LISTA DE FIGURAS}

FIGURA 4.1 Placa de Petri vaselinada. Adição das amostras de unhas com $2 \mathrm{~mL}$ de água deionizada .......................................... 30

FIGURA 4.2 Adição de $50 \mu \mathrm{l}$ de $\mathrm{NaOH} 0,05 \mathrm{M}$ na tampa da placa de Petri distribuída em 3 gotas ................................................ 30

FIGURA 4.3 Fechamento das placas e adição de $2 \mathrm{~mL}$ HMDS ............... 31

FIGURA 4.4 Vedamento imediato do orifício com vaselina e parafilme.. 31

FIGURA 4.5 As gotas de $\mathrm{NaOH}$ foram combinadas numa única gota, tamponadas com $25 \mu \mathrm{L}$ de ácido acético e o volume total foi ajustado para $75 \mu \mathrm{L}$ com água deionlzada ......................... 32

FIGURA 4.6 A leitura foi feita com eletrodo Orion 9409 e um micro eletrodo calomelano de referência..................................... 32

FIGURA 5.1 Contribuição do dentifrício e da dieta, em porcentagem, para a ingestão total de flúor 36

FIGURA 5.2 Contribuição dos alimentos sólidos, água e leite, outros líquidos e dentifrício para a quantidade de flúor ingerido pelas crianças $(n=33)$, em porcentagem............................ 38

FIGURA 5.3 Correlação entre a quantidade de dentifrício colocada na escova e a quantidade de $F$ ingerida na escovação 43 


\section{LISTA DE TABELAS}

TABELA 5.1 Dose de flúor ingerido ( $\mathrm{mg} \mathrm{F} / \mathrm{Kg}$ de peso corporal/dia) através da dieta, do dentifrício e o total, de cada criança $(n=33)$

TABELA 5.2 Dose média diária de flúor ingerido através da dieta, do dentifrício e o total (dieta + escovação) pelas crianças $(n=33)$

TABELA 5.3 Quantidade de flúor ingerido através de alimentos sólidos, água e leite e outros líquidos (mg F/dia)

TABELA 5.4 Quantidade de flúor ingerido pelas crianças $(n=33)$ através dos alimentos sólidos, água e leite, outros líquidos e dentifrício ( $\mathrm{mg} \mathrm{F} / \mathrm{dia}$ ).

TABELA 5.5 Quantidade de flúor ingerido ( $\mathrm{mg} F / \mathrm{dia}$ ) a partir da dieta (D) e de cada grupo de alimentos: sólidos (S), leite e água (LA) e outros líquidos (L), coletados no inverno (1) e verão (2), separadamente 39

TABELA 5.6 Quantidade de flúor ingerido (mg F/dia) a partir da dieta coletada num dia de semana (C) e no fim de semana (R).. 40

TABELA 5.7 Concentração de flúor $(\mu \mathrm{g} / \mathrm{g})$ encontrada nas unhas das mãos das crianças $(n=33)$, na primeira, segunda e terceira coletas 40

TABELA 5.8 Concentração de flúor $(\mu \mathrm{g} / \mathrm{mL})$ nas águas das residências das crianças, na primeira e segunda coleta.

TABELA 5.9 Relação dos dentifrícios utilizados pelas crianças, a concentração de flúor $(\mathrm{ppm})$ relatada no rótulo e a concentração (ppm) encontrada

TABELA 5.10 Quantidade de dentifrício utilizada (g), flúor total utilizado (mg) e flúor ingerido $(\mathrm{mg})$ por escovação 


\section{LISTA DE ABREVIATURAS E SÍMBOLOS}

\begin{tabular}{ll} 
ANOVA & análise de variância \\
CDTA & ácido ciclo-hexano diamino tetra acético \\
DP & desvio padrão \\
F & flúor \\
g & grama \\
HMDS & Hexametil-disilazano ou hexametil disiloxano \\
IC & intervalo de confiança \\
Kg & Kilograma \\
M & molar \\
mg & miligrama \\
mL & mililitro \\
mm & milímetro \\
$\mu g$ & micrograma \\
NIH & National Institute of Health \\
p & nível de significância \\
ppm & parte por milhão \\
r & coeficiente de correlação \\
TISAB & "total ionic exchange adjustment buffer" \\
TF & Índice de Thylstrup e Fejerskov \\
\hline
\end{tabular}




\section{RESUMO}

A prevalência de fluorose dentária vem aumentando devido, principalmente, a quatro fatores: água fluoretada, dentifrícios fluoretados, suplementos e alimentos manufaturados. Sendo assim, muitos estudos avaliam a ingestão diária de flúor em crianças na idade de risco para fluorose dentária. Neste estudo, foi realizada a estimativa da ingestão de flúor a partir da escovação e da dieta. Porém, esta foi analisada separando os alimentos em 3 grupos: sólidos, leite e água, e os outros líquidos. Além disso, foram coletadas unhas, visando seu uso como biomarcador de exposição crônica ao flúor. Participaram 33 crianças na idade de 2-3 anos. O método da dieta duplicada foi realizado para sua coleta em duas estações do ano (inverno e verão) e em dois dias da semana (durante a semana e fim de semana). Houve também coleta de amostras da água consumida pelas crianças no mesmo período da dieta. As unhas das mãos foram coletadas em 3 momentos. As análises da concentração de flúor da dieta, dentifrício, escovação e unhas foram feitas com eletrodo específico (Orion 9409), após difusão facilitada por HMDS. A média ( $\pm D P)$ da ingestão de flúor a partir da dieta e da escovação foi de 0,025 $\pm 0,013$ e 0,106 $\pm 0,085 \mathrm{mg} \mathrm{F} / \mathrm{Kg}$ peso/dia, respectivamente, totalizando $0,13 \mathrm{mg} \mathrm{F} / \mathrm{Kg}$ peso/dia. Houve correlação positiva ( $\mathrm{r}=0,971$; $p<0,0001)$ entre a quantidade de dentifrício utilizada $(0,488 \pm 0,303 \mathrm{~g})$ e a de flúor ingerido por escovação $(0,591 \pm 0,445 \mathrm{mg})$. Dentre os grupos de alimentos, o leite e a água tiveram uma contribuição maior $(0,184 \pm 0,108$ $\mathrm{mg} F /$ dia; $p<0,0001)$ em relação aos alimentos sólidos $(0,072 \pm 0,045 \mathrm{mg}$ F/dia) e aos outros líquidos $(0,066 \pm 0,043 \mathrm{mg} F / d i a)$. Não houve correlação entre a dose diária de flúor ingerido e a concentração de flúor da unhas das mãos ( $r=-0,052, p=0,810)$. Tais resultados indicam que a dose diária de flúor ingerido pelas crianças representa um risco para fluorose dentária. $O$ dentifrício sozinho é responsável por $80 \%$ da ingestão de flúor, enquanto que o leite e a água são os maiores contribuintes dentre os constituintes da dieta. Pequenas variações na ingestão diária de flúor não alteram as concentrações de flúor das unhas das mãos. 


\section{INTRODUÇÃO}

"Sempre é cedo demais para desistir.

Nunca é tarde demais para começar'

Anônimo 


\section{INTRODUÇÃO}

O efeito terapêutico do flúor no controle da cárie dentária é aceito por toda a comunidade científica. Tal efeito foi notado primeiramente por McKay, no início dos anos de 1900 (McKAY ${ }^{91}$, 1928). Ele observou que as pessoas de Colorado Springs que apresentavam fluorose, na época chamada de "mottled enamel", não possuíam cáries. Suspeitava-se de que sua causa fosse uma substância encontrada na água de abastecimento que seria incorporada ao esmalte dentário durante seu desenvolvimento, mas não se sabia que tal substância era o flúor. Em seguida, o flúor foi detectado como a substância que causava tal efeito protetor e estava presente naturalmente na água de abastecimento de Colorado Springs. Posteriormente, DEAN et al. ${ }^{39}$, (1941) e DEAN et al. ${ }^{40}$, (1942) observaram que o flúor existia naturalmente na água de várias regiões dos Estados Unidos em diversas concentrações, e que níveis próximos de $1 \mathrm{ppm}$ de flúor na água produziam o melhor efeito de proteção de cáries em relação à prevalência de fluorose dentária. Em vista do efeito do flúor na prevenção das cáries, em 1945, o flúor foi adicionado à água de abastecimento de Grand Rapids, Michigan. Desde então, o método de fluoretação da água de abastecimento disseminou-se pela América do Norte (WARREN; LEVY ${ }^{138}$, 1999).

Inicialmente, acreditava-se que o efeito terapêutico do flúor na prevenção de cárie era sistêmico. Sendo assim, foram desenvolvidos diversos métodos como a fluoretação da água de abastecimento e suplementos. Atualmente, sabe-se que o efeito do flúor não é somente préeruptivo, mas principalmente pós-eruptivo, através da aplicação tópica (BURT; EKLUND ${ }^{14}$, 1999). Contudo, uma pequena ingestão de flúor através da utilização de alguns métodos de aplicação tópica de flúor, como os dentifrícios fluoretados, é inevitável.

O consumo excessivo de flúor durante o período de desenvolvimento dos dentes pode causar fluorose dentária $\left(\mathrm{DEAN}^{38}, 1934\right.$; DEAN et al. ${ }^{40}$, 1942), resultando num esmalte hipomineralizado, com maior porosidade (FEJERSKOV; MANJI; BAELUM ${ }^{45}$, 1990). 
A prevalência de fluorose dentária tem aumentado tanto em regiões fluoretadas quanto em regiões não fluoretadas (JACKSON et al. ${ }^{68}$, 1999; LEVERETT $^{77}$, 1986; TABARI et al. ${ }^{130}$, 2000; TSUTSUI et al. ${ }^{134}$, 2000) em muitos países, assim como no Brasil (CANCUSSU et al. ${ }^{27}$, 2002; PEREIRA et al. $\left.{ }^{109}, 2000\right)$. Este evento levou muitos pesquisadores a estudarem as razões para esse aumento e seus principais fatores de risco (OSUJI et al. ${ }^{99}$, 1988; PENDRYS; KATZ; MORSE ${ }^{105}$, 1994; PENDRYS; KATZ ${ }^{104}$, 1989; PENDRYS; KATZ; MORSE ${ }^{107}$, 1996; WANG; GROPEN; OGAARD ${ }^{137}$, 1997; PENDRYS ${ }^{106}$, 1995; SKOTOWISKI; HUNT; LEVY ${ }^{126}$, 1995; GRIMALDO et al. ${ }^{56}$, 1995; LALUMANDIER; ROZIER ${ }^{75}$, 1995).

O fator de risco mais importante para fluorose dentária é a quantidade de flúor ingerida proveniente de todas as fontes, durante o período crítico de formação do dente (DEAN et al. ${ }^{40}$, 1942; DENBESTEN ${ }^{41}$, 1999; EVANS ${ }^{42}$, 1991; MASCARENHAS ${ }^{89}$, 2000). Para os incisivos centrais superiores permanentes, que são os dentes de maior importância estética, o período crítico parece ser entre 15 a 24 para os meninos e 21 a 30 para as meninas (EVANS; DARVELL ${ }^{43}$, 1995). Contudo, de acordo com BARDSEN ${ }^{4}$, (1999) um período de mais de dois anos de exposição ao flúor durante os quatro primeiros anos de vida aumenta o risco de desenvolvimento de fluorose nos incisivos superiores. Em relação à dose diária máxima permitida para risco de fluorose dentária, há uma controvérsia na literatura. Alguns autores relatam que esta dose seja $0,1 \mathrm{mg} \mathrm{F} / \mathrm{Kg}$ de peso (FORSMAN ${ }^{49}$, 1977). Outros observaram fluorose dentária com uma ingestão menor que 0,02 mg F/ Kg de peso (BAELUM ${ }^{3}$, 1987). Estima-se que uma ingestão entre 0,05 e $0,07 \mathrm{mg} \mathrm{F} / \mathrm{Kg}$ de peso por dia, seja a dose considerada aceitável (BURT ${ }^{13}$, 1992).

O aumento da prevalência de fluorose dentária está associado ao fato de o flúor estar amplamente distribuído para a população. Estudos sobre fluorose dentária têm encontrado quatro fatores de risco maiores, como o consumo de água fluoretada, suplementos, dentifrícios fluoretados e fórmulas infantis (MASCARENHAS $\left.{ }^{89}, 2000\right)$. Alguns alimentos e bebidas infantis manufaturados também podem contribuir significativamente com a 
ingestão total diária de flúor (BUZALAF et al. ${ }^{18}, 2001$; BULAZAF et al. ${ }^{22}$, 2002). Em vista disso, vários estudos foram conduzidos, avaliando a ingestão de flúor através dos fatores já citados, principalmente em crianças na faixa etária de risco para fluorose dentária (OPHAUG, SINGER; HARLAND ${ }^{99}$, 1985; LEVY et al. ${ }^{81}$, 1995; LEVY; MAURICE; JAKOBSEN ${ }^{79}$, 1993; CLOVIS; HARGREAVES ${ }^{34}$, 1988; LEVY et al. ${ }^{84}$, 2001; GUHACHOWDHURY; DRUMMOND; SMILLIE ${ }^{57}$, 1996; CHOWDHURY, BROWN; SHEPHERD ${ }^{31}$, 1990; KIMURA et al..$^{69}$, 2001; CHITTAISONG et al. ${ }^{30}, 1995$; LIMA; CURY ${ }^{86}$, 2001; BUZALAF et al. ${ }^{25}$, 2004; PESSAN; SILVA; BUZALAF $^{111}$, 2003). No entanto, estes estudos relatam principalmente a ingestão de flúor a partir da dieta e da escovação, sendo que não se separam os diferentes constituintes da dieta em relação ao seu teor de flúor.

Uma forma alternativa de se estimar a ingestão total de flúor por crianças é o emprego de biomarcadores de exposição a ele. Os marcadores biológicos ou biomarcadores são definidos como indicadores que sinalizam eventos em sistemas biológicos ou amostras (COMMITTEE ON BIOLOGICAL MARKERS OF THE NATIONAL RESEARCH COUNCIL ${ }^{35}$, 1987). Um biomarcador não é usado como um teste para diagnóstico, mas como um indicador de uma alteração que poderia levar a uma doença clínica (GRANDJEAN ${ }^{55}$, 1995).

Num Simpósio realizado pelo $\mathrm{NIH}$, em Bethesda, Maryland, EUA, em 1999, foi estabelecida uma agenda internacional de necessidades de pesquisa envolvendo flúor. Entre os tópicos, estava o desenvolvimento de biomarcadores que sejam de fácil coleta e análise, para se determinar a atividade do $\mathrm{F}$ após um tempo específico de sua administração e para se medir a exposição aguda e crônica ao $F\left(C^{2}\right.$ ARKSON $\left.{ }^{33}, 2000\right)$. Entre estes possíveis biomarcadores estão as unhas (WHITFORD et al. ${ }^{141}$, 1999; ARSATI ${ }^{1}$, 2003; RODRIGUES; BASTOS; BUZALAF ${ }^{120}$, 2004; LEVY; BASTOS; BUZALAF ${ }^{85}$, 2004; FUKUSHIMA et al. ${ }^{50}$, 2004; BUZALAF et al. ${ }^{23}$, 2004)

Deste modo, um estudo enfocando o uso da unha como um possível biomarcador da ingestão crônica de flúor por crianças na faixa etária de risco 
para a fluorose dentária e uma avaliação detalhada desta ingestão, através da contribuição individual de diferentes componentes da dieta, bem como da escovação, reveste-se de grande importância. 
"A riqueza da experiência humana perderia uma certa alegria recompensadora se não houvesse limites a superar." Helen Keller 


\section{REVISÃO DE LITERATURA}

Estudos sobre fluorose dentária têm encontrado quatro fatores de risco maiores, como o consumo de água fluoretada, suplementos, dentifrícios fluoretados e fórmulas infantis (MASCARENHAS ${ }^{89}, 2000$ ). Alguns alimentos e bebidas infantis manufaturados também podem contribuir significativamente com a ingestão total diária de flúor (BUZALAF et al. ${ }^{18}$, 2001; BULAZAF et al. ${ }^{22}$, 2002). A seguir faremos uma breve revisão sobre tais fatores.

\section{1 Água fluoretada}

Em vista do efeito do flúor na prevenção das cáries, em 1945, o flúor foi adicionado à água de abastecimento de Grand Rapids, Michigan. Desde então, o método de fluoretação da água de abastecimento disseminou-se pela América do Norte (WARREN; LEVY $\left.{ }^{138}, 1999\right)$ ). No Brasil, iniciou-se em 1953, na cidade de Baixo Guandu - ES (FERREIRA ${ }^{46}$, 1999). Em 1974, foi promulgada a lei 6.050 , que dispõe sobre a fluoretação da água quando houver sistema de tratamento (GEISEL; MACHADO ${ }^{52}$, 1974). O decreto 76.872 de 22 de dezembro de 1975 regulamenta a lei mencionada anteriormente (GEISEL; MACHADO; REIS ${ }^{53}$, 1975). Em 1996, 71,23\% da população brasileira que recebia água tratada consumia também água fluoretada. No Estado de São Paulo, cerca de 92\% dos municípios com água tratada também contavam com a fluoretação (BRASIL $\left.{ }^{9}, 1996\right)$. Atualmente, ainda restam 2000 cidades que possuem estação de tratamento de água, mas não têm o sistema de fluoretação das águas implantado. A meta é que todos os municípios do país atendam essa proposta até 2006 (BRASIL SORRIDENTE $\left.{ }^{11}, 2004\right)$.

A prevalência de fluorose dentária no Brasil, segundo levantamento realizado em 2003, em crianças de 12 anos de idade, utilizado o índice de Dean é de $8,56 \%$. Na região Sudeste esta prevalência é de $13,45 \%$, a maior de todas as regiões do país. $\left(\mathrm{BRASIL}^{10}, 2004\right)$ 
O CDC (Centers for Disease Control ${ }^{28}$, 1991) recomenda que a fluoretação da água de abastecimento público seja mantida em níveis ótimos e, levando-se em consideração a ingestão total de flúor a partir de todas as fontes, seja mantido um nível de ingestão que garanta o benefício da prevenção da cárie dentária e ofereça um risco mínimo de fluorose dentária. A fluoretação da água continua sendo um método eficaz e efetivo, mesmo em regiões onde a prevalência de cárie tem diminuído e onde o custo de implementação do método é maior (O'MULANE ${ }^{98}, 1990$ ).

DEAN et al. ${ }^{40}$ (1942) verificaram que níveis próximos de 1 ppm de flúor nas águas de abastecimento proporcionavam o melhor efeito contra as cáries e o menor nível de fluorose, com apenas 10 a $12 \%$ da população apresentando fluorose muito leve.

De acordo com SELWITZ et al. ${ }^{124}$ (1995), avaliaram a diferença na prevalência de fluorose dentária em regiões otimamente fluoretadas e superfluoretadas, durante os anos de 1980, 1985 e 1990. Os autores observaram que, nas regiões otimamente fluoretadas, houve um aumento na prevalência de fluorose entre os anos de 1980 e 1985, que não continuou entre 1985 e 1990. Já nas regiões superfluoretadas a prevalência de fluorose permaneceu estável ou teve aumentos insignificantes. Segundo ROZIER $^{51}$ (1999), a prevalência de fluorose em regiões com menos de 0,3 ppm de flúor na água de abastecimento tem aumentado.

Por outro lado, alguns autores afirmam que a prevalência de fluorose dentária está relacionada com a concentração de flúor na água. HANDAM ${ }^{58}$ (2003) observou um aumento na prevalência de fluorose dentária à medida que aumentava a concentração de flúor na água de abastecimento, em diferentes regiões da Jordânia. RIORDAN; BANKS ${ }^{116}$ (1991) observaram um maior risco de fluorose dentária em regiões fluoretadas, durante os primeiros quatro anos de vida. ISMAIL et $\mathrm{al}^{66}$. (1993), TABARI et $\mathrm{al}^{130}$. (2000) e STEPHEN et al $^{129}$. (2002), também verificaram maior prevalência em região fluoretada em relação a regiões não fluoretadas. JACKSON et al ${ }^{67}$. (1995) observaram que, em regiões com mais de 1 ppm de flúor, o risco de fluorose dentária é maior em relação a regiões subfluoretadas, enquanto que 
BOTTENBERG et $\mathrm{al}^{8}$. (2004) verificaram que o consumo de água fluoretada acima de 0,7 ppm já representava um fator de risco para fluorose dentária.

Além disto, tem-se relatado que o aumento na concentração de flúor na água resulta numa maior prevalência e severidade das lesões fluoróticas (HELLER; EKLUND; BURT ${ }^{62}$, 1997). Alguns estudos na literatura avaliaram o efeito da interrupção da fluoretação da água de abastecimento público na prevalência de fluorose dentária. BURT; KEELS; HELLER ${ }^{15}$ (2000) analisaram o impacto de uma interrupção não planejada de 11 meses na fluoretação da água de Durham, Carolina do Norte. Foi concluído que a fluorose dentária é sensível a pequenas alterações no nível de flúor na água, principalmente nas idades de 1 a 3 anos, em relação às idades de 4 e 5 anos. No entanto, num estudo subseqüente, (BURT et al. ${ }^{16}, 2003$ ) a prevalência de fluorose, que se esperava aumentar na coorte examinada posteriormente, permaneceu estável, mesmo após a volta da fluoretação. Os autores sugeriram que o período de interrupção não foi longo suficiente para reduzir a prevalência de fluorose. Opondo-se a estes resultados, estão os dados observados por BUZALAF et $a^{24}$. (2004) em Jaú - SP, onde o período de interrupção na fluoretação da água perdurou por sete anos e a prevalência de fluorose foi menor nas coortes que consumiram água fluoretada, em comparação às que não receberam água fluoretada durante o período de risco para fluorose dentária. Sendo assim, os autores sugerem que a água fluoretada não seja um importante fator de risco para fluorose dentária. Provavelmente, a água fluoretada tenha seu maior impacto na prevalência de fluorose indiretamente, através de seu uso no preparo de fórmulas infantis e outros alimentos e bebidas para crianças $\left(B U R T^{13}, 1992\right)$.

\subsection{Dentifrícios Fluoretados}

A associação entre o uso precoce de dentifrícios fluoretados e a prevalência de fluorose dentária está amplamente relatada na literatura, tanto em regiões fluoretadas quanto em regiões não fluoretadas (EVANS ${ }^{42}$, 1991; MASCARENHAS; BURT ${ }^{88}$, 1998; OSUJI et al. ${ }^{100}$, 1988; MILSON; 
MITROPOULUS ${ }^{93}$, 1990; WARREN; LEVY ${ }^{138}$, 1999; PEREIRA et al ${ }^{109}$., 2000; WANG; GROPEN; OGAARD $\left.{ }^{137}, 1997\right)$.

No estudo realizado por OSUJI et al $^{100}$. (1988), numa região fluoretada, foi observado que as crianças que iniciaram a escovação antes dos 25 meses tinham 11 vezes mais chance de desenvolver fluorose quando comparadas àquelas que iniciaram a escovação mais tarde. PEREIRA et $\mathrm{al}^{109}$. (2000) encontraram um risco de fluorose dentária 4,43 vezes maior para crianças que escovavam os dentes antes dos três anos de idade, numa cidade não fluoretada. BUZALAF et $\mathrm{al}^{21}$. (2002) também encontraram resultados confirmando a correlação positiva entre o início precoce a escovação com dentifrício fluoretado e a prevalência de fluorose. PENDRYS; KATZ; MORSE ${ }^{107}$ (1996), encontraram uma forte associação entre fluorose e freqüência de escovação maior que uma vez ao dia, até os dois anos de idade, também numa população que não consumia água fluoretada.

Em 1989/90, na Austrália, observou-se que o uso de dentifrícios fluoretados e suplementos eram fatores de risco para fluorose dentária. Então, foram tomadas algumas medidas para desestimular o consumo de suplementos e a ingestão de dentifrícios, além de promover a utilização de dentifrícios com baixa concentração de flúor para crianças menores de 6 anos. Comparando-se dados de levantamento realizados em 1989/90 e 2000, os autores concluíram que a prevalência de fluorose, assim como o consumo de suplementos e ingestão de dentifrícios foi reduzido, sem haver um aumento na cárie dentária. Como os dentes examinados em 2000 estavam no período crítico para fluorose em 1992-95, logo após aquelas medidas serem tomadas, os autores esperam que os dentes mineralizados no final dos anos 90 apresentem um resultado melhor (RIORDAN ${ }^{119}$, 2002).

O uso precoce de dentifrícios não está associado somente à prevalência, mas também a uma maior severidade de fluorose dentária. MASCARENHAS; BURT ${ }^{88}$ (1998) observaram, entre as crianças que possuíam fluorose, maior severidade naquelas que iniciaram o hábito da escovação antes dos dois anos de idade. Já RIORDAN ${ }^{117}$ (1993) encontrou 
maior severidade de fluorose entre crianças que começaram a escovação antes dos 9 meses de idade e entre as que deglutiam dentifrícios.

Outras variáveis relacionadas ao uso de dentifrícios e risco de fluorose são a freqüência das escovações (BOTTENBERG et al. ${ }^{8}, 2004$ ), a quantidade de dentifrício utilizada e a quantidade ingerida durante as escovações (RICHARDS; BANTING $\left.{ }^{115}, 1996\right)$.

O uso de dentifrícios fluoretados com sabores especiais para crianças leva a um consumo em maiores quantidades em relação aos demais dentifrícios, podendo esse ser um fator agravante para crianças na idade de risco para fluorose dentária (LEVY, MAURICE; JAKOBSEN ${ }^{78}$, 1992). Outro fator importante é que crianças mais jovens ainda não possuem um reflexo de expectoração adequado, sendo necessário que os dentistas orientem os pais quanto ao risco de fluorose dentária e ao uso de pequenas quantidades de dentifrício durante a escovação (LEVY, MAURICE; JAKOBSEN ${ }^{79}$, 1993; NOURJAH; HOROITZ; WAGENER ${ }^{97}$, 1994). RIORDAN ${ }^{117}$ (1993) encontrou associação entre prevalência de fluorose e apreciação do sabor do dentifrício.

Dentifrícios com baixas concentrações de flúor para crianças menores têm sido desenvolvidos em vários países (BELTRAN; SZPUNAR ${ }^{7}, 1988$; HOROWITZ ${ }^{64}$, 1992) como uma alternativa para diminuir a ingestão de flúor. No entanto, a segurança e eficácia na prevenção da cárie dentária devem ser garantidas. Vários estudos clínicos longitudinais têm sido desenvolvidos a fim de se avaliar a efetividade dos dentifrícios de baixa concentração de flúor. Alguns deles não encontraram diferenças significativas entre o padrão (1000 - 1100ppm) e dentifrícios de baixa concentração de flúor (250-550 ppm) (FORSMAN ${ }^{48}$, 1974; KOCH et al. ${ }^{70}$, 1982; WINTER et al. ${ }^{142}$, 1989; GERDIN $^{54}$, 1974). Já, REED ${ }^{114}$ (1973), MITROPOULOS et al ${ }^{94}$. (1984) e $\mathrm{KOCH}$ et al $^{71}$. (1990) afirmam que dentifrícios de baixa concentração de flúor parecem ser menos efetivos em comparação aos que contêm 1000 ppm. AMMARI et al. $^{2}$ (2003), numa revisão sistemática, relatam que os estudos disponíveis na literatura permitem afirmar que os dentifrícios com 250 ppm são menos efetivos que aqueles contendo 1000 ppm. No entanto, para os 
dentifrícios com concentração em torno de 500 ppm, são necessários mais estudos.

\subsection{Suplementos}

O consumo de suplementos fluoretados tem sido considerado com um fator de risco para fluorose dentária, tanto em regiões fluoretadas (KUMAR et al. $^{73}$, 1989; PENDRYS; KATZ; MORSE ${ }^{105}$, 1994, PENDRYS; KATZ ${ }^{108}$, 1998) quanto em regiões não fluoretadas (HOLT et al. ${ }^{63}$, 1994; JACKSON et al. $^{68}$, 1999; KUMAR et al. $^{73}$, 1989; KUMAR; SWANGO ${ }^{74}$, 1999; LALUMANDIER; ROZIER ${ }^{75}$, 1995; PENDRYS; KATZ ${ }^{104}$, 1989; PENDRYS; KATZ; MORSE ${ }^{107}$, 1996; WANG; GROPEN; OGAARD ${ }^{137}$, 1997, ISMAIL et al. $^{65}$, 1990; BOTTENBERG et al ${ }^{8}$., 2004; CLARK; BERKOWITZ ${ }^{32}$, 1997). O uso de suplementos deveria ser mais conservador, considerando todas as fontes de água fluoretada, de abastecimento ou mineral (LEVY, MAURICE; JAKOBSEN $^{80}$, 1993; TOUMBA; CURZON ${ }^{132}$, 1994, LEVY et al. ${ }^{82}$, 1995), restrito para crianças de alto risco à cárie e com baixa ingestão de flúor através de outras fontes (LEVY; KIRITSY; WARREN ${ }^{83}$, 1995). Segundo BROTHWELL; LIMEBACK ${ }^{12}$, (1999), suplementos não deveriam ser recomendados, a menos que seja feita uma análise do teor de flúor da água da residência. No entanto, LEVY et $a^{81}$. (1995) afirmam que somente a concentração de flúor na água pode não ser mais apropriada como parâmetro na indicação de suplementos, e que outras fontes deveriam ser levadas em consideração. De acordo com FOMON; EKSTRAND; ZIEGLER ${ }^{47}$ (2000) suplementos não deveriam ser prescritos na primeira infância e deveria haver critérios mais rigorosos para sua administração a crianças. RIORDAN $^{118}$ (1993) propõe que a recomendação de suplementos de flúor seja direcionada somente para pessoas de alto risco à cárie, começando com a idade mínima de 6 meses, na forma de pastilhas para maximizar o efeito tópico, com a concentração máxima de $0,50 \mathrm{mg}$ para reduzir o risco de fluorose e superdosagem e não ter um limite máximo de idade recomendada, já que a cárie pode ocorrer em qualquer idade, além de um novo esquema de dosagem. 


\subsection{Alimentos e bebidas infantis}

Segundo LEVY; MAURICE; JAKOBSEN ${ }^{80}$ (1993) somente $85 \%$ e $2 \%$ das crianças aos 6 e 9 meses, respectivamente, eram amamentadas, e aos 12 meses, $75 \%$ consumiam fórmulas infantis. O leite humano apresenta baixos teores de flúor, em torno de 0,019 ppm e o leite de vaca, 0,022 ppm (KOPARAL; ERTUGRUL; OZTEKIN ${ }^{72}$, 2000). RAHUL; HEDGE; MUNSHI ${ }^{112}$ (2003) encontraram uma concentração média de 0,08 ppm $F$ no leite humano e de 0,12 ppm $\mathrm{F}$ no leite de vaca.

A concentração de flúor em fórmulas infantis apresenta grandes variações. Das fórmulas infantis em pó comercializadas no Brasil, BUZALAF et $\mathrm{al}^{17}$. (2001) encontraram uma concentração de 0,01 a 0,75 ppm, quando preparadas com água deionizada, 0,91 a 1,65 ppm, com água de abastecimento e de 0,02 a 1,37 ppm quando preparadas com água mineral. Na Austrália, SILVA; REYNOLDS ${ }^{125}$ (1996) encontraram uma concentração de 0,031 a $0,532 \mathrm{ppm}$ para as fórmulas preparadas com água sem flúor. $\mathrm{Na}$ Tailândia, foram encontrados valores de 0,14 a $0,64 \mu \mathrm{g} / \mathrm{g}$ e no Japão, de 0,37 a $1 \mu \mathrm{g} / \mathrm{g}$ (CHITTAISONG et al. $\left.{ }^{30}, 1995\right)$. LATIFAH; RAZAK ${ }^{76}$ (1989) analisaram fórmulas infantis da Malásia e observaram que a concentração de flúor foi de 0,100 a $0,158 \mathrm{ppm}$, quando preparadas com água deionizada, e de 0,346 a 0,395 ppm, com água fluoretada a 0,379 ppm. No estudo realizado por VAN WINKLE ${ }^{135}$ (1995), as fórmulas prontas para beber, concentradas líquidas e em pó apresentaram 0,30, 0,24 e 0,24 ppm de flúor, respectivamente, todas preparadas com água deionizada. Na Índia, RAHUL; HEDGE; MUNSHI ${ }^{112}$ (2003) encontraram fórmulas infantis com concentrações entre 1,95 ppm e 7,45 ppm, também preparadas com água deionizada.

As fórmulas infantis à base de soja apresentam um teor mais alto de flúor (BUZALAF et al. ${ }^{17}$, 2001; LATIFAH; RAZAK ${ }^{76}$, 1989; McKNIGHTHANES et al. ${ }^{92}$, 1988; SILVA; REYNOLDS ${ }^{125}$, 1996; RAHUL; HEDGE; MUNSHI $\left.{ }^{112}, 2003\right)$. No estudo de LATIFAH; $\operatorname{RAZAK}^{76}$ (1989), as fórmulas à base de soja apresentaram de 0,236 a $0,438 \mathrm{ppm}$, quando preparadas com 
água deionizada, e de 0,447 a 0,473, quando preparadas com água a 0,379 ppm F. Segundo SILVA; REYNOLDS ${ }^{125}$ (1996), o consumo das fórmulas à base de soja analisadas proporcionaria uma dose de flúor acima do limite de $0,07 \mathrm{mg} \mathrm{F} / \mathrm{kg}$ de peso corporal, em crianças de 1 mês. Esses resultados estão de acordo com os estudos de BUZALAF et al. ${ }^{17}$ (2001) e McKNIGHTHANES et al. ${ }^{92}$ (1988).

É importante salientar que a maioria das fórmulas infantis, quando preparadas com água otimamente fluoretada, proporcionam uma ingestão diária de flúor acima da dose recomendada de 0,05 a 0,07 $\mathrm{mg} \mathrm{F} / \mathrm{kg}$ de peso corporal (BUZALAF et al. ${ }^{17}$, 2001; LATIFAH; RAZAK ${ }^{76}$, 1989; McKNIGHTHANES et al. ${ }^{92}$, 1988; SILVA; REYNOLDS ${ }^{125}$, 1996; BUZALAF et al. ${ }^{25}$, 2004).

No Brasil, BUZALAF et al. ${ }^{17}$ (2001) analisaram o teor de flúor em 9 marcas comerciais de leite em pó, preparados com água deionizada, mineral e de abastecimento público, e relacionaram-no com a ingestão diária de flúor. A água de abastecimento público apresentou 0,9 ppm. As águas minerais variaram de 0,02 a 0,69 ppm de flúor. Nas fórmulas infantis, a concentração de flúor variou de 0,01 a 0,75 ppm, de 0,91 a 1,65 ppm e de 0,02 a 1,37 ppm, quando preparadas com água deionizada, água de abastecimento público e água mineral, respectivamente. Quando reconstituídas com água deionizada, somente uma fórmula à base de soja (Nestogeno Soy) poderia levar a uma ingestão diária maior que 0,07 mg F/kg de peso corporal, para crianças de 12 meses. Para crianças de 1 mês, seu consumo proporcionaria uma ingestão de flúor próxima de 0,1 mg F/kg de peso corporal. Quando reconstituída com água de abastecimento público, a ingestão de flúor seria de 0,097 a 0,247 mg F/dia, o que está acima da dose máxima recomendada. Os autores recomendam a utilização de água mineral não fluoretada para o preparo de leites em pó.

Num estudo posterior de BUZALAF et al. ${ }^{25}$ (2004) foram analisadas 4 marcas americanas de fórmulas infantis, preparadas com água deionizada, e outras 5 diferentes marcas de água mineral. A concentração de flúor variou de 0,076 a 0,214 ppm e de 0,092 a 1,053 ppm para as fórmulas preparadas 
com água deionizada e mineral, respectivamente. Quando preparadas com água deionizada, nenhuma das fórmulas atingiu a dose máxima recomendada $(0,07 \mathrm{mg} \mathrm{F} / \mathrm{Kg} / \mathrm{dia})$. Porém, quando preparadas com algumas águas minerais, contendo de 0,623 a 0,839 ppm de flúor, todas as fórmulas ultrapassaram a dose máxima recomendada. Os autores recomendam que algumas marcas de águas minerais comercializadas para o consumo infantil não sejam utilizadas para diluir fórmulas infantis.

As águas minerais normalmente apresentam baixa concentração de flúor, sendo seu uso, portanto, indicado no preparo de fórmulas infantis concentradas (CHAN; STARK; JESKE, ${ }^{29}$ 1990; STANNARD et al. ${ }^{128}$, 1990; WEINBERGER ${ }^{139}$, 1991; TOUMBA; CURZON ${ }^{132}$, 1994; VAN WINKLE et al. $^{135}$, 1995; VILLENA et al. $^{136}$, 1996; BUZALAF et al. ${ }^{17}, 2001$; RAMIRES et al. $\left.^{113}, 2004\right)$

Os hábitos alimentares das crianças mudaram substancialmente nas últimas décadas. FOMON; EKSTRAND; ZIEGLER ${ }^{47}$ (2000) relataram que, na década de $80,28 \%$ das crianças americanas entre 4 e 5 anos, consumiam refrigerantes e, na década de 90 , essa porcentagem subiu para 48,2\%. PANG; PHILLIPS; BAWDEN ${ }^{103}$ (1992) observaram que refrigerantes, sucos, chá, café e Gatorade ${ }^{\circledR}$ eram responsáveis por $60 \%$ do consumo de bebidas, em crianças de 2 a 10 anos de idade.

Os refrigerantes apresentam concentrações variadas de flúor. HEINTZE; BASTOS ${ }^{61}$ (1996) encontraram uma amplitude de 0,05 a 0,79 ppm nos refrigerantes encontrados no mercado nacional, concordando com os resultados de HEILMAN et al. ${ }^{60}$ (1999), que encontraram uma variação de 0,02 a 1,28 ppm de flúor. A justificativa dessa variação seriam os diversos níveis de flúor na água utilizada na produção das bebidas.

A concentração de flúor nos sucos geralmente é baixa. HEINTZE; BASTOS $^{61}$ (1996) encontraram uma média de 0,6 ppm. Num outro estudo de BASTOS et al. ${ }^{5}$ (2000), 30,76\% dos sucos analisados tiveram de 0,25 a 0,5 ppm $F$ e 26,92\%, abaixo de 0,1 ppm, sendo que as maiores concentrações eram de sucos nos sabores guaraná e uva. PANG; PHILLIPS; BAWDEN ${ }^{103}$ (1992) também encontraram uma concentração alta, 
de 1,7 ppm, numa marca de suco de uva. Essa alta concentração de flúor em sucos de uva é explicada pela presença de agrotóxicos utilizados no cultivo da uva, que permanecem em suas cascas.

BUZALAF et al. ${ }^{19}$ (2002) observaram uma concentração em torno de $2,57 \pm 0,99$ para infusão de chá de Camellia sinensis, $0,7 \pm 0,20 \mu \mathrm{g} / \mathrm{mL}$ para chás prontos para o consumo, e 1,10 $\pm 0,15 \mu \mathrm{g} / \mathrm{mL}$ para sucos em pó contendo chá. Para o chá com a maior concentração de flúor (Apichá - chá preto), o consumo de $200 \mathrm{~mL}$ representa uma ingestão acima da dose máxima diária recomendada de $0,07 \mathrm{mg} \mathrm{F} / \mathrm{kg}$ peso, para uma criança de 2 anos $(12 \mathrm{~kg})$. Apesar do flúor presente no chá ser biodisponível, contribui pouco com a ingestão de flúor, devido ao seu baixo consumo (TRAUTNER; SIEBERT ${ }^{133}$, 1986). Porém, algumas bebidas à base de chá, estudadas por BEHRENDT; OBERSTE; WETZEL ${ }^{6}$ (2002), apresentam sabor doce, podendo ser mais agradável ao paladar de crianças. Uma quantidade de 44 marcas desse tipo de bebida foi analisada, sendo que 14 deles apresentaram menos que 0,6 ppm de flúor, 10 produtos entre 0,6 e 1,0 ppm F, 16 produtos entre 1,1 e 1,5 ppm F, 2 deles entre 1,6 e 2,0 e outros dois produtos apresentaram mais que 2,0 ppm $\mathrm{F}$.

Análises de alimentos infantis, realizadas por HEILMAN et al. ${ }^{59}$ (1997), revelaram uma ampla variação da concentração de flúor, entre 0,01 a 8,38 $\mu \mathrm{g} \mathrm{F/g}$, sendo que as carnes de frango foram responsáveis pelos valores mais altos, de 1,05 a $8,38 \mu \mathrm{g} / \mathrm{g}$. Num estudo realizado por CHITTAISONG et al. ${ }^{30}$ (1995), os alimentos apresentaram de 0,21 a 0,88 $\mu \mathrm{g}$ $\mathrm{F} / \mathrm{g}$, exceto uma marca à base de sardinha, que apresentou 2,94 $\mathrm{gg} \mathrm{F} / \mathrm{g}$. Estes resultados estão em contradição com o estudo de NISHIJIMA et al $^{96}$. (1993), que encontraram somente 0,54 a 0,86 $\mu \mathrm{g} / \mathrm{g}$ para comidas à base de carne e peixe, assim como no estudo de TRAUTNER; SIEBERT ${ }^{133}$ (1986), em que se relatou que osso de frango e peixe são pobres fontes de flúor.

Outros alimentos e bebidas infantis manufaturados podem contribuir significativamente com a ingestão total de flúor na infância, representando fatores de risco para fluorose dentária, especialmente quando somados a outras fontes de flúor. No Brasil, foram analisados cereais, papinhas e 
derivados lácteos. A concentração média encontrada foi de 3,016 ppm, 0,061 ppm e 0,020 ppm F, respectivamente. Alguns produtos apresentaram concentração elevada de flúor, como por exemplo, Mucilon ${ }^{\circledR}$ e Neston ${ }^{\circledR}$, que apresentaram 2,44 e 6,2 $\mathrm{\mu g} / \mathrm{g}$ de flúor. O achocolatado Toddynho ${ }^{\circledR}$ apresentou 1,2 ppm de flúor. Para crianças de 2 anos de idade, somente uma dose diária desses produtos já proporcionaria mais que $25 \%$ da dose máxima de $0,07 \mathrm{mg} \mathrm{F/kg}$ de peso corporal/dia (BUZALAF et al. ${ }^{22}$, 2002).

Analisando o flúor total e o flúor solúvel de alguns alimentos brasileiros de consumo infantil, BUZALAF et al. ${ }^{26}$ (2004) encontraram que os cereais analisados continham todo flúor solúvel, enquanto que os leites tinham $50 \%$ do flúor solúvel e as bolachas, 20\%. Uma dose recomendada pelo fabricante de Neston contribui com $30 \%$ da dose máxima permitida, para uma criança de 2 anos, e uma caixinha de Toddynho, 15\%. Já as bolachas recheadas, sem recheio, e biscoitos de maisena, 3, 32 e 20 unidades, correspondem a $16 \%$ da dose máxima recomendada, para uma criança de 2 anos de idade. No entanto, 25\% da absorção do flúor ocorre no estômago e, $75 \%$, no intestino. Portanto, a biodisponibilidade do flúor pode ser maior.

Para se estimar a ingestão diária de flúor por crianças, tem-se procurado avaliar a ingestão a partir da dieta (dieta duplicada) e da escovação.

A ingestão de dentifrícios parece ser um dos maiores contribuintes para a quantidade total de flúor ingerida por uma criança. De acordo com LIMA; CURY ${ }^{86}$ (2001), o dentifrício contribui com 55\% da dose total média de flúor ingerido e a dieta, com $45 \%$. Os autores concluem que a diminuição da quantidade de dentifrício utilizada na escovação seja a medida mais apropriada para diminuir a ingestão de flúor.

PAIVA $^{101}$ (1999) observou que 64,43\% (0,871 mg) do dentifrício utilizado na escovação de crianças de 20 a 30 meses de idade era ingerido, correspondendo a 0,0514 mg F/kg peso/dia.

Analisando a quantidade de flúor ingerida através da dieta e do dentifrício, em crianças de 4-5 anos e de 6-7 anos, PESSAN; SILVA; 
BUZALAF $^{111}$ (2003) encontraram uma ingestão total de 0,056 mg F/kg peso corporal $( \pm 0,040)$, sendo que $0,018 \mathrm{mg} \mathrm{F} / \mathrm{kg}$ peso corporal foi proveniente da dieta e 0,037 mg F/kg peso corporal, do dentifrício para as crianças de 4-5 anos e uma ingestão total de $0,057 \mathrm{mg} \mathrm{F} / \mathrm{kg}$ peso corporal $( \pm 0,052)$, sendo que a dieta contribuiu com 0,016 $\mathrm{mg} \mathrm{F} / \mathrm{kg}$ peso corporal e o dentifrício, com 0,041 mg F/kg peso corporal, para as crianças de 6-7 anos. Foi observado que $33,33 \%$ das crianças estavam expostas a uma dose de flúor acima da dose recomendada $(0,07 \mathrm{mg} \mathrm{F} / \mathrm{kg}$ peso corporal), sendo o dentifrício a principal fonte de flúor. Já crianças de 19 a 38 meses, de duas cidades brasileiras fluoretadas, Ibiá e Piracicaba, ingeriram uma média de 0,088 \pm 0,049 e 0,090 $\pm 0,022 \mathrm{mg} \mathrm{F} / \mathrm{kg}$ de peso corporal/dia, respectivamente. Uma porcentagem de 53,1 e 74,2 das crianças de Ibiá e Piracicaba, respectivamente, estavam expostas a uma dose diária de flúor acima da dose de risco para fluorose dentária $(0,07 \mathrm{mg} \mathrm{F} / \mathrm{kg}$ peso corporal). (PAIVA; LIMA; CURY ${ }^{102}$, 2003) Em crianças japonesas de 3 a 5 anos, MURAKAMI et al. ${ }^{95}$ (2002) encontraram um ingestão média de flúor total a partir da dieta e da escovação de 0,35 $\pm 0,19 \mathrm{mg} / \mathrm{dia}$, correspondendo a 0,021 $\pm 0,012 \mathrm{mg} / \mathrm{kg}$ de peso corporal.

LIMA; CURY ${ }^{87}$ (2003) não observaram diferença na ingestão de flúor durante as quatro estações, em crianças de 20 a 30 meses, residentes em uma região de clima subtropical. Porém, houve um período de subfluoretação da água de abastecimento durante o estudo. Ajustando essas variações, a ingestão de flúor durante a primavera e o verão foi maior que a observada durante as estações de outono e inverno.

\subsection{Unha como biomarcador de exposição crônica ao flúor}

Para indicar uma alteração que poderia levar a uma doença clínica (GRANDJEAN ${ }^{55}$, 1995) tem-se os marcadores biológicos ou biomarcadores, os quais são indicadores que sinalizam eventos em sistemas biológicos ou amostras (Committee on Biological Markers of the National Research Council $^{35}$, 1987). Um dos tópicos do simpósio realizado pelo National Institute of Health, em Bethesda, Maryland, EUA, em 1999, era a avaliação 
de possíveis biomarcadores, que fossem de fácil coleta e análise, para a exposição ao $\mathrm{F}$ em humanos (CLARKSON ${ }^{33}$, 2000). Atendendo a essas características, o uso das unhas, como indicadoras de exposições crônicas e subcrônicas ao flúor, foi discutido.

A coleta de amostras de unhas é simples, e não invasiva. McDONNELL; O'MULLANE ${ }^{90}$ (2001) avaliaram a velocidade de crescimento e o comprimento no qual as unhas poderiam ser cortadas, para a análise de F em crianças de 2 a 3 anos de idade. As médias obtidas foram 0,7 $\mathrm{mm} /$ semana (variação 0,5 - 0,9 mm) e 7,5 mm (variação 6,4 - 9,2 mm), respectivamente.

Existem vários estudos sugerindo o uso de unhas como biomarcadores para a exposição ao flúor em humanos (CZARNOWSKI; KRECHNIAK ${ }^{36}$, 1990; CZRNOWISKI et al. ${ }^{37}$, 1996; SCHMIDT; LEUSCHKE $^{123}$, 1990; SPATE et al. ${ }^{127}$, 1994; WHITFORD et al. ${ }^{141}$, 1999, RODRIGUES et al. ${ }^{120}, 2004$; LEVY et al. $\left.{ }^{85}, 2004\right)$.

No intuito de se padronizar uma metodologia para análise da concentração de flúor em unhas, WHITFORD et al. ${ }^{141}$ (1999) realizaram um estudo no qual foram avaliadas diversas variáveis da concentração de flúor nas unhas de humanos. A análise foi realizada com eletrodo através de difusão facilitada por HMDS. Através desse estudo, pode-se observar que a área de superfície das unhas (intacta, cortada em pequenos pedaços e pulverizadas), imersão em água deionizada por 6 horas, água fluoretada (1ppm) por 2 horas e remoção da matéria orgânica por incineração não afetaram a leitura da concentração de flúor. As unhas dos pés apresentaram a metade da concentração das unhas das mãos. O aumento da ingestão de flúor em $3 \mathrm{mg} /$ dia por um mês resultou numa maior concentração de flúor nas unhas, e as unhas de crianças brasileiras residentes em áreas com 0,1, 1,6 e 2,3 ppm de flúor apresentaram concentrações diferentes, estatisticamente significativas, com uma relação direta entre a concentração de flúor das unhas e das águas.

O uso da unha como biomarcador de exposição ao flúor em crianças parece um assunto ainda controverso, na literatura. Segundo RODRIGUES; 
BASTOS; BUZALAF ${ }^{120}$ (2004), as unhas das mãos e pés podem ser convenientes biomarcadores para exposição subcrônica ao flúor dos dentifrícios fluoretados para crianças pequenas. Em seu estudo, crianças de 2 a 3 anos de idade utilizaram dentifrício placebo por 28 dias. Em seguida, utilizaram dentifrício fluoretado por mais 28 dias e retornaram novamente ao dentifrício placebo pelo mesmo período de dias. O pico de concentração de flúor nas unhas ocorreu 16 semanas depois do começo do uso de dentifrício fluoretado.

LEVY; BASTOS; BUZALAF ${ }^{85}$ (2004) também sugerem o uso das unhas das mãos e dos pés como biomarcadores de exposição crônica de flúor a partir da dieta, já que foi encontrada correlação entre a concentração de flúor nas unhas das mãos e dos pés e a ingestão de flúor através da dieta, em crianças de 2 a 6 anos de idade, residentes em duas cidades, fluoretada e não fluoretada. Neste estudo, houve diferença estatisticamente significativa entre a concentração de flúor nas unhas das crianças residentes na cidade fluoretada e na não fluoretada.

Contudo, ARSATI ${ }^{1}$ (2003) encontrou dados discordantes dos estudos previamente citados. A autora encontrou diferença estatisticamente significativa entre a concentração de flúor das unhas de crianças residentes em três cidades, com diferentes concentrações de flúor na água de abastecimento. Porém, não foi encontrada correlação entre a concentração de flúor das unhas das mãos e o uso de dentifrício fluoretado. 
“Na vida, não existe nada a temer, mas a entender."

Marie Curie 


\section{PROPOSIÇÃO}

O objetivo deste estudo foi:

> Estimar a ingestão de flúor total diária de 33 crianças, na faixa etária de 2 - 3 anos de idade, através da dieta e da escovação;

> Analisar a contribuição dos diferentes constituintes da dieta (sólidos, água e leite, outros líquidos) na ingestão de flúor;

> Avaliar a correlação entre a ingestão diária de flúor e a concentração de flúor nas unhas das mãos das mesmas crianças, para possível identificação de um biomarcador da ingestão de flúor e um preditor de risco para fluorose dentária. 


\section{MATERIAL E MÉTODOS}

"Separe um tempo para rir.

O riso é a música da alma."

Anônimo 


\section{MATERIAL E MÉTODOS}

\subsection{Obtenção das amostras}

Para a realização deste estudo longitudinal de acompanhamento da ingestão de flúor, a amostra foi composta por 33 crianças, de 2 a 3 anos de idade, das creches e berçários públicos do município de Bauru-SP. Os responsáveis pelas crianças receberam uma Carta de Informação ao Paciente e assinaram o Termo de Consentimento Livre e Esclarecido, de acordo com as normas do Comitê de Ética em Pesquisa da Faculdade de Odontologia de Bauru, USP. (ANEXO 1).

Os pais foram entrevistados, respondendo a um questionário (ANEXO 2) sobre o tipo de leite usualmente consumido pela criança (leite de vaca, leite em pó, leite de soja), e sobre a água utilizada para preparo do leite em pó, caso este seja o leite consumido, o uso e quantidade de dentifrício fluoretado consumido, assim como freqüência das escovações, consumo de cereais e outros tipos de alimentos infantis manufaturados e o uso de suplementos. As mães receberam as devidas orientações em relação a hábitos que possivelmente causariam fluorose dentária, (ANEXO 3) a fim de evitá-los e corrigi-los, caso estes estivessem ocorrendo. Foi feita coleta da dieta duplicada e estimativa da ingestão de dentifrício pelas crianças, de acordo com a metodologia relatada por GUHA-CHOWDHURRY; DRUMMOND; SMILLIE ${ }^{53}$ (1996). A dieta duplicada foi coletada em 2 épocas distintas (inverno e verão), com intervalo de 5 meses, e sempre em 2 dias, sendo um, durante a semana e o outro, no final de semana, levando em consideração alterações da dieta quando as crianças estão nas creches e outro, no fim de semana, quando as crianças estão na residência. Os alimentos da dieta duplicada foram coletados separadamente em três grupos: leite e água, sólidos e outros líquidos. Os pais e funcionários da creche foram orientados para colocar nos recipientes a mesma quantidade de alimento consumido pela criança, exceto cascas e sementes de frutas e ossos. Os alimentos foram mantidos congelados a $-20^{\circ} \mathrm{C}$ até a data da análise. No mesmo período de coleta da dieta, foram coletadas 2 amostras de água das residências das crianças e das creches, para posterior análise 
do teor de flúor. Também foram coletadas três amostras das unhas das mãos das crianças, com intervalo de dois meses entre as coletas, sendo que duas delas foram coletadas no mesmo período da coleta da dieta e a outra amostra coletada num período intermediário entre as coletas das dietas. A simulação da escovação foi realizada por dois dias seguidos. Para tanto, as escovas das crianças foram levemente umedecidas com água deionizada e pesadas (balança AND, modelo EK-200). Após a colocação do dentifrício de acordo com o costume habitual das crianças, a escova foi novamente pesada. Fazendo a subtração destes valores, sabe-se a quantidade de dentifrício utilizada pela criança. Um recipiente de plástico era fornecido à criança, caso sentisse necessidade de expectoração do dentifrício e a lavagem da boca foi feita com água deionizada. O resíduo de dentifrício que permaneceu na escova foi removido através da lavagem da escova em 20 $\mathrm{mL}$ de água deionizada contido em um recipiente plástico. No dia da escovação simulada, foi coletada uma amostra do dentifrício utilizado pela criança para confirmação da concentração de F.

\subsection{Análises de flúor}

\section{Unhas, dieta, dentifrício e escovação}

Os fragmentos das unhas das mãos de cada criança, em cada data, foram analisados conjuntamente, sendo que houve apenas um resultado para cada criança, em cada data correspondente. Os fragmentos foram limpos por fricção contra um pedaço de tecido umedecido em água deionizada, deixados em ultra-som por 10 minutos e foram então secos a $60^{\circ} \mathrm{C}$ e pesados $( \pm 0,01 \mathrm{mg})$. No caso da dieta, a mesma foi homogeneizada com volumes conhecidos de água deionizada, previamente à análise. Os dentifrícios foram diluídos na proporção de $1 \mathrm{~g}$ de dentifrício para $1000 \mathrm{~mL}$ de água deionizada. Para análise do $F$ através da escovação, foi utilizado o método de GUHA-CHOWDHURRY; DRUMMOND; SMILLIE ${ }^{53}$ (1996), com uma modificação: o volume expectorado foi adicionado ao volume do resíduo proveniente da escova, obtendo-se, então, somente uma amostra 
para leitura do flúor não ingerido. Desta forma, o número de amostras para leitura do flúor foi reduzido.

A análise de flúor foi feita após difusão facilitada por HMDS, pelo método de TAVES ${ }^{128}$ (1968), modificado por WHITFORD ${ }^{137}$ (1996). Para tanto, as amostras foram colocadas em placas de Petri plásticas (Falcon, $\mathrm{n}^{\circ}$ 1007), juntamente com $2 \mathrm{~mL}$ de água. Na tampa dessas placas, foram colocados $50 \mu \mathrm{L}$ de $\mathrm{NaOH}$ 0,05 M, distribuídos em 3 gotas. As placas foram, então, fechadas, seladas com vaselina e, por um orifício feito previamente na tampa, foi colocado hexametil-disiloxano (HMDS, marca Aldrich, 2,0 mL em ácido sulfúrico $3 \mathrm{M}$ ). O orifício foi imediatamente selado com vaselina e parafilme. As placas foram colocadas, então, numa mesa agitadora orbital plana (Nova Técnica, modelo NT 145), em velocidade 2-3, durante a noite. No dia seguinte, as tampas foram removidas, invertidas, e as gotas de $\mathrm{NaOH}$ foram combinadas numa única gota. $\mathrm{O} N \mathrm{NaH}$ foi tamponado pela adição de $25 \mu \mathrm{L}$ de ácido acético $0,2 \mathrm{M}$. O volume total foi, então, ajustado para $75 \mu \mathrm{L}$ com água deionizada, usando uma pipeta. A gota, que contém todo flúor das unhas, foi analisada com o eletrodo Orion 9409 e um microeletrodo de referência calomelano (Accumet, número de catálogo \#13-62079), ambos acoplados ao potenciômetro Orion EA 940. Durante a leitura, os dois eletrodos foram mantidos unidos através de bandas de borracha e colocados em contato com a gota, na parte interna da tampa da placa.

Validação da análise:

A técnica de difusão facilitada por HMDS apresenta as vantagens de separar o F da amostra, eliminando interferentes e, ao mesmo tempo, concentrá-la, o que incrementa o limite de detecção do $\mathrm{F}$ pelo eletrodo sensível, que é de $0,02 \mu \mathrm{g} / \mathrm{mL}$, conforme consta do manual do fabricante. Uma vez que nossa amostra tem um volume final de $0,075 \mathrm{~mL}$, após a difusão facilitada por HMDS, podemos detectar quantidades de F acima de $0,0015 \mu \mathrm{g}$. Considerando que o peso das amostras de unhas obtidas de crianças nesta faixa etária é baixo, é necessário utilizar uma técnica bastante sensível para análise. 
As soluções-padrão (contendo 0,0095, 0,019, 0,095, 0,19 e 0,95 $\mu \mathrm{g} \mathrm{F}$ para as unhas; 0,019, 0,095, 0,190, 0,950, 1,900, 4,750, 7,500 $\mu \mathrm{g} F$ - para a dieta; 0,950, 1,900, 4,750 e 7,500 $\mu \mathrm{g}$ F - para a escovação e dentifrícios ) empregadas na realização da curva de calibração foram preparadas por diluição seriada de um estoque-padrão contendo $0,1 \mathrm{M}$ de $\mathrm{F}$ (Orion) e difundidas em triplicata, em concomitância com as amostras a serem analisadas. Foi feita a primeira leitura antes de se começar a ler as amostras; a segunda, quando a metade das amostras já tinha sido lida, e a terceira, após o término da leitura das amostras.

As leituras, obtidas em milivoltagem $(\mathrm{mV})$, foram convertidas para $\mu \mathrm{g}$ de F, através do Programa Excel (Microsoft, versão 2000). A média das leituras obtidas a partir dos padrões foi inserida na planilha, e então, foi calculada a porcentagem de variação entre a quantidade de $\mathrm{F}$ medida e a esperada pelos padrões. Somente curvas de calibração com porcentagem de variação de até $5 \%$ para todos os padrões e $r \geq 0,99$ foram aceitas, contemplando a exatidão do método.

Além disto, padrões que não sofreram difusão foram preparados usando-se as mesmas soluções ( $\mathrm{NaOH}$ 0,05 $\mathrm{M}$ e ácido acético 0,20 M) usadas para se preparar os padrões e amostras que sofreram difusão. Estes padrões não difundidos foram feitos de modo a ter exatamente a mesma concentração de $F$ que os padrões que sofreram difusão. A comparação das leituras de $\mathrm{mV}$ mostrou que o $\mathrm{F}$ nos padrões difundidos foi completamente captado e analisado.

As amostras da dieta foram analisadas em triplicata, da escovação e dentifrício, em duplicata, e as de unhas, se possível (quando a massa foi superior a 10,00 mg), em duplicata. A porcentagem de concordância calculada entre as análises a fim de se preservar a precisão das mesmas foi de $94,41 \%$. Em adição, medições de $F$ em 10\% das amostras foram repetidas, gerando um percentual de reprodutibilidade das análises de $95,95 \%$. 


\section{Água}

A concentração de $\mathrm{F}$ presente nas amostras de água foi determinada em triplicata, usando-se o eletrodo Orion 9609, após serem tamponadas com um volume idêntico de TISAB II (tampão de ajuste da força iônica total), contendo CDTA (ácido ciclo-hexano diamino tetracético) 0,4\%, pH 5,0.

Validação da análise:

A curva de calibração foi realizada com os mesmos cuidados descritos para validação da análise de $\mathrm{F}$ nas unhas.

A porcentagem de concordância calculada entre as análises a fim de se preservar a precisão das mesmas foi de $96,24 \%$. Em adição, medições de $\mathrm{F}$ em $10 \%$ das amostras foram repetidas, gerando um percentual de reprodutibilidade das análises de 95,32\%.

\subsection{Análise estatística}

O teste ANOVA de medidas repetidas foi usado para detectar diferença entre os diferentes grupos de alimentos, sendo complementado pelo teste de comparações múltiplas Tukey-Kramer, para comparações individuais entre a ingestão de $\mathrm{F}$ através dos alimentos sólidos, água e leite, e outros líquidos, adotando-se um nível de significância de $5 \%$. Os mesmos testes foram empregados para se detectar diferenças entre as concentrações de $\mathrm{F}$ presentes nas unhas das crianças, nas diferentes datas de coleta.

$\mathrm{A}$ ingestão de $\mathrm{F}$ total (dieta e escovação) foi relacionada à média da concentração de $\mathrm{F}$ presente nas unhas, utilizando-se o coeficiente de correlação de Pearson, adotando-se um nível de significância de 5\%. 0 mesmo teste foi feito para se avaliar a correlação entre a quantidade de dentifrício colocada na escova de dentes, e a ingestão de flúor, a partir da escovação.

O teste $\mathrm{t}$ pareado foi empregado para avaliar a diferença entre a ingestão de flúor através da dieta e da escovação, bem como para avaliar a diferença na quantidade de flúor ingerido, entre os dois dias de coleta da dieta (dieta total e seus componentes, separadamente) e entre as diferentes 
estações do ano, entre a concentração de flúor presente na água ingerida pelas crianças, nos dois dias de coleta, adotando-se um nível de significância de $5 \%$.

O teste t não pareado foi utilizado para se avaliar a diferença entre a concentração de $\mathrm{F}$ presente no rótulo dos dentifrícios e a concentração analisada em nosso laboratório, adotando-se um nível de significância de $5 \%$.

\section{4 llustrações}

As fotos seguintes ilustram a metodologia de análise de flúor das unhas feita após difusão facilitada por HMDS, pelo método de TAVES ${ }^{128}$ (1968), modificado por WHITFORD ${ }^{137}$ (1996). A mesma metodologia foi utlizada para a dieta e dentifrício. 


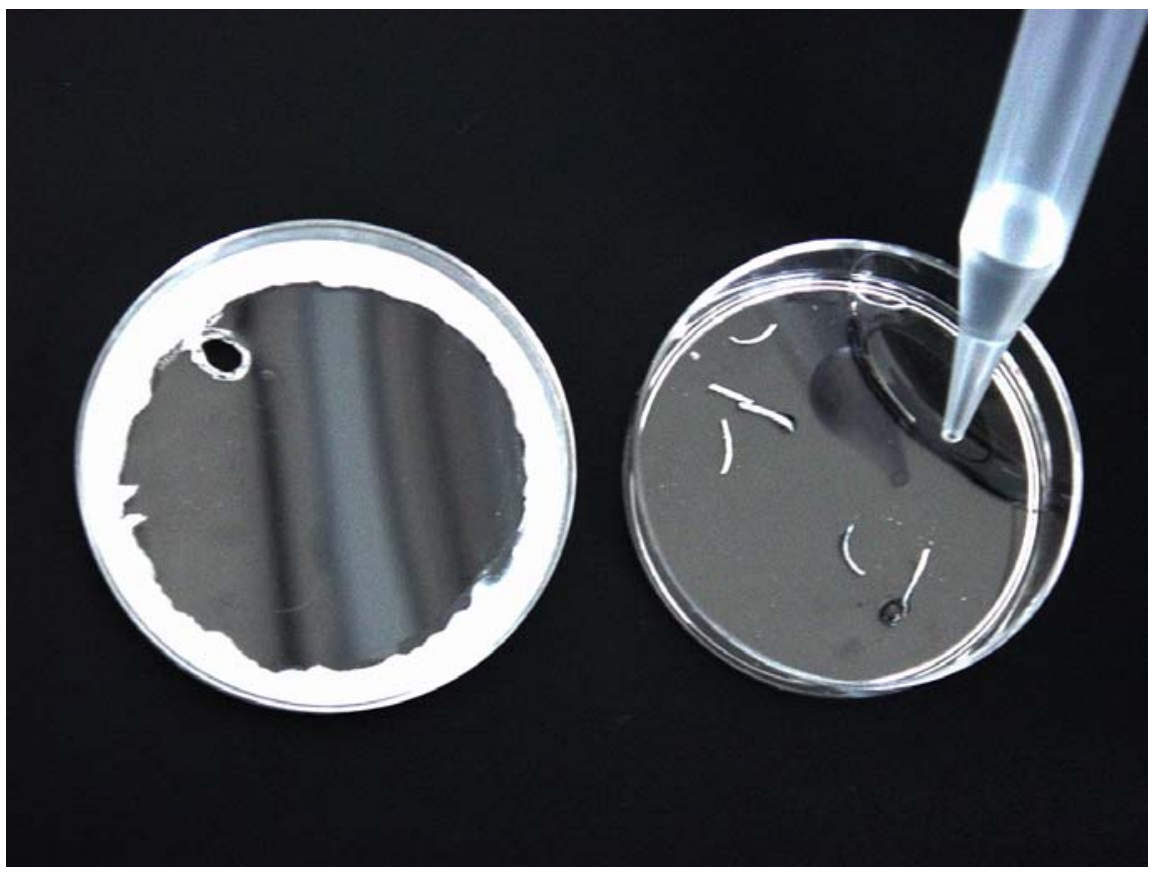

Figura 4.1 - Placa de Petri vaselinada. Adição das amostras de unhas com $2 \mathrm{~mL}$ de água deionizada

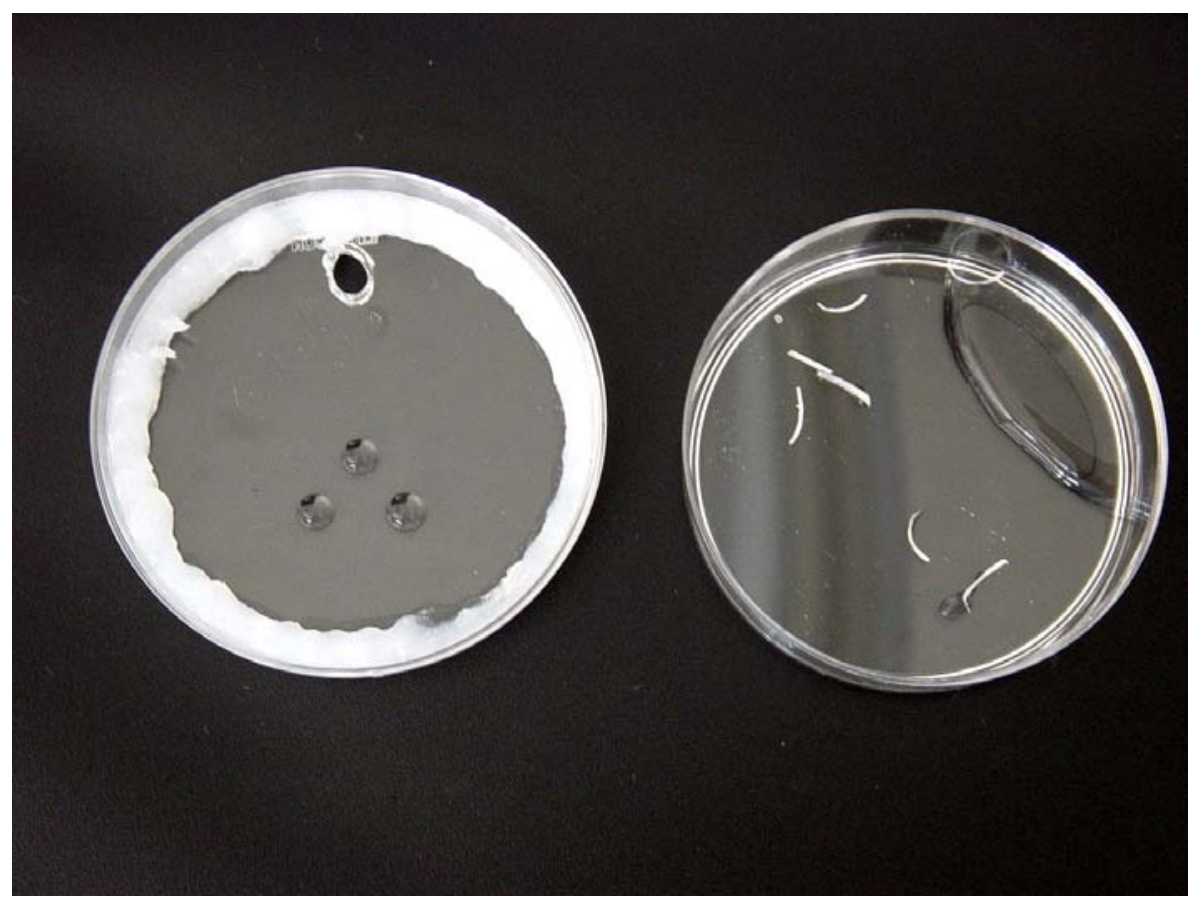

Figura 4.2 - Adição de $50 \mu \mathrm{L}$ de $\mathrm{NaOH} 0,05 \mathrm{M}$ na tampa da placa de Petri distribuída em 3 gotas 


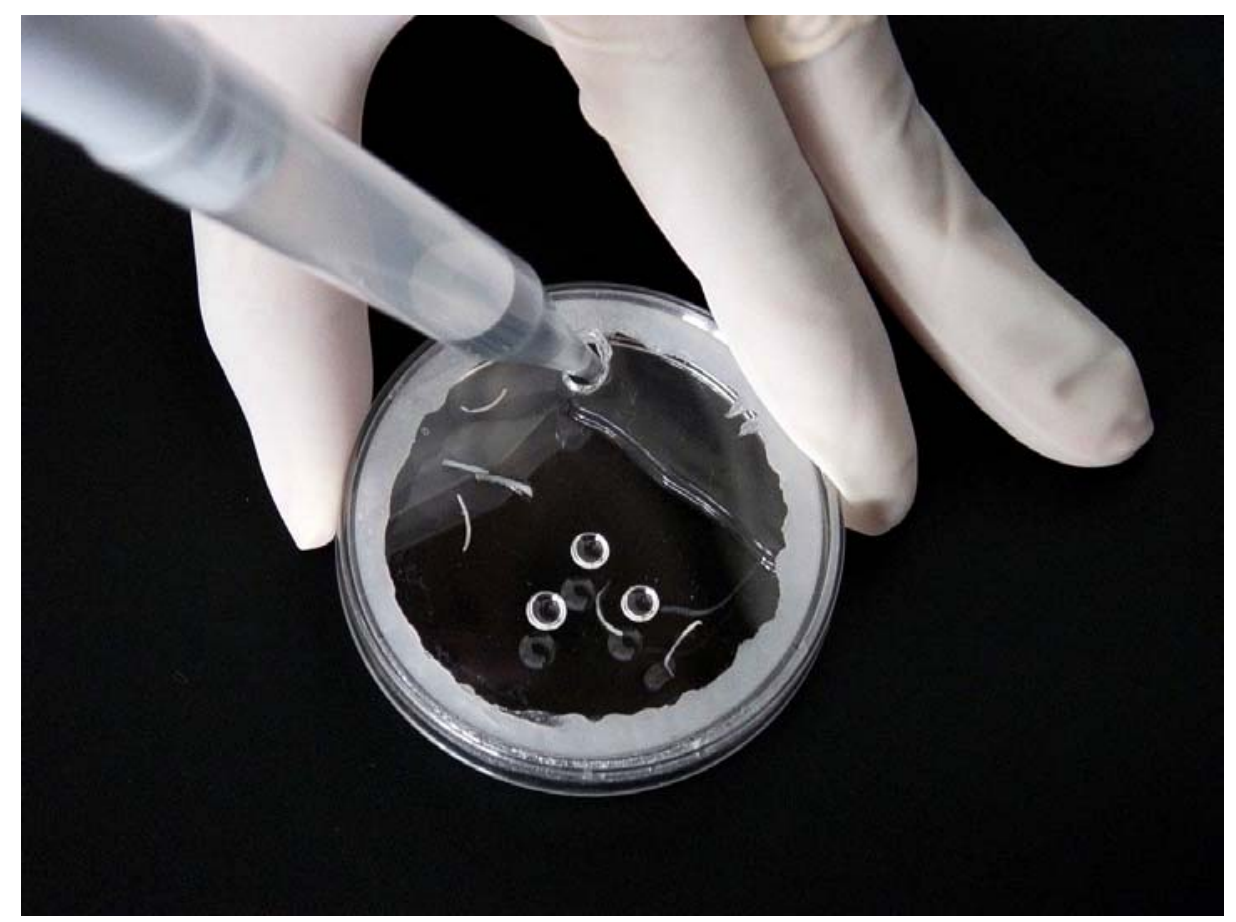

Figura 4.3 - Fechamento das placas e adição de $2 \mathrm{~mL}$ HMDS

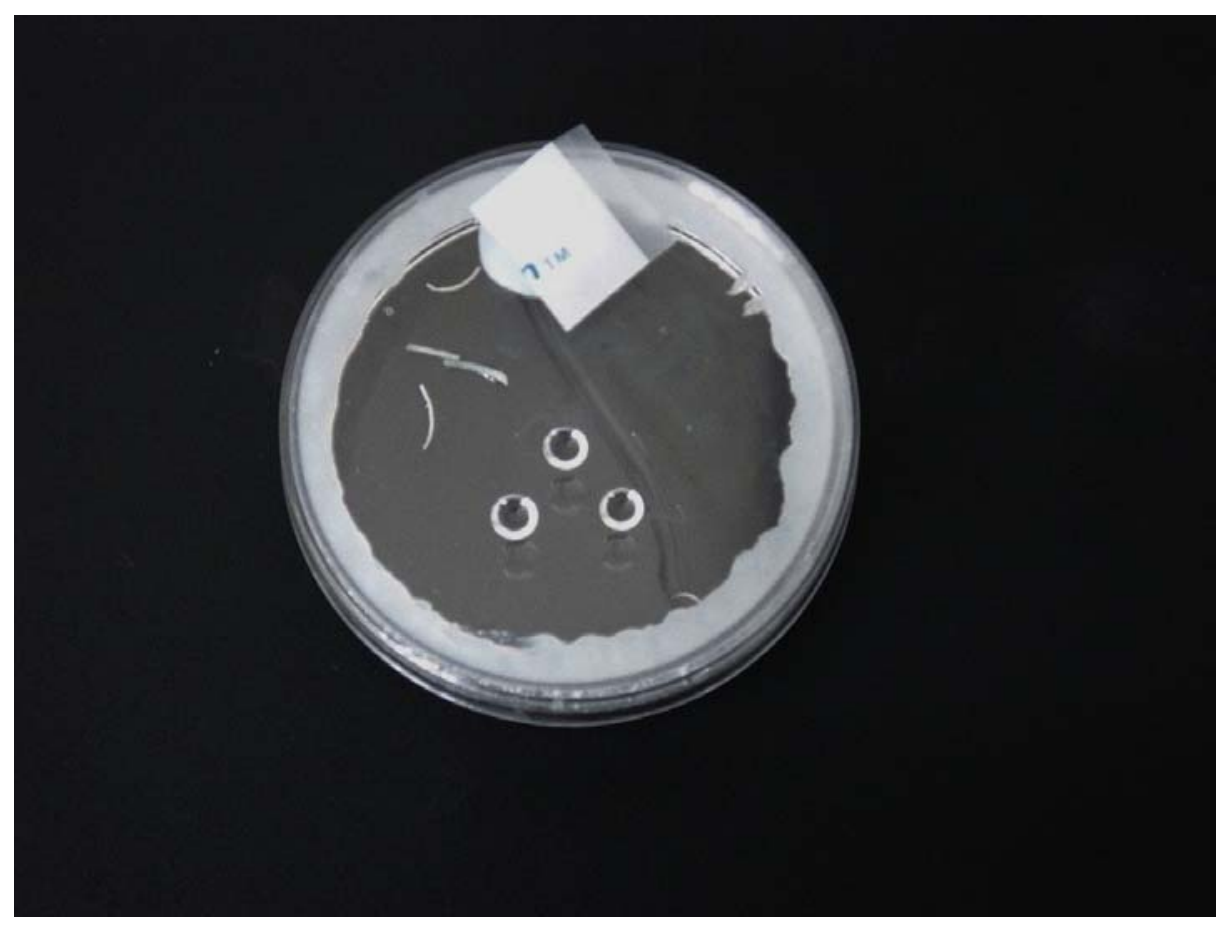

Figura 4.4 - Vedamento imediato do orifício com vaselina e parafilme 


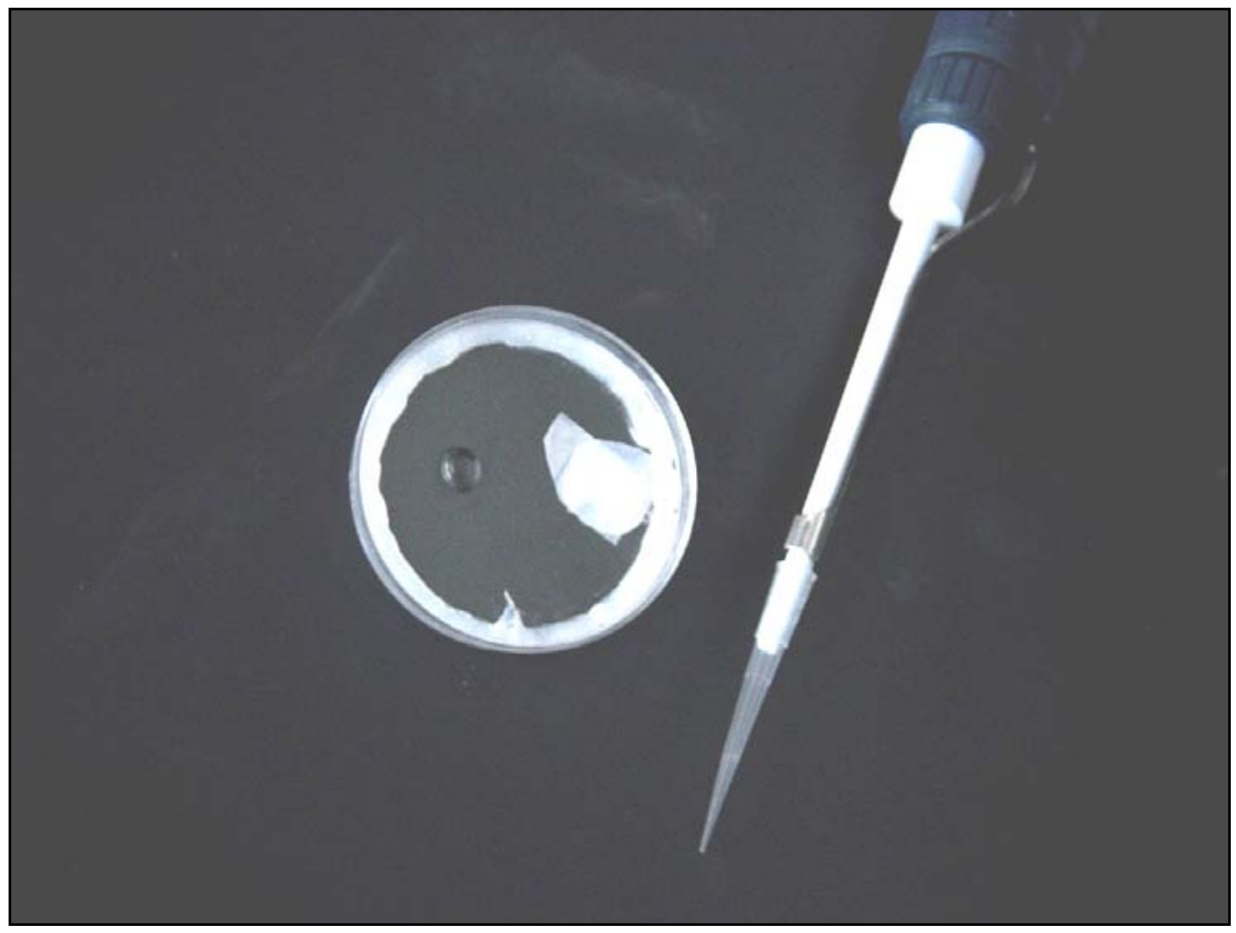

Figura 4.5 - As gotas de $\mathrm{NaOH}$ foram combinadas numa única gota, tamponada com $25 \mu \mathrm{l}$ de ácido acético $0,2 \mathrm{M}$, e o volume total foi ajustado para 75 $\mu \mathrm{L}$ com água deionizada

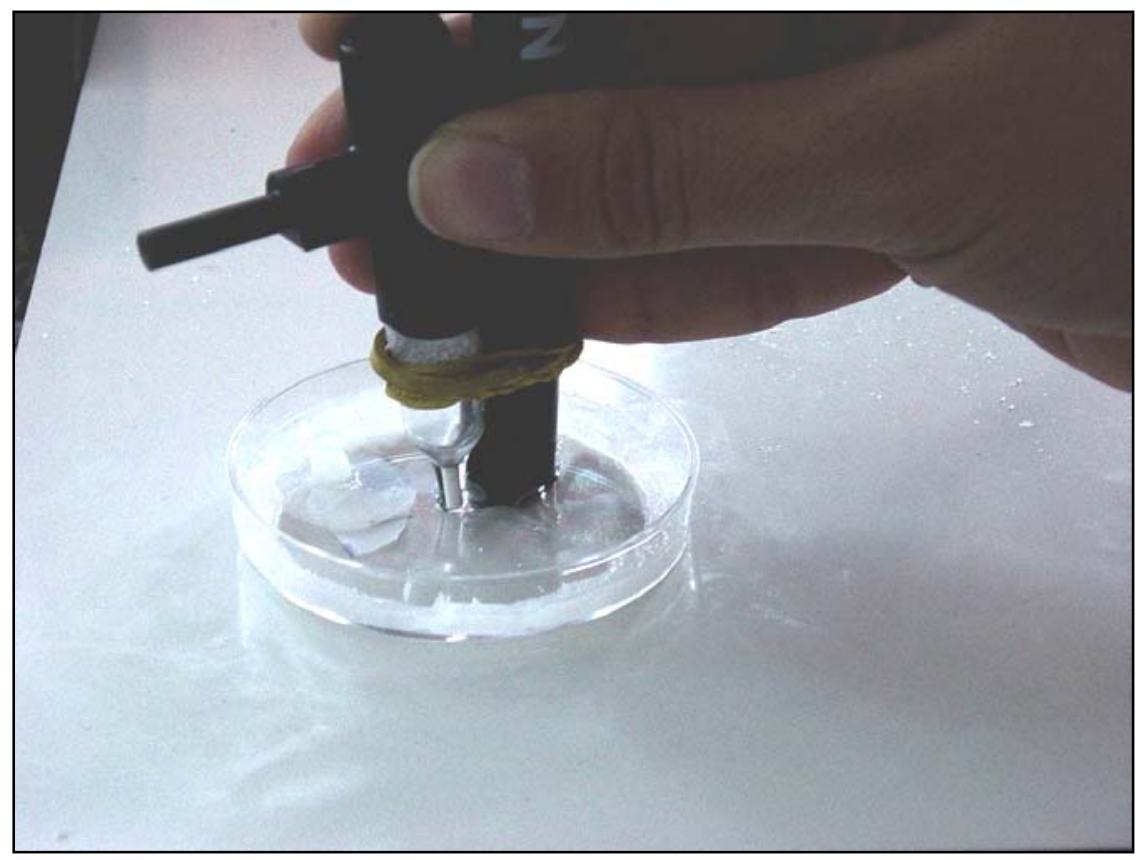

Figura 4.6 - A leitura foi feita com eletrodo Orion 9409 e um micro eletrodo calomelano de referência 


\section{RESULTADOS}

"A felicidade entra sorrateiramente por uma porta que você não sabia que havia deixado aberta." John Barrymore 
5 RESULTADOS

A tabela 5.1 mostra a dose de flúor ingerido $(\mathrm{mg} \mathrm{F} / \mathrm{Kg}$ de peso corporal/dia) através da dieta, do dentifrício e o total de cada criança $(n=33)$.

Tabela 5.1 - Dose de flúor ingerido ( $\mathrm{mg} \mathrm{F/Kg} \mathrm{de} \mathrm{peso} \mathrm{corporal/dia)} \mathrm{através}$ da dieta, do dentifrício e o total de cada criança $(n=33)$.

\begin{tabular}{cccc}
\hline criança & dieta & dentifrício & total \\
\hline 1 & 0,011 & 0,040 & 0,051 \\
2 & 0,014 & 0,040 & 0,065 \\
3 & 0,029 & 0,096 & 0,125 \\
4 & 0,033 & 0,022 & 0,055 \\
5 & 0,032 & 0,164 & 0,196 \\
6 & 0,070 & 0,141 & 0,211 \\
7 & 0,043 & 0,040 & 0,083 \\
8 & 0,017 & 0,176 & 0,193 \\
9 & 0,046 & 0,076 & 0,122 \\
10 & 0,027 & 0,084 & 0,111 \\
11 & 0,024 & 0,261 & 0,285 \\
12 & 0,021 & 0,142 & 0,163 \\
13 & 0,045 & 0,132 & 0,177 \\
14 & 0,012 & 0,401 & 0,413 \\
15 & 0,036 & 0,256 & 0,292 \\
16 & 0,026 & 0,256 & 0,282 \\
17 & 0,023 & 0,004 & 0,027 \\
18 & 0,021 & 0,015 & 0,036 \\
19 & 0,021 & 0,086 & 0,107 \\
20 & 0,025 & 0,072 & 0,097 \\
21 & 0,026 & 0,107 & 0,134 \\
22 & 0,028 & 0,101 & 0,129 \\
23 & 0,028 & 0,111 & 0,138 \\
24 & 0,028 & 0,110 & 0,138 \\
25 & 0,034 & 0,033 & 0,067 \\
26 & 0,022 & 0,078 & 0,101 \\
27 & 0,017 & 0,073 & 0,091 \\
28 & 0,010 & 0,018 & 0,028 \\
29 & 0,015 & 0,055 & 0,070 \\
30 & 0,009 & 0,106 & 0,114 \\
31 & 0,013 & 0,024 & 0,037 \\
32 & 0,003 & 0,082 & 0,085 \\
33 & 0,024 & 0,090 & 0,114 \\
\hline & & &
\end{tabular}


Conforme podemos observar, na tabela $5.1,72,67 \%(n=24)$ das crianças $(n=33)$ excederam a dose limite de $0,07 \mathrm{mg} \mathrm{F} / \mathrm{Kg}$ de peso corporal/dia.

A tabela 5.2 mostra a dose média de flúor ingerido através da dieta, do dentifrício e o total (dieta + dentifrício) pelas crianças.

Tabela 5.2 - Dose média diária de flúor ingerido através da dieta, do dentifrício e o total (dieta + escovação) pelas crianças $(n=33)$.

\begin{tabular}{clccc}
\hline \multicolumn{1}{c}{ F ingerido } & & Dieta & Dentifrício & Total \\
\hline \multirow{2}{*}{ (mg F/dia) } & média & $0,321^{\mathrm{a}}$ & $1,346^{\mathrm{b}}$ & 1,67 \\
\cline { 2 - 5 } & DP & 0,162 & 1,024 & 1,046 \\
\cline { 2 - 5 } & Mínimo & 0,040 & 0,043 & 0,289 \\
\cline { 2 - 5 } & Máximo & 0,841 & 4,735 & 4,879 \\
\cline { 2 - 5 } & IC 95\% & $0,264-0,379$ & $0,982-1,709$ & $1,296-2,038$ \\
\hline \multirow{3}{*}{ corporal /dia) } & média & $0,025^{\mathrm{a}}$ & $0,106^{\mathrm{b}}$ & 0,13 \\
\cline { 2 - 5 } & DP & 0,013 & 0,085 & 0,087 \\
\cline { 2 - 5 } & Mínimo & 0,003 & 0,004 & 0,027 \\
\cline { 2 - 5 } & Máximo & 0,070 & 0,401 & 0,413 \\
\cline { 2 - 5 } & IC 95\% & $0,021-0,029$ & $0,076-0,137$ & $0,104-0,165$
\end{tabular}

* Os valores seguidos por letras diferentes significam diferença estatisticamente significativa $(p<0,0001)$.

Através da tabela 5.2 pode-se verificar que o flúor ingerido através do dentifrício da escovação foi significativamente maior $(p<0,0001)$ em relação ao flúor ingerido através da dieta.

O gráfico 5.1 mostra a contribuição do dentifrício e da dieta, em porcentagem, para a ingestão total de flúor. 


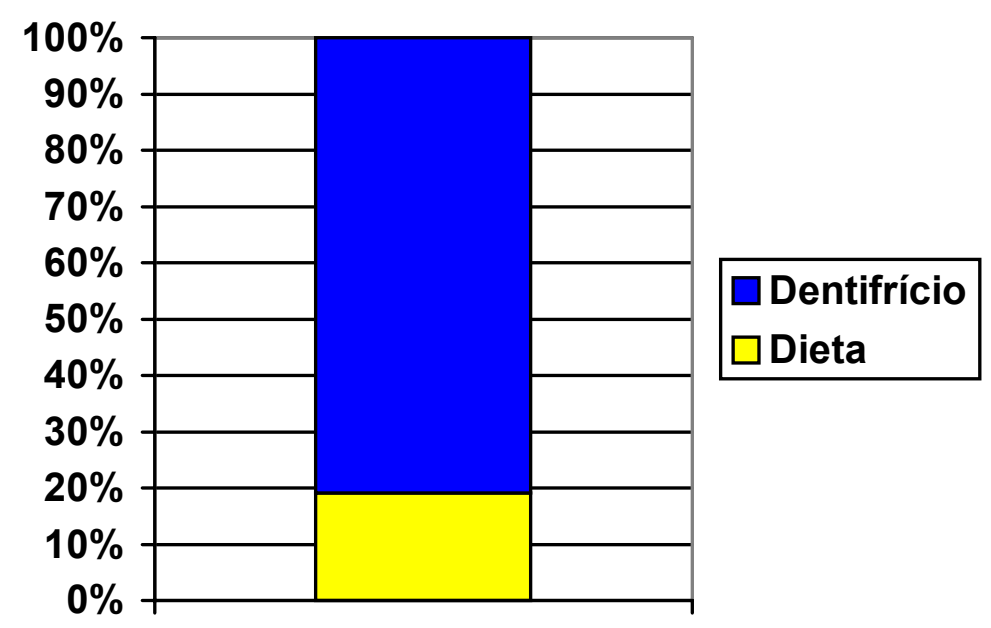

Figura 5.1 - Contribuição do dentifrício e da dieta, em porcentagem, para a ingestão total de flúor.

Através da figura 5.1, pode-se observar que o dentifrício contribui com cerca de $80 \%$ da ingestão total de flúor.

A tabela 5.3 mostra os valores da quantidade de flúor ingerido através dos alimentos sólidos, água e leite e outros líquidos. 
Tabela 5.3 - Quantidade de flúor ingerido através de alimentos sólidos, água e leite e outros líquidos (mg F/dia).

\begin{tabular}{llc}
\hline Grupo de alimentos & F ingerido (mg F/dia) \\
\hline Sólidos & média (\%) & $0,072^{\mathrm{a}}(22,36 \%)$ \\
& DP & 0,045 \\
& Mínimo & 0,013 \\
& Máximo & 0,185 \\
& IC 95\% & $0,056-0,088$ \\
\hline Água e leite & média (\%) & $0,184^{\mathrm{b}}(57,14 \%)$ \\
& DP & 0,108 \\
& Mínimo & 0,002 \\
& Máximo & 0,485 \\
& IC 95\% & $0,146-0,222$ \\
\hline Outros líquidos & média (\%) & $0,066^{\mathrm{a}}(20,50 \%)$ \\
& DP & 0,043 \\
& Mínimo & 0,002 \\
Máximo & 0,171 \\
& IC 95\% & $0,050-0,081$
\end{tabular}

* Os valores seguidos por letras diferentes significam diferença estatisticamente significativa $(p<0,0001)$.

Através da tabela 5.3 , pode-se observar que dentre os componentes da alimentação das crianças, a água e o leite tiveram uma contribuição significativamente maior $(p<0,0001)$ para a ingestão de flúor através da dieta, em relação aos outros alimentos.

A tabela 5.4 mostra os valores da quantidade de flúor ingerido pelas crianças através dos alimentos sólidos, água e leite, outros líquidos e dentifrício. 
Tabela 5.4 - Quantidade de flúor ingerido pelas crianças $(n=33)$ através dos alimentos sólidos, água e leite, outros líquidos e dentifrício (mg F/dia).

\begin{tabular}{lcccc}
\hline & \multicolumn{2}{c}{ Dieta } & Dentifrício \\
\hline & Sólidos & Água e leite & $\begin{array}{c}\text { Outros } \\
\text { líquidos }\end{array}$ \\
\hline média & $0,072^{\mathrm{a}}$ & $0,184^{\mathrm{b}}$ & $0,066^{\mathrm{a}}$ & $1,346^{\mathrm{C}}$ \\
DP & 0,045 & 0,108 & 0,043 & 1,024 \\
Mínimo & 0,013 & 0,002 & 0,002 & 0,04 \\
Máximo & 0,185 & 0,485 & 0,171 & 4,74 \\
IC 95\% & $0,056-0,088$ & $0,146-0,222$ & $0,050-0,081$ & $0,982-1,709$ \\
\hline
\end{tabular}

* Os valores seguidos por letras diferentes significam diferença estatisticamente significativa $(p<0,0001)$.

Os dados da tabela 5.4 estão ilustrados na figura 5.2. Conforme se observa, o dentifrício contribui com $81 \%$ da ingestão diária de flúor e a dieta, com 19\%. Dentre os componentes da dieta, os maiores contribuintes para a ingestão diária de flúor são a água e o leite.
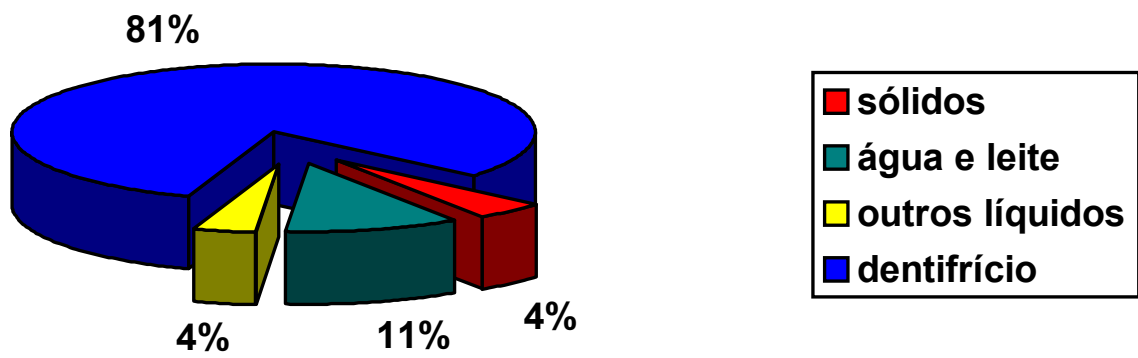

Figura 5.2 - Contribuição dos alimentos sólidos, água e leite, outros líquidos e dentifrício para a quantidade de flúor ingerido pelas crianças $(n=33)$, em porcentagem. 
A tabela 5.5 mostra a quantidade de flúor ingerido ( $\mathrm{mg} \mathrm{F/dia)} \mathrm{a} \mathrm{partir}$ da dieta (D) e de cada grupo de alimentos: sólidos, leite e água e outros líquidos, coletados no inverno e verão, separadamente.

Tabela 5.5 - Quantidade de flúor ingerido (mg F/dia) a partir da dieta (D) e de cada grupo de alimentos: sólidos (S), leite e água (LA) e outros líquidos $(L)$, coletados no inverno (1) e verão (2), separadamente.

\begin{tabular}{lcccccccc}
\hline \multicolumn{1}{c}{$\mathbf{F}$} & S1 & S2 & LA1 & LA2 & L1 & L2 & D1 & D2 \\
ingerido & \multicolumn{1}{c}{} & & & & & & & \\
\hline média & 0,071 & 0,082 & 0,199 & 0,171 & 0,065 & 0,067 & 0,318 & 0,296 \\
DP & 0,058 & 0,062 & 0,157 & 0,091 & 0,052 & 0,054 & 0,208 & 0,142 \\
Mínimo & 0,004 & 0,008 & 0,002 & 0,025 & 0,002 & 0,003 & 0,006 & 0,075 \\
Máximo & 0,219 & 0,291 & 0,627 & 0,379 & 0,236 & 0,251 & 0,714 & 0,720 \\
IC 95\% & 0,050 & 0,060 & 0,142 & 0,138 & 0,047 & 0,048 & 0,240 & 0,243 \\
& - & - & - & - & - & - & - & - \\
& 0,091 & 0,104 & 0,253 & 0,203 & 0,084 & 0,087 & 0,396 & 0,349
\end{tabular}

* Não houve diferença estatisticamente significativa para nenhum dos parâmetros analisados.

Através da tabela 5.5, pode-se observar que a quantidade de flúor ingerido através da dieta, durante o inverno, não foi estatisticamente diferente da quantidade de flúor ingerido durante o verão, assim como a quantidade de flúor proveniente de cada grupo de alimentos, analisado separadamente.

A tabela 5.6 mostra a quantidade de flúor ingerido (mg F/dia) a partir da dieta coletada num dia de semana, quando as crianças estavam nas creches, e no fim de semana, quando as crianças estavam em suas residências. 
Tabela 5.6 - Quantidade de flúor ingerido (mg F/dia) a partir da dieta coletada num dia de semana $(C)$ e no fim de semana $(R)$.

\begin{tabular}{lcc}
\hline \multicolumn{1}{c}{ F ingerido } & $\mathbf{C}$ & $\mathbf{R}$ \\
\hline média & 0,341 & 0,287 \\
DP & 0,131 & 0,198 \\
Mínimo & 0,106 & 0,031 \\
Máximo & 0,603 & 0,830 \\
IC 95\% & $0,291-0,391$ & $0,213-0,364$
\end{tabular}

* Não houve diferença estatisticamente significativa entre os parâmetros analisados.

Através da tabela 5.6, pode-se observar que a quantidade de flúor ingerido pelas crianças durante a semana, nas creches, não foi estatisticamente diferente da quantidade de flúor ingerido no fim de semana, nas residências.

A tabela 5.7 mostra a concentração de flúor $(\mu \mathrm{g} / \mathrm{g})$ encontrada nas unhas das mãos das crianças $(n=33)$, na primeira, segunda e terceira coletas, e a média das coletas.

Tabela 5.7 - Concentração de flúor $(\mu \mathrm{g} / \mathrm{g})$ encontrada nas unhas das mãos das crianças $(n=33)$, na primeira, segunda e terceira coletas.

\begin{tabular}{lccc}
\hline & $\mathbf{1}^{\mathrm{a}}$ coleta & $\mathbf{2}^{\mathrm{a}}$ coleta & $\mathbf{3}^{\mathrm{a}}$ coleta \\
\hline Média & $3,111^{\mathrm{a}}$ & $2,220^{\mathrm{b}}$ & $3,526^{\mathrm{a}}$ \\
DP & 1,136 & 1,465 & 1,397 \\
Mínimo & 1,305 & 0,454 & 0,893 \\
Máximo & 6,584 & 7.625 & 7,781 \\
IC 95\% & $2,708-3,514$ & $1,701-2,740$ & $3,031-4,022$ \\
\hline seguidos & por & letras diferentes & significam diferença estatisticamente \\
ativa $(p<0,05)$. & & &
\end{tabular}


Através da tabela 5.7, pode-se observar que a concentração de flúor contida nas unhas da segunda coleta foi significativamente menor que a concentração das unhas da primeira e terceira coletas.

Analisando as crianças que apresentaram uma estimativa de ingestão de flúor diária acima de $0,07 \mathrm{mg} \mathrm{F} / \mathrm{Kg}$ peso corporal/dia, não houve correlação entre a concentração de flúor nas unhas das mãos e a dose diária de flúor ingerido $(r=-0,052, p=0,810)$.

A tabela 5.8 mostra a concentração de flúor $(\mu \mathrm{g} / \mathrm{mL})$ na água das residências das crianças, na primeira e segunda coleta.

Tabela 5.8 - Concentração de flúor $(\mu \mathrm{g} / \mathrm{mL})$ na água das residências das crianças, na primeira e segunda coleta.

\begin{tabular}{lcc}
\hline & $\mathbf{1}^{\mathrm{a}}$ coleta & $\mathbf{2}^{\mathrm{a}}$ coleta \\
\hline Média & $0,761^{\mathrm{a}}$ & $0,570^{\mathrm{b}}$ \\
DP & 0,278 & 0,282 \\
Mínimo & 0,056 & 0,025 \\
Máximo & 1,155 & 0,870 \\
IC 95\% & $0,654-0,869$ & $0,460-0,679$
\end{tabular}

* Valores seguidos por letras diferentes significam diferença estatisticamente significativa $(p<0,01)$.

Através da tabela 5.8, pode-se observar que a concentração de flúor nas águas das residências das crianças, coletada inicialmente, foi estatisticamente maior que a concentração de flúor encontrada na segunda coleta.

Não houve correlação entre a concentração de flúor nas unhas das mãos e a concentração de flúor na água ( $r=0,2520, p=0,2349)$.

A tabela 5.9 mostra a relação dos dentifrícios utilizados pelas crianças, a concentração de flúor relatada no rótulo e a concentração encontrada. 
Tabela 5.9 - Relação dos dentifrícios utilizados pelas crianças, a concentração de flúor (ppm) relatada no rótulo e a concentração (ppm) encontrada.

\begin{tabular}{ccc}
\hline Dentifrícios & F rótulo $(\mathbf{p p m})$ & F encontrado (ppm) \\
\hline Contente Kids & $1000 \mathrm{MFP}$ & 1485 \\
Colgate Jr & $1100 \mathrm{NaF}$ & 1147 \\
Snoopy & $1100 \mathrm{MFP}$ & 1530 \\
Tandy & $1100 \mathrm{NaF}$ & 1093 \\
Tandy $^{2}$ & $1100 \mathrm{NaF}$ & 1160 \\
Colgate & $1500 \mathrm{MFP}$ & 1686 \\
Ice Fresh & 1093 \\
Ice Fresh & $1500 \mathrm{MFP}$ & 1631 \\
Ice Fresh & $1500 \mathrm{MFP}$ & 1623 \\
Ice Fresh & $1500 \mathrm{MFP}$ & 1787 \\
Sorriso $^{2}$ & $1500 \mathrm{MFP}$ & 1439 \\
Sorriso $^{2}$ & $1500 \mathrm{MFP}$ & 1667 \\
Sorriso $^{3}$ & $1500 \mathrm{MFP}$ & 1574 \\
Sorriso $^{4}$ & $1500 \mathrm{MFP}$ & 1482
\end{tabular}

${ }^{*}$ Números diferentes para as mesmas marcas de dentifrícios correspondem a tubos de diferentes creches onde foram realizadas as escovações.

** Não houve diferença estatisticamente significativa entre os parâmetros analisados.

Através da tabela 5.9, pode-se observar que não houve diferença estatisticamente significativa $(p>0,10)$ entre as concentrações dos dentifrícios analisadas e as relatadas nos rótulos dos mesmos. 
A tabela 5.10 mostra a quantidade de dentifrício utilizada (g), a quantidade de flúor total utilizado $(\mathrm{mg})$, bem como a de flúor ingerido $(\mathrm{mg})$ por escovação. Houve uma ingestão média de $77,4 \%$ da quantidade de dentifrício colocada na escova. A correlação entre as duas variáveis está expressa na figura 5.3.

Tabela 5.10 - Quantidade de dentifrício utilizada (g), flúor total utilizado (mg) e flúor ingerido $(\mathrm{mg})$ por escovação.

\begin{tabular}{lccc}
\hline & Dentifrício & F total & F ingerido \\
\hline Média & 0,488 & 0,763 & 0,591 \\
DP & 0,303 & 0,502 & 0,445 \\
Mínimo & 0,040 & 0,044 & 0,011 \\
Máximo & 1,320 & 0,656 & 1,759 \\
IC 95\% & $0,418-0,559$ & $0,647-0,879$ & $0,488-0,694$ \\
\hline
\end{tabular}

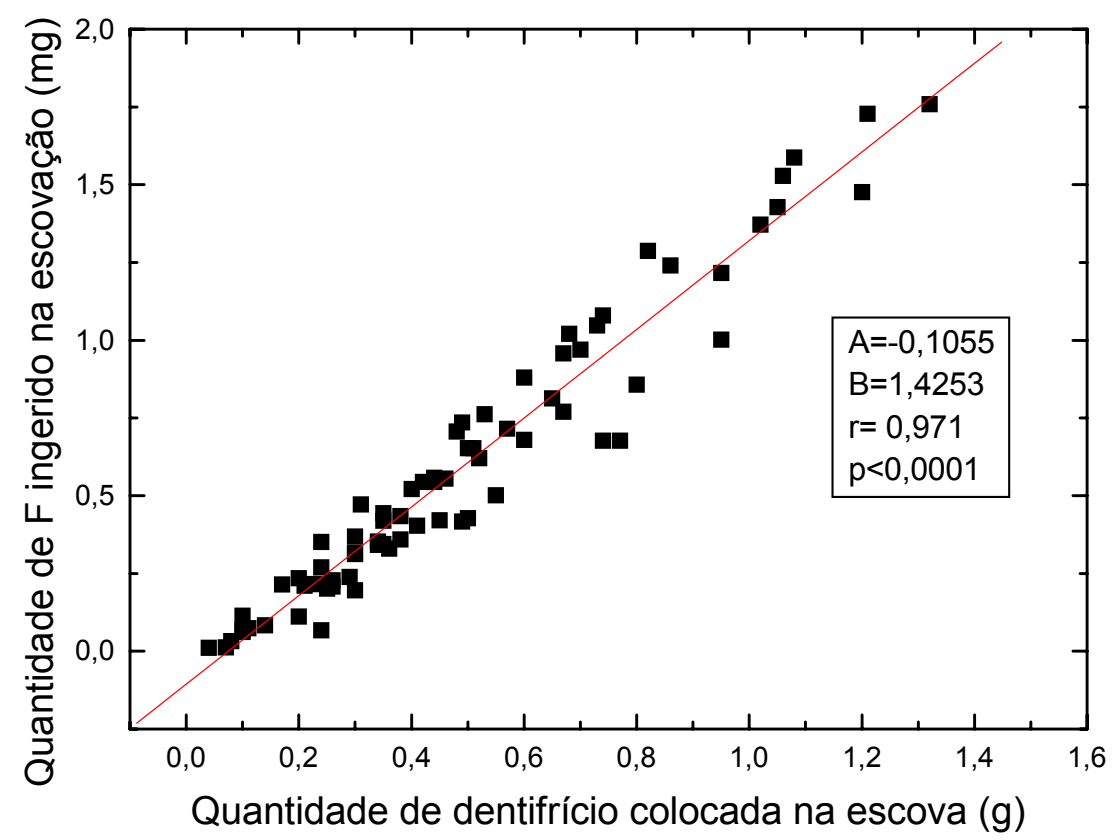

Figura 5.3 - Correlação entre a quantidade de dentifrício colocada na escova e a quantidade de $F$ ingerida na escovação. 
Através da figura 5.3, pode-se observar que houve uma correlação positiva $(r=0,971 ; p<0,0001)$ entre a quantidade de dentifrício colocada na escova e a quantidade de flúor ingerido na escovação.

A freqüência média de escovações diárias relatadas pelos pais foi de $2,36 \pm 0,74$ (1-4). A idade média, em meses, em que as crianças iniciaram a escovação foi de 13,87 $\pm 5,13$ (6-24). Quando questionados se as crianças ingeriam dentifrício em outros momentos além da escovação, 19 dos 33 pais responderam que sim. A maioria das crianças $(n=30)$ foi amamentada, numa média de 9,3 \pm 7,8 (1-30) meses. Somente 5 dos 33 pais relataram que seus filhos consumiam leite em pó. A renda média per capta das famílias foi de $R \$ 143,52 \pm 84,08(20-400)$. 
Ao fazer uma retrospectiva de sua vida, você descobrirá que os momentos em que viveu realmente foram aqueles nos quais você fez coisas com espírito de amor." Henry Drummond 


\section{DISCUSSÃO}

A dose de ingestão de flúor, em crianças na idade de risco, para fluorose dentária vem sendo uma preocupação desde que tem se notado uma tendência de aumento na prevalência de fluorose dentária, no mundo todo (JACKSON et al. ${ }^{68}$, 1999; LEVERETT ${ }^{77}$, 1986; TABARII ${ }^{130}$, 2000; TSUTSUI; YAGI; HOROWTZ ${ }^{134}$, 2000; PEREIRA et al. ${ }^{109}$, 2000). Para que se possa saber o risco para fluorose dentária, previamente ao aparecimento da alteração, tem-se estudado a possibilidade do uso de marcadores biológicos de exposição ao flúor, como, por exemplo, a unha. Neste estudo, foi estimada a ingestão total de flúor a partir da dieta e do dentifrício, assim como observada sua relação com a concentração de flúor nas unhas das mãos de crianças, na faixa etária de risco para fluorose dentária, nos incisivos centrais permanentes.

Porém, os estudos que realizam a estimativa da ingestão de flúor a partir da dieta, com crianças brasileiras, analisam-na como um todo (LIMA; CURY $^{86}$, 2001; PESSAN; SILVA; BUZALAF ${ }^{111}$, 2003; PAIVA; LIMA; CURY ${ }^{102}$ 2003). Neste estudo, a dieta foi analisada separadamente, a fim de se avaliar qual a contribuição de cada constituinte da dieta das crianças. Os alimentos foram separados e analisados em três grupos distintos: sólidos, leite e água e outros líquidos, levando em consideração o estudo de CLOVIS; HARGREAVES ${ }^{34}$ (1988), em que o leite e a água foram as bebidas mais consumidas por crianças canadenses. Neste estudo, as crianças participantes freqüentam creches municipais de Bauru e apresentam nível sócio-econômico baixo; portanto, os outros líquidos são ingeridos em menor freqüência que o leite e a água. No estudo de ROJAS-SANCHEZ et al. ${ }^{121}$ (1999), a dieta foi dividida em dois grupos, separando os alimentos sólidos das bebidas.

A dose de flúor ingerida a partir da dieta foi de $0,025 \pm 0,013(0,003$ a $0,70) \mathrm{mg} \mathrm{F} / \mathrm{kg}$ peso/dia. Tais resultados são semelhantes aos encontrados por LEVY; BASTOS; BUZALAF ${ }^{85}$ (2004), em que a ingestão média de flúor a partir da dieta foi de $0,029 \mathrm{mg} \mathrm{F} / \mathrm{Kg}$ peso corporal/dia, para crianças de 2 a 6 anos, residentes em Bauru. Como observado na tabela 5.2, dentre os 
constituintes da dieta, a água e o leite foram o grupo que tiveram maior contribuição na ingestão de flúor, a partir da dieta $(0,184 \pm 0,108 \mathrm{mg} F /$ dia $)$, em relação ao grupo dos alimentos sólidos $(0,072 \pm 0,045 \mathrm{mg} F /$ dia $)$ e dos outros líquidos $(0,066 \pm 0,043 \mathrm{mg} F / d i a)$. Os resultados encontrados por ROJAS-SANCHEZ et al. ${ }^{121}$ (1999), na cidade fluoretada de Indianápolis, com crianças de 16 a 40 meses de idade, foram de $146 \pm 17 \mu \mathrm{g}$ F/dia para os alimentos sólidos e $396 \pm 52 \mu \mathrm{g}$ F/dia para as bebidas. Apesar da idade das crianças e a quantidade total de flúor ingerido, nos dois estudos, não serem os mesmos, a contribuição dos líquidos para a ingestão total de $\mathrm{F}$ a partir da dieta, foi semelhante (73\% no trabalho de ROJAS-SANCHEZ et al. ${ }^{121}, 1999$ e $77 \%$ no presente estudo). O leite de vaca apresenta baixa concentração de flúor, em torno de 0,022 ppm (KOPARAL; ERTUGRUL; OZTEKIN ${ }^{72}$, 2000); contudo, o leite em pó, principalmente se preparado com água fluoretada, pode ser um importante fator na ingestão de flúor. (BUZALAF ${ }^{17}$ et al., 2001; LATIFAH; RAZAK ${ }^{76}$, 1989; McKNIGHT-HANES et al. ${ }^{92}$, 1988; SILVA; REYNOLDS ${ }^{125}$, 1996; BUZALAF et al. ${ }^{25}$, 2004). BUZALAF et al. $^{17}$ (2001) encontraram uma concentração de 0,91 a 1,65 ppm, em leites em pó brasileiros, quando preparados com água de abastecimento fluoretada. A água fluoretada exerce um papel importante na ingestão de flúor, entretanto, esta contribuição é mais indireta, quando a água é usada para preparar alimentos e bebidas (BURT $\left.{ }^{13}, 1992\right)$. Ainda no mesmo estudo de ROJASSANCHEZ et al $^{121}$. (1999), a estimativa da ingestão de flúor de crianças residentes em duas comunidades não fluoretadas e uma fluoretada foi comparada. Analisando-se somente o grupo dos alimentos sólidos, não foi encontrada diferença estatisticamente significativa entre a ingestão de flúor das crianças residentes na região fluoretada (146 $\pm 17 \mu \mathrm{g} F /$ dia) e das nas regiões não fluoretadas (116 \pm 24 e $132 \pm 16 \mu \mathrm{g}$ F/dia). Porém, a ingestão de flúor a partir das bebidas foi significativamente maior na região fluoretada (396 $\pm 52 \mu \mathrm{g} \mathrm{F/dia} \mathrm{)} \mathrm{que} \mathrm{nas} \mathrm{regiões} \mathrm{não} \mathrm{fluoretadas} \mathrm{(103} \pm 22$ e $257 \pm 59 \mu \mathrm{g}$ F/dia). Segundo os autores, a ingestão de flúor a partir das bebidas está diretamente relacionada com o nível de flúor da água de abastecimento. No Brasil, no estudo de LEVY; BASTOS; BUZALAF ${ }^{85}$ (2004), a ingestão total de 
flúor a partir da dieta foi de 0,55 0,61 e de 0,09 \pm 0,06 mg para crianças de 2-6 anos, residentes em áreas fluoretada e não fluoretada, respectivamente, corroborando que, dentre os componentes da dieta, a água tem um importante papel na ingestão total de flúor.

Em Bauru, a fluoretação da água de abastecimento público sofre alguns problemas na manutenção da concentração ótima de flúor. As médias da concentração de flúor encontrada na água de abastecimento foram de 0,761 $\pm 0,278(0,056$ a 1,155) $\mu \mathrm{g} / \mathrm{mL}$ e 0,570 $\pm 0,282(0,025$ a $0,870) \mu \mathrm{g} / \mathrm{mL}$, para a primeira e segunda coletas, respectivamente. Dentre as amostras $(n=10)$ que não estavam dentro da faixa de concentração de flúor recomendada $(0,6$ a $0,8 \mathrm{ppm})$, a maioria $(\mathrm{n}=7)$ apresentava uma concentração inferior ao recomendado, portanto, prejudicando a prevenção da cárie. Estes dados confirmam estudos prévios, em que foi encontrada uma grande variação (0,01 a 9,35 ppm) na concentração de flúor na água de abastecimento de Bauru (BUZALAF et al. ${ }^{20}$, 2002). Houve também uma grande variabilidade entre as amostras da mesma área em dias diferentes, e entre áreas diferentes, e uma porcentagem de $82 \%$ das amostras estava abaixo do nível mínimo aceitável.

A média da dose diária de ingestão total de flúor $(0,13 \pm 0,087 \mathrm{mg}$ $\mathrm{F} / \mathrm{Kg}$ de peso corporal/dia) foi ligeiramente maior que a encontrada no estudo de $\operatorname{ARSATI}^{1}$ (2003) $(0,084 \pm 0,032 \mathrm{mg} \mathrm{F} / \mathrm{Kg}$ de peso corporal/dia) e PAIVA; LIMA; CURY ${ }^{87}$ (2003) (0,088 $\pm 0,049$ e 0,090 $\pm 0,022 \mathrm{mg} \mathrm{F/Kg} \mathrm{de}$ peso corporal/dia), em que as crianças eram da mesma faixa etária e brasileiras. No estudo de ROJAS-SANCHEZ et al ${ }^{121}$. (1999), a média da ingestão de flúor de crianças americanas de 16 a 40 meses de idade, residentes em região fluoretada, foi de $0,070 \pm 0,007 \mathrm{mg} \mathrm{F} / \mathrm{Kg}$ de peso corporal/dia. Em outro estudo realizado com crianças japonesas de 3 a 5 anos (MURAKAMI et al. ${ }^{95}$, 2002), a dose encontrada também foi menor $(0,021 \pm 0,012)$ que a observada no presente estudo. Em crianças brasileiras de 4-5 anos e de 6-7 anos, residentes em região fluoretada, PESSAN; SILVA; BUZALAF ${ }^{111}$ (2003) encontraram uma ingestão total de $0,056 \mathrm{mg} \mathrm{F} / \mathrm{kg}$ peso corporal $( \pm 0,040)$ e $0,057 \mathrm{mg} \mathrm{F} / \mathrm{kg}$ peso corporal 
$( \pm 0,052)$. Levando-se em consideração a dose limite de $0,07 \mathrm{mg} \mathrm{F} / \mathrm{kg}$ peso corporal/dia (BURT $\left.{ }^{13}, 1992\right)$, as crianças deste estudo apresentaram uma média superior ao recomendado. Dentre o total de 33 crianças da amostra, 24 delas $(72,7 \%)$ tiveram a ingestão acima do limite.

Através da tabela 5.5, pode-se observar que a quantidade de flúor ingerido através da dieta, durante o inverno $(0,318 \pm 0,208 \mathrm{mg} F /$ dia), não foi estatisticamente diferente da quantidade de flúor ingerido durante o verão $(0,296 \pm 0,142 \mathrm{mg} F /$ dia $)$, assim como a quantidade de flúor proveniente de cada grupo de alimentos analisados separadamente. Existe alguma controvérsia na literatura a respeito da ingestão de flúor a partir da dieta nas diferentes estações do ano. Os resultados do presente trabalho não estão de acordo com os encontrados por LIMA; CURY ${ }^{87}$ (2003), em que a ingestão de flúor durante as estações da primavera e verão foi estatisticamente maior que a observada durante o outono e inverno. Porém, para que tais resultados fossem encontrados, foi necessário realizar alguns cálculos, já que foi observada uma maior concentração de flúor na água de abastecimento durante o outono e inverno. Já em Bauru, como relatado anteriormente, a concentração de flúor na água de abastecimento está sujeita a variações durante o ano.

Também não foi encontrada diferença entre a quantidade de flúor ingerido pelas crianças durante a semana, nas creches $(0,341 \pm 0,131 \mathrm{mg}$ F/dia), e a quantidade de flúor ingerido no fim de semana, nas residências $(0,287 \pm 0,198 \mathrm{mg} F /$ dia $)$. Tais resultados estão em acordo com os achados de GUHA-CHODHURY; DRUMMOND; SMILLIE ${ }^{57}$ (1996), que coletaram 3 amostras de dieta duplicada ao longo de 1 ano e LIMA; CURY ${ }^{86}$ (2001), que coletaram amostras de dieta duplicada por 2 dias seguidos, em quatro períodos do ano, com crianças na faixa etária de risco para fluorose dentária, e também não encontraram diferenças significativas entre as concentrações de F. Por outro lado, ROJAS-SANCHEZ et al. ${ }^{121}$ (1999), encontraram diferenças significativas quando realizaram a coleta da dieta duplicada em 2 ou 3 dias durante uma semana, sendo 1 dos dias no fim de semana. Os autores sugerem que, para uma estimativa mais precisa, seria 
recomendável que as coletas da dieta fossem feitas por 3 dias na semana, e de 3 a 4 vezes ao ano. Porém, tal procedimento demanda maiores gastos, tanto em relação à dieta, quanto aos reagentes laboratoriais. Além disso, há uma maior chance de perda dos participantes durante o desenvolvimento da pesquisa. Outro fator a ser considerado é a relevância destas possíveis diferenças, uma vez que a ingestão de flúor a partir do dentifrício, na idade entre 2-3 anos, corresponde a $80 \%$ da ingestão total de flúor diária.

Seguindo este raciocínio, em todos os estudos em que foi realizada a estimativa da ingestão de flúor através da dieta e da escovação, o dentifrício foi o maior contribuinte para a ingestão total de flúor, em comparação com a dieta. Neste estudo, a ingestão de flúor através da escovação foi de 0,106 \pm $0,085(0,004$ a 0,401) $\mathrm{mg} \mathrm{F} / \mathrm{kg}$ peso/dia, dose esta que já excede o limite recomendado $(0,07 \mathrm{mg} \mathrm{F} / \mathrm{kg}$ peso corporal/dia). A ingestão de flúor através do dentifrício correspondeu à cerca de $80 \%$ da ingestão total de flúor. Para LIMA; CURY ${ }^{86}$ (2001), essa porcentagem encontrada foi de $55 \%$ e para PAIVA $^{101}$ (1999), foi de $64,43 \%$, correspondendo a 0,052 e 0,0514 mg F/kg peso/dia, respectivamente.

Dos dentifrícios consumidos pelas crianças durante as escovações, foi observado que duas marcas de dentifrícios infantis, Contente Kids e Snoopy, que relatavam possuir 1000 e 1100 ppm de flúor, respectivamente, apresentaram uma concentração maior que o relatado (1485 e 1530 ppm). Porém, não se pode afirmar que haja uma constância nestas concentrações, já que somente os tubos utilizados pelas crianças na escovação foram analisados. Além disso, foi encontrada uma concentração acima de 1500 ppm em 7 das 14 análises realizadas, o que colabora para uma ingestão elevada de flúor a partir do dentifrício.

Através da figura 5.3, pode-se observar uma correlação positiva entre a quantidade de dentifrício utilizada e a quantidade de flúor ingerido por escovação. Também se pode observar que $77,4 \%$ do dentifrício colocado na escova foi ingerido pelas crianças. Este dado é semelhante ao relatado por PAIVA; LIMA; CURY ${ }^{102}$ (2003), que relataram uma ingestão de 64,6\% e 
$57,4 \%$ para crianças residentes em comunidades brasileiras, de idade semelhante à das crianças do presente estudo.

A eficácia cariostática do dentifrício está relacionada ao seu uso tópico, não havendo necessidade de ingestão. Somando-se a isto o fato de que o dentifrício é a principal fonte de ingestão de flúor, torna-se evidente a importância de se orientar os pais e responsáveis sobre a necessidade de se utilizar uma pequena quantidade de dentifrício durante a escovação, já que a quantidade de dentifrício ingerida é diretamente relacionada à quantidade colocada na escova. No entanto, esta medida é de difícil controle, uma vez que, muitas vezes, tanto o pai quanto a mãe da criança trabalham e a pessoa responsável pelos cuidados da criança nem sempre entende a importância de se controlar a ingestão de flúor através da escovação. Assim, uma outra alternativa possível seria o uso de dentifrícios com concentração reduzida de flúor, que idealmente não deve apenas reduzir a ingestão de flúor, mas também deve ser igualmente efetiva na prevenção de cáries como as concentrações disponíveis no mercado de 1000-1500 ppm F. Têm sido realizados alguns estudos clínicos longitudinais sobre a efetividade de dentifrícios com baixas concentrações de F. REED ${ }^{13}$ (1973); MITROPOULOS et al. ${ }^{94}$ (1984) e KOCH et al. ${ }^{71}$ (1990) concluíram que os dentifrícios com baixas concentrações de $\mathrm{F}$ podem ser um pouco menos efetivos do que os dentifrícios de $1000 \mathrm{ppm}$. O único estudo com dentifrício de baixa concentração que usou amostras de crianças pré -escolares é o de um dentifrício de 500-550 ppm, o qual foi relatado por WINTER et al. ${ }^{142}$ (1989). Este estudo de três anos, duplo cego, comparou a efetividade de dentifrícios com 550 e 1.000 ppm $\mathrm{F}$ em crianças, que tinham dois anos de idade no "baseline", pela medição dos incrementos no índice ceo. O incremento de cárie foi levemente mais alto (10\%) no grupo que utilizou dentifrício de baixa concentração de $F$ depois de três anos, mas a diferença não foi estatisticamente significativa. Os autores concluíram que "a pasta de dente com baixa concentração de $\mathrm{F}$ apresentou uma atividade anti-cáries similar ao da pasta controle e que poderia, então, ser recomendada para crianças jovens". Entretanto, esta conclusão foi baseada em um único 
estudo e experimentos adicionais de tais dentifrícios devem ser conduzidos. Numa revisão sistemática de estudos comparando a eficácia anti-cárie de dentifrícios infantis com concentrações de flúor com 600 ppm ou menos com dentifrícios contendo 1000 ppm ou mais, AMMARI et al $^{2}$. (2003), concluíram que os estudos disponíveis na literatura permitem afirmar que os dentifrícios com 250 ppm são menos efetivos que aqueles contendo 1000 ppm. No entanto, para os dentifrícios com concentração em torno de 500 ppm, são necessários mais estudos. Um estudo realizado in situ revelou que um dentifrício, com 550 ppm, mas com pH reduzido, para aumentar a sua reatividade com o esmalte dentário, teve a mesma eficácia cariostática do dentifrício "gold standard" (Crest, 1100 ppm F) (PERES et al. ${ }^{110}, 2001$ ). Um trabalho recém realizado em nosso laboratório (dados ainda não publicados) revelou que um dentifrício com concentração de $F$ reduzida (550 ppm) e com $\mathrm{pH}$ acidulado levou a concentrações de $\mathrm{F}$ na saliva similares às do dentifrício "gold standard" (Crest, 1100 ppm F). Isto ajudaria a explicar a possível semelhança de eficácia de um dentifrício, com baixa concentração de flúor e $\mathrm{pH}$ reduzido, em relação aos dentifrícios convencionais.

No presente estudo, a concentração média de flúor ingerida a partir da escovação foi de $0,106 \mathrm{mg} / \mathrm{Kg}$ peso corporal/dia. Considerando-se que a maioria dos dentifrícios utilizados pelas crianças do estudo possuía 1500 ppm F, o uso de um dentifrício com concentração de flúor de 500 ppm reduziria a ingestão de flúor a partir do dentifrício para $0,035 \mathrm{mg} / \mathrm{Kg}$ peso corporal/dia, o que, somado à ingestão de flúor pela dieta $(0,025 \mathrm{mg} / \mathrm{Kg}$ peso corporal/dia), levaria a uma ingestão total de flúor de $0,060 \mathrm{mg} / \mathrm{Kg}$ peso corporal, dentro da dose diária recomendada $\left(B U R T^{13}, 1992\right)$. Porém, pode estar ocorrendo uma superestimativa da ingestão de flúor a partir do dentifrício. Num recente estudo de Pessan et al. ${ }^{111}, 2003$ que monitorou a excreção urinária de flúor em crianças de 4-7 anos de idade, usando dentifrício placebo ou fluoretado, especulou que esta superestimação poderia ser em torno de $50 \%$, sendo explicada por um conjunto de fatores: diferença na absorção do $\mathrm{NaF}$ comparada com o MFP, redução na biodisponibilidade do flúor se ingerido logo após a refeição, superestimação 
da freqüência de escovação pelas mães e perda do dentifrício que fica ao redor da boca.

Considerando-se o dentifrício como a maior fonte de ingestão de $\mathrm{F}$ para crianças de 2-3 anos, ainda que os dados presentes na literatura possam estar superestimados, e levando-se em conta que a eficácia clínica dos dentifrícios com concentração de F em torno de 500 ppm ainda não está clinicamente comprovada, o melhor balanço em termos de controle de cárie e prevenção de fluorose seria o uso de pequenas quantidades de um dentifrício de concentração de flúor em torno de 500 ppm para crianças menores que 3 anos e de baixo ou moderado risco à cárie.

A coleta de amostras de unhas é simples e não invasiva, e existem vários estudos sugerindo o uso de unhas como biomarcadores para a exposição ao flúor em humanos (CZARNOWSKI; KRECHNIAK ${ }^{36}$, 1990; CZRNOWISKI et al. $^{37}$, 1996; SCHMIDT; LEUSCHKE, ${ }^{123}$ 1990; SPATE et al. $^{127}$, 1994; WHITFORD et al. ${ }^{141}$, 1999; LEVY; BASTOS; BUZALAF ${ }^{85}$, 2004; RODRIGUES; BASTOS; BUZALAF ${ }^{120}$, 2004).

Um estudo recente (RODRIGUES; BASTOS; BUZALAF ${ }^{120}$, 2004), em que crianças brasileiras de 2 a 3 anos de idade passaram por um período do estudo sem consumir dentifrício fluoretado, e outro período com dentifrício fluoretado (1500 ppm F), pôde ser observado um pico de concentração de flúor nas unhas 16 semanas após o início o uso de dentifrício fluoretado. Este aumento na concentração de flúor nas unhas após o uso do dentifrício fluoretado foi da ordem de 3 vezes. Entretanto, os autores não mediram a ingestão total de flúor das crianças, a partir da dieta e do dentifrício. Os resultados do presente estudo, que mostram uma contribuição de $80 \%$ do dentifrício fluoretado para a ingestão total diária de flúor, poderiam ajudar a explicar esse aumento na concentração de flúor nas unhas das mãos, observado por RODRIGUES; BASTOS; BUZALAF ${ }^{120}$ (2004).

Há ainda alguns trabalhos na literatura mostrando que a unha pode ser usada como um biomarcador para diferenciar crianças expostas cronicamente a diferentes níveis de flúor a partir da água (WHITFORD et al. $^{141}$, 1999; ARSATI ${ }^{1}$, 2003; LEVY; BASTOS; BUZALAF ${ }^{85}$, 2004; 
FUKUSHIMA et al. $\left.{ }^{50}, 2004\right)$. Nestes trabalhos, houve uma diferença significativa na concentração de flúor encontrada nas unhas de crianças expostas à água de abastecimento não fluoretada, otimamente fluoretada ou hiperfluoretada. No presente estudo, entretanto, não houve correlação entre a ingestão diária total de flúor das crianças e a concentração de flúor presente nas unhas. Convém ressaltar que todas as crianças estavam expostas às mesmas condições, apesar de haver variações individuais na quantidade de flúor ingerido diariamente. Desse modo, surge a questão da sensibilidade, especificidade e valores de predição, quando se pretende usar as unhas como biomarcador de exposição ao flúor e preditor de fluorose dentária. É possível que as unhas só possam diferenciar níveis de exposição ao flúor quando estes forem muito discrepantes. De fato, SAMPAIO et al. ${ }^{122}$ (2003), numa tentativa de validar a concentração de flúor nas unhas das mãos como biomarcador para fluorose dentária, examinaram, para fluorose dentária, usando o índice TF, crianças que residiam em áreas do Estado da Paraíba contendo concentração natural de $F$ na água de 0,1, 1,6 e 2,3 mg $\mathrm{F} / \mathrm{L}$. Estas crianças tinham sido previamente examinadas quanto à concentração de $\mathrm{F}$ presente nas unhas das suas mãos (WHITFORD et al. ${ }^{141}$, 1999). Foram encontrados escores TF variando de 0 a 5 . Para as crianças com TF $0(n=11)$ e $5(n=7)$, a concentração média (erro padrão) de flúor encontrada nas unhas foi de $1,91(0,2)$ e $7,58(2,7) \mathrm{mg} / \mathrm{kg}$, respectivamente, sendo as diferenças entre estes grupos estatisticamente significativas. No entanto, para TF 1, 2, 3 e 4, somente casos individuais foram observados com concentrações de $F$ nas unhas de 2,76, 4,99, 5,20 e 7,9 mg/Kg, respectivamente. Os autores concluíram que a análise de flúor nas unhas pode ser usada como biomarcador para identificar indivíduos com risco a desenvolver fluorose dentária com um grau TF de no mínimo 5 , sendo necessários estudos adicionais para se determinar a sensibilidade desse biomarcador para identificar indivíduos de risco para fluorose dentária leve (TF 1, 2 e 3). Os resultados do presente estudo parecem estar de acordo com os achados de SAMPAIO et al. ${ }^{122}$ (2003), no sentido de que pequenas variações na ingestão diária de $\mathrm{F}$ não podem ser detectadas nas unhas das 
mãos, e isto poderia sugerir que, se estas crianças apresentarem fluorose quando da erupção de seus incisivos permanentes, a mesma deverá ser leve (TF 1, 2 ou 3). As crianças do presente estudo continuarão a ser monitoradas e, no futuro, quando da erupção dos incisivos permanentes, serão examinadas para fluorose dentária, o que poderá ajudar a determinar a sensibilidade da análise de flúor nas unhas como preditor de risco de fluorose dentária. Outro fator que merece atenção, quando se fala neste assunto, é a possível susceptibilidade genética à fluorose dentária, já demonstrada em diferentes linhagens de camundongos por EVERETT et al. $^{44}$ (2002). Apesar de isto não ter ainda sido mostrado em humanos, há alguns relatos na literatura de ocorrência de fluorose dentária com níveis de ingestão de flúor baixos $\left(0,02 \mathrm{mg} / \mathrm{Kg}\right.$ peso corporal/dia) (BAELUM et al. ${ }^{3}$, 1987), o que nos faz crer que esta susceptibilidade individual ao flúor também ocorre em humanos.

Um achado de difícil explicação, no presente estudo, foi o fato de a concentração média de flúor encontrada nas unhas na segunda coleta $(2,220 \pm 1,465 \mu \mathrm{g} / \mathrm{g})$ ter sido significativamente menor que a encontrada na primeira $(3,111 \pm 1,136 \mu \mathrm{g} / \mathrm{g})$ e terceira $(3,526 \pm 1,397 \mu \mathrm{g} / \mathrm{g})$ coletas. No estudo de LEVY; BASTOS; BUZALAF ${ }^{85}$ (2004), tais diferenças entre coletas não foram encontradas, embora o número amostral tenha sido menor $(n=15)$. No nosso estudo, apesar de não ter havido diferenças significativas na ingestão de flúor a partir da dieta coletada em diferentes períodos, pôdese notar uma diminuição significativa na concentração de flúor presente na água de abastecimento na segunda coleta, além de flutuações na concentração de flúor na água de abastecimento de Bauru serem comumente relatadas (BUZALAF ${ }^{20}$ et al., 2002). Entretanto, sendo a contribuição da dieta para a ingestão total diária de flúor pequena, este fato não explicaria totalmente a redução na concentração de flúor presente nas unhas das mãos. Outra possível explicação para a redução na concentração de flúor nas unhas das mãos seria uma mudança de hábito temporária e imediata após as mães terem recebido as recomendações, por questões éticas, sobre a quantidade de dentifrício a ser utilizado, quando responderam 
ao questionário. Se assim ocorreu, então é possível que a unha seja um biomarcador sensível à exposição de flúor a partir do dentifrício, sugerindo a necessidade de maiores estudos para se analisar a viabilidade do uso da unha como biomarcador de exposição ao flúor, bem como a sensibilidade deste biomarcador. 
Tenha coragem para lidar com as grandes tristezas da vida e paciência para lidar com as pequenas; e, depois de ter cumprido laboriosamente sua tarefa diária, vá dormir em paz. Deus continua acordado. Victor Hugo 


\section{CONCLUSÕES}

Através dos resultados obtidos pode-se concluir que:

$\checkmark$ A dose de flúor diária ingerida pelas crianças através da dieta e da escovação representa um risco para fluorose dentária, sendo a ingestão a partir da escovação quatro vezes maior que a partir da dieta.

$\checkmark$ Dentre os alimentos da dieta, o leite e a água são os que mais contribuem na ingestão de flúor.

$\checkmark$ Não houve correlação entre a quantidade de flúor ingerida e a concentração de flúor presente nas unhas das mãos, sugerindo que a unha não é um biomarcador sensível para a detecção de pequenas variações na ingestão diária de flúor. 
"O amor que damos é o único que guardamos"

Elbert Hubbard 
ANEXO 1 - Carta de Informação e Termo de Consentimento Livre e Esclarecido

\author{
Universidade de São Paulo \\ Faculdade de Odontologia de Bauru \\ Al. Dr. Octávio Pinheiro Brisolla, 9-75 - Bauru-SP - CEP 17012-901 - C.P. 73 \\ PABX (0XX14)235-8000 - FAX (0XX14)223-4679 \\ Departamento de Ciências Biológicas \\ e-mail: dep-cib@,fob.usp.br- Fone: (0XX14)235-8282
}

\title{
CARTA DE INFORMAÇÃO
}

Senhores pais e responsáveis,

Venho por meio desta informar-Ihes que a Cirurgiã-Dentista Beatriz Simões de Almeida, orientada pela Profa. Dra. Marília Afonso Rabelo Buzalaf, do Departamento de Ciências Biológicas, da Faculdade de Odontologia de Bauru - USP, realizará uma pesquisa na qual analisará a exposição ao flúor de crianças de 21 a 30 meses de idade, sendo que aos 7 anos essas criançs serão examinadas quanto à presença de fluorose.

Fluorose é uma alteração que acomete os dentes quando há um consumo de flúor em excesso durante sua formação. Freqüentemente, apresenta-se na forma e manchas brancas.

As mães serão entrevistadas sobre os hábitos alimentares das crianças, uso de pasta de dentes com flúor e suplementos através da aplicação de um questionário. Além disso será realizada a coleta de duas amostras de água da torneira das residências das crianças e das creches, num intervalo de cinco meses, e de três amostras de unhas das mãos, num intervalo de dois meses.

Caso sejam observados hábitos que possam causar algum risco de fluorose, as mães serão devidamente orientadas.

Para finalidades didático-pedagógicas, fotos dos pacientes alvo deste benefício poderão ser utilizadas em divulgação em periódicos, livros e eventos científicos. 
Por estar ciente abaixo o responsável legal assina, confirmando o recebimento de via de igual teor, explicada nos mínimos detalhes pela equipe de pesquisadores.

Bauru - SP, _ I I

ASSINATURA DO RESPONSÁVEL LEGAL PELO MENOR

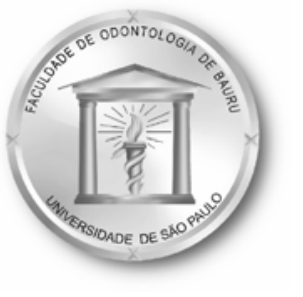

Universidade de São Paulo

Faculdade de Odontologia de Bauru

Al. Dr. Octávio Pinheiro Brisolla, 9-75 - Bauru-SP - CEP 17012-901 - C.P. 73

PABX (0XX14)235-8000 - FAX (0XX14)223-4679

Departamento de Ciências Biológicas

e-mail: dep-cib@,fob.usp.br- Fone: (0XX14)235-8282

\section{TERMO DE CONSENTIMENTO LIVRE E ESCLARECIDO}

Pelo presente instrumento que atende as exigências legais, o senhor portador da cédula

de identidade $n$. , após leitura minuciosa da CARTA DE INFORMAÇÃO, devidamente explicada pelos profissionais em seus mínimos detalhes, ciente dos serviços e procedimentos aos quais será submetido, não restando quaisquer dúvidas a respeito do lido e do explicado, firma seu CONSENTIMENTO LIVRE E ESCLARECIDO em concordância em participar da pesquisa proposta no que lhe é cabível conforme a CARTA DE INFORMAÇÃO.

Fica claro que, o paciente e/ou seu representante legal, pode a qualquer momento retirar seu CONSENTIMENTO LIVRE E ESCLARECIDO e deixar de participar do estudo alvo da pesquisa, e, ciente que todo trabalho realizado torna-se informação confidencial guardada por força do sigilo profissional ( Art. $9^{\circ}$ do Código de Ética Odontológica)

Por estarem entendidos e conformados, assinam o presente termo.

Bauru, I_ I

Responável Legal

Pesquisador

ANEXO 2 - Questionário

UNIVERSIDADE DE SÃO PAULO

FACULDADE DE ODONTOLOGIA DE BAURU 


\section{QUESTIONÁRIO}

\section{Responsável pelas informações e}

coleta:

Nome

da

mãe:

Nome

do

pai:

Nome

da

criança:

Sexo:

DN:

Peso:

$\mathrm{Kg}$

Endereço:

Telefone:

Instituição

à

qual

a

criança

pertence:

\section{ANAMNESE}

1- Está fazendo uso de algum medicamento? Sim:

Não: Qual?

2- Já foi ao dentista? Sim: Não:

3- Já fez aplicação de flúor profissional: Sim:

Não: Que tipo?

4- Tem escova de dente? Sim:

Não: Qual marca e tipo?

5- Tem pasta de dente? Sim: Não:

Qual marca?

6- A criança escovou os dentes hoje? Sim: Não: Não se lembra:

7- A criança escovou os dentes ontem? Sim: Não: Não se lembra:

8- Freqüência de escovações:

Momentos: 
9- Com que idade começou a escovar os dentes:

10- Quem realiza as escovações da criança?

11- Quanto de pasta é colocado sobre a escova?

Toda a extensão da cerda: Metade: Menos da metade:

12- Quem coloca a pasta na escova?

13- A criança tem o hábito de ingerir dentifrício em outros momentos além da escovação? Sim: Não:

14- A criança usa que tipo de água: Torneira: Poço: Mineral: + de uma:

15- A criança toma regularmente comprimido fluorado? Sim: Não:

16- A criança foi amamentada? Sim:_ Não: Até que idade:

17- Costuma tomar qual tipo de leite? Leite de vaca: Leite em pó: Leite de soja:__ Outro tipo:__ Mais de um tipo:

18- Costuma comer comidas infantis prontas para o consumo? Sim: Não:

Qual?

Quando?

19- Costuma consumir bebidas prontas? Sim: Não: Qual? Quando?

20- Costuma consumir chá? Sim: Qual? Não: Quando? 
21- Costuma comer cereais tipo Neston, Mucilon? Sim: Não: Quando e quanto?

22- Qual a renda familiar? Quantas pessoas vivem desta renda?

23- Marque um " $X$ " nos itens que você possui e a respectiva quantidade:

( ) automóvel:

( ) máquina de lavar roupa:

( ) TV cores:

( ) vídeo cassete:

( ) banheiro:

( ) aspirador:

( ) empregada mensalista:

( ) geladeira:

( ) rádio:

24- Qual a sua escolaridade?

( ) analfabeto/primário incompleto

( ) primário completo $/ 1^{\circ}$ grau incompleto

( ) $1^{\circ}$ grau completo $/ 2^{\circ}$ grau incompleto

( ) $2^{\circ}$ grau completo/Superior incompleto

( ) superior completo

Recomendações:

Nome do entrevistador: Data: 


\title{
ANEXO 3 - Orientações aos pais
}

\author{
UNIVERSIDADE DE SÃO PAULO \\ FACULDADE DE ODONTOLOGIA DE BAURU
}

\section{ORIENTAÇÕES}

Seguem-se algumas orientações para que as crianças sejam expostas ao flúor com o mínimo de risco para causar fluorose dentária.

1- Coloque uma pequena quantidade de pasta dentária na escova da criança, o equivalente a um grão de feijão.

2- As escovações devem sempre ser supervisionadas por um adulto, para a criança não engolir muita pasta.

3- Se for utilizado leite em pó, diluí-lo em água mineral já que esta, normalmente, contém um baixo teor de flúor.

4- Não faça uso de suplementos, porque a cidade de Bauru possui água fluoretada e a somatória dos métodos não é recomendável.

5- Procure evitar o consumo regular de produtos com alto teor de flúor como Toddynho ${ }^{\circledR}$, Mucilon ${ }^{\circledR}$ e Neston ${ }^{\circledR}$. 


\section{REFERÊNCIAS BIBLIOGRÁFICAS}

Se você estiver enrolado demais, é sinal de que está com muita roupa." Jane Ann Clark 


\section{REFERÊNCIAS BIBLIOGRÁFICAS}

1. ARSATI, Y.B.O.L. A unha como indicador biológico de exposição a fluoreto para prever risco de fluorose dental. Piracicaba, 2003. 75p. Tese (Doutorado) - Faculdade de Odontologia de Piracicaba, Universidade de Campinas.

2. AMMARI, A.B.; BLOCH-ZUPAN, A.; ASHLEY, P.F. Systematic review of studies comparing the anti-caries efficacy of children's toothpaste containing $600 \mathrm{ppm}$ of fluoride or less with high fluoride toothpastes of 1,000 ppm or above. Caries Res, v.37, n.2, p.85-92. Mar-Apr 2003

3. BAELUM, V. et al. Daily dose of fluoride and dental fluorosis. Tandlaegebladet, v.91, p.452-6, June 1987.

4. BARDSEN, A. "Risk periods" associated with the development of dental fluorosis in maxillary permanent central incisors: a meta analysis. Acta Odontol Scand, v.57, n.5, p.247-56, Oct. 1999.

5. BASTOS, J.R. de M. et al. Conteúdo de flúor observado nos refrescos em pó encontrados no comércio de Bauru - SP. Rev Inst Ciên, v.18, n.2, p.123-128, jul./dez., 2000.

6. BEHRENDT, A.; OBERSTE, V.; WETZEL, W.E. Fluoride concentration and $\mathrm{pH}$ of iced tea products. Caries Res, v.36, n.6, p.405-410, 2002.

7. BELTRAN, E.D.; SZPUNAR, S.M. Fluoride in toothpastes for children: suggestion for change. Pediatr Dent, v.10, p.185-8, 1988.

8. BOTTENBREG, $P$. et al. Prevalence and determinants of enamel fluorosis in Flemish schoolchildren. Caries Res, v38, n.1, p. 20-8, 2004.

\footnotetext{
NBR 10719 da ABNT (Associação Brasileira de Normas Técnicas)

** Normas recomendadas para uso no âmbito da Universidade de São Paulo, com base no documento "Referências Bibliográfica: exemplos", emanado do Conselho Supervisor Integrado de Bibliotecas da USP, em reunião de 20 de setembro.
} 
9. BRASIL, Ministério da Saúde. Situação da fluoretação da água de abastecimento público. Brasil - 1996. Disponível na Internet. http://www.saude.gov.br/sps/areastecnicas/Bucal/inicial.htm 27 nov. 2001

10. BRASIL, Ministério da Saúde. Projeto SB Brasil 2003. Condições de saúde bucal da população brasileira 2002-2003. Brasília 2004, 51p.

11. BRASIL SORRIDENTE. Disponível na internet. http://portalweb01.saude.gov.br/saude/visualizar texto.cfm?idtxt=19 40621 de maio de 2004.

12. BROTHWELL, D.J.; LIMEBACK, H. Fluorosis risk in grade 2 students residing in a rural area with widely varying natural fluoride. Community Dent Oral Epidemiol, v.27, n.2, p.130-6, Apr. 1999.

13. BURT, B.A. The changing patterns of systemic fluoride intake. J Dent Res, v.71, n.5, p.1228-37, May 1992.

14. BURT, B.A.; EKLUND, S.A. Fluoride: human heath and caries prevention. In:

Dentistry, dental practice and community. 5.ed. Philadelphia, WB Saunders, 1999, Cap, p.279-96.

15. BURT, B.A.; KEELS, M.A.; HELLER, K.E. The effects of a break in water fluoridation on the development of dental caries and fluorosis. J Dent Res, v.79, n.2, p.761-9, Feb. 2000.

16. BURT, B.A.; KEELS, M.A.; HELLER, K.E. Fluorosis development in seven age cohorts after an 11-month break in water fluoridation. $\mathbf{J}$ Dent Res, v.82, n.1, p.64-8, Jan., 2003.

17. BUZALAF M.A.R. et al. Fluoride content in infant formulas prepared with deionized, bottled mineral and fluoridated drinking water. ASDC J Dent Child, v.68, n.1, p.37-41, Jan./Feb. 2001.

18. BUZALAF, M.A.R.; CURY, J.A.; WHITFORD, G.M. Fluoride exposures and dental fluorosis: a literature review. Rev FOB, v.9, n.1/2, p.1-10, jan./mar. 2001.

19. BUZALAF, M.A.R. et al. Fluoride content of several brands of teas and juices found in Brazil and risk of dental fluorosis. Rev FOB, v.10, n.4, p.263-7, out./dez. 2002. 
20. BUZALAF, M.A.R. et al. Fluctuations in public water fluoride level in Bauru, Brazil. J Publ Health Dent, v.62, n.3, p.173-6, Summer 2002.

21. BUZALAF, M.A.R. et al. Association between the early use of toothpaste and other variables with dental fluorosis: a transversal retrospective study. Rev. FOB, v.10, n.3, p.196-200, jul./set. 2002.

22. BUZALAF, M.A.R. et al. Fluoride content of infant foods in Brazil and risk of dental fluorosis. ASDC J Dent Child, v.69, n.2, p.196-200, May/Aug. 2002

23. BUZALAF, M.A.R et al. Nail and bone surface as biomarkers for acute fluoride exposure in rats. J Analytical Toxicology, v.28, n.4, p.249252, May/Jun 2004.

24. BUZALAF, M.A.R. et al. Enamel fluorosis prevalence after a 7-year interruption in water fluoridation in Jaú, São Paulo, Brazil. J Publ Health Dent, v.64, n.4, p.205-8, Fall 2004.

25. BUZALAF, M.A.R. et al. Risk of fluorosis associated to consumption of infant formulas prepared with bottled water. J Dent Child, v.71, n.2, p.in pr, 2004.

26. BUZALAF, M.A.R. et al. Total and acid-soluble fluoride content of infant foods, beverages and biscuits from Brazil. Foods Add Contam, v.21, n.3, p.210-5, Mar. 2004.

27. CANGUSSU, M.C.; NARVAI, P.C.; CASTELLANOS FERNANDEZ, R.; DJEHIZIAN, V. Dental fluorosis in Brazil: a critical review. Cad Saude Publica, v.18, n.1, p.7-15, Jan-Feb. 2002

28. Centers for Disease Control. Public Health Service report on fluoride benefits and risks. J Am Dent Assoc, v.266, n.8, p.1661-2,1066-7, 1991.

29. CHAN, J.T.; STARK, C.; JESKE, A.H. Fluoride content of bottled waters: implications for dietary fluoride supplementation. Tex Dent J, v.107, n.4, p.17-21, Apr. 1990.

30. CHITTAISONG, C. et al. Estimation of fluoride intake in relation to $F$, $\mathrm{Ca}, \mathrm{Mg}$ and $\mathrm{P}$ contents in infant formulas. Bul Tokyo Dent Coll, 
v.36, n.1, p.19-26, Feb. 1995

31. CHOWDHURY, N.G.; BROWN, R.H.; SHEPHERD, M.G. Fluoride intake of infants in New Zeland. J Dent Res, v.69, n.12, p.1828-33, Dec. 1990.

32. CLARK, D.C.; BERKOWITZ, J. The influence of various fluoride exposures on the prevalence of esthetic problems resulting from dental fluorosis. J Public Health Dent, v.57, n.3, p.144-9, Summer 1997.

33. CLARKSON, J.J. International collaborative research on fluoride. $\mathbf{J}$ Dent Res, v.79, n.4, p.893-904, Mar. 2000.

34. CLOVIS, J.; HARGREAVES, J.A. Fluoride intake from beverage consumption. Community Dent Oral Epidemiol, v.16, n.1, p.11-5, Feb. 1988.

35. COMMITTEE ON BIOLOGICAL MARKERS OF THE NATIONAL RESEARCH COUNCIL. Biological markers in environmental health reseach. Environ Health Perspec , v.74, p.3-9, 1987.

36. CZARNOWSKI, W.; KRECHNIAK, J. Fluoride in the urine, hair, and nails of phosphate fertilizer workers. Brit J Ind Med, v.47, p.349-51, 1990.

37. CZARNOWSKI, W. et al. Fluoride in drinking water and human urine in norther and central Poland. Sci Total Environ, v.191, n.1/2, p.17784, Nov. 1996.

38. DEAN HT. Classification of mottled enamel diagnosis. J Am Dent Ass, v.21, p.1421-6, 1934.

39. DEAN, H.T.; ARNOLD, F.A. JR; ELVOLVE, E. Domestic water and dental caries: II. A study of 2,832 white children, aged 12-14 years, of eight suburban Chicago communities, including Lactobacillus acidophilus studies of 1,761 children. Public Health Rep, v.56, p.761-92, 1941.

40. DEAN, H.T.; ARNOLD, F.A.; ELVOLVE, E. Domestic water and dental caries: V. Additional studies of the relation of fluoride domestic waters to dental caries experience in 4,425 children, aged 12-14 
years, of 13 cities in 4 states. Public Health Rep, v.57, p.1155-79, 1942.

41. DENBESTEN, P.K. Biological mechanisms of dental fluorosis relevant to the use of fluoride supplements. Community Dent Oral Epidemiol, v.27, n.1, p.41-7, Feb. 1999.

42. EVANS, D.J. A study of developmental defects in enamel in 10-yearold high social class children residing in a non-fluoridated area. Community Dent Health, v.8, n.1, p.31-8, Mar. 1991.

43. EVANS, R.W.; DARVELL, B.W. Refining the estimate of the critical period for susceptibility to enamel fluorosis in human maxillary central incisors. J Public Health Dent, v.55, n.4, p.238-49, Fall 1995.

44. EVERETT, E.T. et al. Dental fluorosis: variability among different inbred mouse strains. J Dent Res, v.81, n.11, p.794-8, Nov., 2002.

45. FEJERSKOV, O.; MANJI, F.; BAELUM, V. The nature and mechanisms of dental fluorosis in man. J Dent Res, v.69, n.Spec. Iss., p.692-700, 1990.

46. FERREIRA, H.C.G. et al. Avaliação do teor de flúor na água de abastecimento público do município de Vitória-ES. Rev da Assoc Paul Cir Dent, v.53, n.6, p.455-9, nov./dez. 1999.

47. FOMON, S.J.; EKSTRAND, J.; ZIEGLER, E.E. Fluoride intake and prevalence of dental fluorosis: trends in fluoride intake with special attention to infants. J Public Health Dent, v.60, n.3, p.131-9, Summer 2000.

48. FORSMAN, B. Studies on the effect of dentifrices with low fluoride content. Community Dent Oral Epidemiol, v.2, p.166-175, 1974

49. FORSMAN, B. Early supply of fluoride and enamel fluorosis. Scand $\mathbf{J}$ Dent Res, v.85, n.1, p.22-30, Jan. 1977.

50. FUKUSHIMA et al. Unha como biomarcador de exposição crônica ao flúor através da água. Braz Oral Res, v.18, p.170, Sept. 2004 Supll $\left(21^{\text {st }}\right.$ Annual SBPqO Meeting)/ abstract n. Pb106/

51. GARY ROZIER R. The prevalence and severity of enamel fluorosis in 
North American children. J Public Health Dent, v.59, n.4, p.239-46, Fall 1999.

52. GEISEL, E.; MACHADO, P.A. Lei N 6.050 de 24 de maio de 1974. Disponível na Internet. http://www.saude.gov.br/sps/areastecnicas/Bucal/inicial.htm 27 nov. 2001.

53. GEISEL, E.; MACHADO, P.A.; REIS, M.R. Decreto № 76.872 de 22 de dezembro de $1975 . \quad$ Disponível na Internet. http://www.saude.gov.br/sps/areastecnicas/Bucal/inicial.htm 27 nov. 2001.

54. GERDIN, P.O. Studies in dentifrices, 8: clinical testing of an acidulated, nongrinding dentifrice with reduced fluorine contents. Sven Tandlak Tidskr, v.67, n.5, p.283-97, 1974.

55. GRANDJEAN, P. Biomarkers in epidemiology. Clin Chem, v.12, p.1800-3, Dec. 1995.

56. GRIMALDO, M. et al. Endemic fluorosis in San Luis Potosi, Mexico. I. Identification of risk factors associated with human exposure to fluoride. Environ Res, v.68, n.1, p.25-30, Jan. 1995.

57. GUHA-CHOWDHURY, N.; DRUMMOND, B.K.; SMILLIE, A.C. Total fluoride intake in children aged 3 to 4 years - a longitudinal study. J Dent Res, v.75, n.7, p.1451-7, July 1996.

58. HAMDAN, M.A.M. The prevalence and severity of dental fluorosis among 12-years-old schoolchildren in Jordan. Int J Paediatr Dent, v.13, n.2, p.85-92, Mar. 2003.

59. HEILMAN, J.R. et al. Fluoride concentration of infants foods. J Am Dent Assoc, v.128, n.7, p.857-63, July 1997.

60. HEILMAN, J.R. et al. Assessing fluoride leves of carbonated soft drinks. J Am Dent Assoc, v.130, n.11, p.1593-9, Nov. 1999.

61. HEINTZE, S.D.; BASTOS, J.R. de M. Avaliação do teor de flúor e pH em bebidas no mercado nacional. Rev da Assoc Paul Cir Dent, v.50, n.4, p.339-45, jul./ago. 1996.

62. HELLER, K.E.; EKLUND, S.A.; BURT, B.A. Dental caries and dental 
fluorosis at varying water fluoride concentrations. J Public Health Dent, v.57, n.3, p.136-43, Summer 1997.

63. HOLT, R.D. et al. Enamel opacities and dental caries in children who used a low fluoride toothpaste between 2 and 5 years of age. Int Dent J, v.44, n.4, p.331-41, Aug. 1994.

64. HOROWITZ, H.S. The needs for toothpastes with lower than conventional fluoride concentrations for preschool-aged children. J Public Health Dent, v.52, p.216-21, Summer 1992.

65. ISMAIL, A.I. et al. Prevalence of dental caries and dental fluorosis in students, 11-17 years of age, in fluoridated and non-fluoridated cities in Quebec. Caries Res, v.24, n.4, p.290-7, 1990.

66. ISMAIL, A.I. et al. Should the drinking water of Truro, Nova Scotia, be fluoridated? Water fluoridation in the 1990s. Community Dent Oral Epidemiol, v.21, n.3, p.118-25, June 1993.

67. JACKSON, R.D. et al. Dental fluorosis and caries prevalence in children residing in communities with different levels of fluoride in the water. J Public Health Dent, v.55, n.2, p.79-84, Spring 1995.

68. JACKSON, R.D. et al. Dental fluorosis in children residing in communities with different water fluoride levels: 33-month follow-up.

Pediatr Dent, v.21, n.4, p.248-54, July/Aug. 1999.

69. KIMURA, T. et al. Fluoride intake from food and drink in Japanese children aged 1-6 years. Caries Res, v.35, n.1, p.47-9, Jan./Feb. 2001.

70. $\mathrm{KOCH}, \mathrm{G}$. Effect of 250 and 1000 ppm fluoride dentifrice on caries: a three-year clinical study. Swed Dent J, v.6, n.14, p.233-8, 1982.

71. $\mathrm{KOCH}, \mathrm{G}$. Caries preventive effect of fluoride dentifrices with and without anticalculus agents: a three-year control clinical trial. Caries Res, v.24, p.72-9, 1990.

72. KOPARAL, E.; ERTUGRUL, F.; OZTEKIN, K. Fluoride levels in breast milk and infants foods. J Clin Pediatr Dent, v.24, n.4, p.299-302, Summer 2000.

73. KUMAR, J.V. et al. Trends in dental fluorosis and dental caries 
prevalences in Newburgh and Kingston, NY. Am J Public Health, v.79, n.5, p.565-9, May 1989.

74. KUMAR, J.V.; SWANGO, P.A. Fluoride exposure and dental fluorosis in Newburgh and Kingston, New York: policy implications. Community Dent Oral Epidemiol, v.27, n.3, p.171-80, June 1999.

75. LALUMANDIER, J.A.; ROZIER, G.R. The prevalence and risk factors of fluorosis among patients in a pediatric dental practice. Pediatr Dent, v.17, n.1, p.19-25, jan./Feb. 1995.

76. LATIFAH, R.; RAZAK, I.A. Fluoride levels in infant formulas. J Pedod, v.13, n.4, p.323-7, Summer 1989.

77. LEVERETT, D.H. Prevalence of dental fluorosis in fluoridated and in non-fluoridated communities-a preliminary investigation. J Public Health Dent, v.46, p.184-7, Fall 1986.

78. LEVY, S.M.; MAURICE, T.J.; JAKOBSEN, J.R. A pilot study of preschoolers' use of regular-flavored dentifrices and those flavored for children. Pediatr Dent, v.14, n.6, p.388-91, Nov./Dec. 1992.

79. LEVY, S.M.; MAURICE, T.J.; JAKOBSEN, J.R. Dentifrice use among preschool children. J Am Dent Assoc, v.124, n.9, p.57-60, Sept. 1993.

80. LEVY, S.M.; MAURICE, T.J; JAKOBSEN, J.R. Feeding patterns, water souces and fluoride exposures of infants on 1 year-old. J Am Dent Assoc, v.124, p.65-9, Apr. 1993.

81. LEVY, S.M. et al. Infants' fluoride intake from drinking water alone, and from water added to formula, beverages, and food. J Dent Res, v.74, n.7, p.1399-1407, July 1995a.

82. LEVY, S.M. et al. Infants' fluoride ingestion from water, supplements and dentifrice. J Am Dent Assoc, v.126, n.12, p.1625-32, Dec. 1995.

83. LEVY, S.M.; KIRITSY, M.C.; WARREN, J.J. Sources of fluoride intake in children. J Public Health Dent, v.55, n.1, p.39-52, Winter 1995.c.

84. LEVY, S.M. et al. Patterns of fluoride intake from birth to 36 months. J Public Health Dent, v.61, n.2, p.707, Spring 2001. 
85. LEVY, F.M.; BASTOS, J.R.M.; BUZALAF, M.A.R. Nails as biomarkers of chronic exposure to fluoride from the diets of children in negligibly and optimally fluoridated communities. J Dent Children, v.71, n.2, p. in press, 2004

86. LIMA, Y. B. O.; CURY, J.A. Ingestão de flúor por crianças pela água e dentifrício. Rev Saúde Pública, v.35, n.6, p.576-81, dez. 2001.

87. LIMA, Y.B.O.; CURY, J.A. Seasonal variation of fluoride intake by children in a subtropical region. Caries Res, v.37, n.5, p.335-8, Sept./Oct. 2003.

88. MASCARENHAS, A.K.; BURT, B.A. Fluorosis risk from early exposure to fluoride toothpaste. Community Dent Oral Epidemiol, v.26, n.4, p.241-8, Aug. 1998.

89. MASCARENHAS, A.K. Risk factors for dental fluorosis: A review of the recent literature. Pediatr Dent, v.22, n.4, p.269-77, July/Aug. 2000.

90. McDONNELL, S.T.; O'MULLANE, D. Fingernails, a fluoride biomarker - relevance of growth rate and length. J Dent Res, v.80, n.4, p.1145, 2001.

91. McKay FS. The relation of mottled enamel to caries. J Am Dent Assoc v.15, p.1429-37, 1928.

92. McKNIGHT-HANES, M.C. et al. Fluoride content of infant formulas: soy-based formulas as potential factor in dental fluorosis. Pediatr Dent, v.10, n.3, p.189-94, Sept. 1988.

93. MILSOM, K.; MITROPOULOS, C.M. Enamel defects in 8-year-old children in fluoridated and non-fluoridated parts of Cheshire. Caries Res, v.24, n.4, p.286-9, 1990.

94. MITROPOULOS, C.M. et al. Relative efficacy of dentifrices containing 250 or 1000 ppm F in preventing dental caries - report of a 32-month clinical trial. Community Dent Healh, v.1, p.193-200, Nov. 1984.

95. MURAKAMI, T. et al. Fluoride intake in Japanese children aged 3-5 years 93.by the duplicate-diet technique. Caries Res, v.36, n.6, p.386-90, Nov./Dec. 2002.

96. NISHIJIMA, M.T. et al. A comparison of dietary fluoride intakes from 
food samples in Japan and Brazil. Bull Tokyo Dent Coll, v.34, n.2, p.43-50, May 1993.

97. NOURJAH. P; HOROWITZ, A.M.; WAGENER, D.K. Factors associated with the use of fluoride supplements and dentifrice by infants and toddlers. J Public Health Dent, v.54, n.1, p.47-54, Winter 1994.

98. O'MULLANE, D.M. The future of water fluoridation. J Dent Res, v.69, n.Spec Iss., p.756-9, Feb. 1990.

99. OPHAUG, R.H.; SINGER, L.; HARLAND, B.F. Dietary fluoride intake of 6-month-old and 2-year-old children in four dietary regions of the United States. Am J Clin Nutr, v.42, p.701-707, Oct. 1985.

100. OSUJI, O.O. et al. Risk factors for dental fluorosis in a fluoridated community. J Dent Res, v.67, n.12, p.1488-92, Dec. 1988.

101. PAIVA, S.M. Ingestão total de flúor através da dieta e de dentifrícios: determinação da dose em relação ao risco de fluorose dental. São Paulo, 1999. 59p. Tese (Doutorado) - Universidade de São Paulo, Faculdade de Odontologia.

102. PAIVA, S.M.; LIMA, Y.B.O.; CURY, J.A. Fluoride intake by Brazilian children from two communities with fluoridated water. Community Dent Oral Epidemiol, v.31, n.3, p.184-91, June 2003.

103. PANG, D.T.Y.; PHILLIPS, C.L.; BAWDEN, J.W. Fluoride intake from beverage consumption in a sample of North Carolina children. $\mathbf{J}$ Dent Res, v.71, n.7, p.1382-8, July 1992.

104. PENDRYZ, D.G.; KATZ, R.V. Risk of enamel fluorosis associated with fluoride supplementation, infant formula, and fluoride dentifrice use. Am J Epidemiol, v.130, n.6, p.1199-208, Dec. 1989.

105. PENDRYZ, D.G.; KATZ, R.V.; MORSE, D.E. Risk factors for enamel fluorosis in a fluoridated population. Am J Epidemiol, v.140, n.5, p.461-71, Sept. 1994.

106. PENDRYS, D.G. Risk of fluorosis in a fluoridated population. Implications for the dentist and hygienist. J Am Dent Ass, v.126, n.12, p.1617-24, Dec. 1995. 
107. PENDRYS, D.G.; KATZ, R.V.; MORSE, D.E. Risk factors for enamel fluorosis in a nonfluoridated population. Am J Epidemiol, v.143, n.8, p.808-15, Apr. 1996.

108. PENDRYZ, D.G.; KATZ, R.V. Risk factors for enamel fluorosis in optimally fluoridated children born after the US manufacturer's decision to reduce the fluoride concentration of infant formulae. Am J Epidemiol, v.148, n.10, p.967-74, Nov. 1998.

109. PEREIRA, A.C. et al. Dental caries and fluorosis prevalence study in a nonfluoridated Brazilian community: trend analysis and toothpaste association. ASDC J Dent Child, v.67, n.2, p.132-5, Mar./Apr. 2000.

110. PERES, P.E.C.; DEL BEL CURY, A.A.; CURY, J.A. Avaliação in situ de uma formulação de dentifrício com concentração reduzida de flúor. Pesq. Odont. Bras., v. 15, p. 83, 2001. /Abstract n. A103/

111. PESSAN, J.P.; SILVA, S.M.B.; BUZALAF, M.A.R. Evaluation of the total fluoride intake of 4-7-year-old children from diet and dentifrice. J Appl Oral Science Bauru, v.11, n.2, p.150-156, Apr./June 2003.

112. RAHUL, P.; HEGDE, A.M.; MUNSHI, A.K. Estimation of the fluoride concentrations in human breast milk, cow's milk and infant formulae. J Clin Pediatr Dent, v.27, n.3, p.257-60, Spring 2003.

113. RAMIRES, I. et al. Avaliação da concentração de flúor e do consumo de água mineral. Revista Saúde Pública, v.38, n.3, p.459-465, June 2004 .

114. REED, M.W. Clinical evauation of three concentrations of sodium fluoride in dentifrices. J Am Dent Ass, v.87, n.7, p.1401-5, Dec. 1973.

115. RICHARDS, A; BANTING, D.W. Fluoride toothpastes. In: Fejerskov, O.; Ekstrand, J.; Burt, B.A. Fluoride in dentistry. 2.ed. Copenhagen, Munksgaard, 1996, p. 328-46.

116. RIORDAN, P.J.; BANKS, J.A. Dental fluorosis and fluoride exposure in Western Australia. J Dent Res, v.70, n.7, p.1022-8, July 1991.

117. RIORDAN, P.J. Dental fluorosis, dental caries and fluoride exposure among 7-year-olds. Caries Res, v.27, n.1, p.71-7, 1993. 
118. RIORDAN, P.J. Fluoride supplements in caries prevention: a literature review and proposal for a new dosage schedule. J Public Health Dent, v.53, n.3, p.174-89, Summer 1993.

119. RIORDAN, P.J. Dental fluorosis decline after changes to supplement and toothpaste regimens. Community Dent Oral Epidemiol, v.30,n.3, p.233-40, June 2002.

120. RODRIGUES, M.H.C.; BASTOS, J.R.M.; BUZALAF, M.A.R. Fingernails and toenails as biomarkers of subchronic exposure to fluoride from dentifrice in 2- to 3-year-old children. Caries Res, v.38, n.2, p.109-14, 2004

121. ROJAS-SANCHES, F. et al. Fluoride intake from foods, beverages and dentifrice by young children in communities with negligible and optimally fluoridated water: a pilot study. Community Dent Oral Epidemiol, v.27, n.4, p.288-97, Aug. 1999.

122. SAMPAIO, F.C. et al. Validation of fingernail fluoride as a biomarker for dental fluorosis. Caries Res, v.37, p.291-2, 2003 /Abstract n. 72/

123. SCHMIDT, C.W.; LEUSCHKE, W. Fluoride content in finger nails of individuals with and without chronic fluoride exposure. Fluoride, v.23, p.79-82, 1990

124. SELWITZ, R.H. et al. Prevalence of dental caries and dental fluorosis in areas with optimal and above-optimal water fluoride concentrations: a 10-year follow-up survey. J Public Health Dent, v.55, n.2, p.85-93, Spring 1995.

125. SILVA, M.; REYNOLDS, E.C. Fluoride content of infant formulae in Australia. Aust Dent J, v.41, n.1, p.37-42, Feb. 1996.

126. SKOTOWSKI, M.C.; HUNT, R.J.; LEVY, S.M. Risk factors for dental fluorosis in pediatric dental patients. J Public Health Dent, v.55, n.3, n.154-9, Summer 1995.

127. SPATE, V.L. et al. Determination of fluoride in human nails via cyclic instrumental neutron activation analysis. J Radioanalyt Nucl Chem, v.170, p.27-33, 1994

128. STANNARD, J. et al. Fluoride content of some bottled waters and 
recommendation for fluoride supplementation. J Pedod, v.14, n.2, p.103-7, Winter 1990.

129. STEPHEN, K.W. et al. A blind caries and fluorosis prevalence study of school-children in naturally and nonfluoidated townships of Morayshire, Scotland. Community Dent Oral Epidemiol, v.30, n.1, p.70-9, Feb. 2002.

130. TABARI, E.D. et al. Dental fluorosis in permanent incisor teeth in relation to water fluoridation, social deprivation and toothpaste use in infancy. Br Dent J, v.189, n.4, p.216-20, Aug. 2000.

131. TAVES, D.R. Separation of fluoride gy rapid diffusion using hemamethyldisiloxane. Talanta, v.15, p.969-74, 1968.

132. TOUMBA, K.J.; CORZON, M.E.J. The fluoride content of bottled drinking waters. Br Dent J, v.176, n.7, p.266-8, Apr. 1994.

133. TRAUTNER, K.; SIEBERT, G. An experimental study of bio-availability of fluoride from dietary sources in man. Archs Oral Biol, v.31, n.4, p.223-8, 1986.

134. TSUTSUI, A.; YAGI, M. HOROWITZ, A.M. The prevalence of dental caries and fluorosis in japanese communities with up to $1.4 \mathrm{ppm}$ of naturally occurring fluoride. J Public Health Dent, v.60, n.3, p.14753, Summer 2000.

135. VAN WINKLE, S. Water and formula fluoride concentrations: significance for infants fed formula. Paediatr Dent, v.17, n.4, p.30510, July/Aug. 1995.

136. VILLENA, R.S.; BORGES, D.G.; CURY, J.A. Avaliação da concentração de flúor em águas minerais comercializadas no Brasil. Rev Saúde Pública, v.30, n.6, p.512-8, Dec. 1996.

137. WANG, N.J.; GROPEN, A.M.; OGAARD, B. Risk factors associated with fluorosis in a non-fluoridated population in Norway. Comm Dent Oral Epidemiol, v.25, n.6, p.396-401, Dec. 1997.

138. WARREN, J. J.; LEVY, S.M. A review of fluoride dentifrice related to dental fluorosis. Pediatr Dent, v.21, n.4, p.265-71, July/Aug. 1999.

139. WEINBERGER, S.J. Bottled drinking waters: are the fluoride 
concentrations shown on the labels accurate? Int J Paed Dent, v.1, n.3, p.143-6, Dec. 1991.

140. WHITFORD, G.M. The metabolism and toxicity of fluoride. 2.ed. Basel: Karger, 1996.

141. WHITFORD, G.M. et al. Fingernail fluoride: a method for monitoring fluoride exposure. Caries Res, v.33, p.462-7, Nov./Dec. 1999.

142. WINTER, G.B.; HOLT, R.D.; WILLIAMS, B. Clinical trial of a lowfluoride toothpaste for young children. Int Dent J, v.39, n.4, p.22735, Dec. 1989. 
"Ou a vida é uma aventura ousada, ou não é nada."

Helen Keller 


\section{ABSTRACT}

The prevalence of dental fluorosis has been increasing due to four main factors: fluoridated water, dentifrices, supplements and manufactured foods. Thus, many studies evaluate the total daily fluoride intake of children at the age of risk to dental fluorosis. In the present study the fluoride intake from diet and dentifrice were estimated. However, 3 constituents of the diet were evaluated separately: solids; water and milk; other beverages. In addition, fingernails were collected in order to analyze the viability of their use as biomarkers of chronic fluoride exposure. Thirty-tree 2-3-year-old children participated in the study. The duplicate plate method was used for diet collection in two seasons (winter and summer) and in 2 separate days over a 1-week period (one during the week and another during one day on the following weekend). The water consumed by the children was collected on the same days the diets were collected. Fingernails were collected three times. Fluoride analysis in diet, dentifrice and fingernails were analyzed with the ion-specific electrode (Orion 9409) after HMDS-facilitated diffusion. Mean $( \pm S D)$ fluoride intake from diet and dentifrice was $0.025 \pm 0.013$ and $0.106 \pm$ $0.085 \mathrm{mg} / \mathrm{Kg}$ body weight/day, respectively, totalizing $0.130 \mathrm{mg} / \mathrm{Kg}$ body weight/day. A strong positive correlation $(r=0.971, p<0.0001)$ was seen between the amount of dentifrice loaded onto the brush $(0.488 \pm 0.303 \mathrm{~g})$ and the amount of fluoride ingested during toothbrushing $(0.591 \pm 0.445 \mathrm{mg})$. Among the constituents of the diet, water and milk had a significantly higher contribution to the fluoride intake $(0.184 \pm 0.108 \mathrm{mg} / \mathrm{day}, p<0.0001)$, when compared to solids $(0.072 \pm 0.045 \mathrm{mg} / \mathrm{day})$ and other beverages $(0.066 \pm$ $0.043 \mathrm{mg} /$ day). No correlation was observed between the amount of fluoride ingested daily and fingernails fluoride concentrations $(r=-0.052, p=0.810)$. These results indicate that the daily dose of fluoride ingested by the children represents a risk for the development of dental fluorosis. In addition, the dentifrice alone is responsible for $80 \%$ of the daily fluoride intake, while among the constituents of the diet, water and milk are the most important 
contributors. Small variations in the daily fluoride intake do not alter fingernails fluoride concentrations. 
APÊNDICE 
"Fluoride intake from dentifrice and different constituents of the diet by 2-3-year-old children living in a fluoridated community in Brazil: impact on fingernail fluoride levels". Beatriz Simões de Almeida ${ }^{1}$

Vanessa Eid da Silva Cardoso ${ }^{2}$

Marília Afonso Rabelo Buzalaf ${ }^{3}$

${ }^{1}$ MS Candidate in Public Health, Bauru Dental School, University of São Paulo, Bauru, Brazil

${ }^{2}$ MS, PhD Candidate in Biochemistry, Institute of Chemistry, University of São Paulo, Bauru, Brazil

${ }^{3} \mathrm{PhD}$, Associate Professor, Department of Biological Sciences, Area of Biochemistry, Bauru Dental School, University of São Paulo, Bauru, Brazil

Running title: Fluoride intake by 2-3-year-old Brazilian children

Address of correspondence:

Professor Marília Afonso Rabelo Buzalaf

Faculdade de Odontologia de Bauru - Universidade de São Paulo

Al. Octávio Pinheiro Brisolla, 9-75

V. Universitária - Bauru - SP - Brasil

CEP: $17012-901$

mbuzalaf@fob.usp.br 
Almeida BS, Cardoso VES, Buzalaf MAR. Fluoride intake from dentifrice and different constituents of the diet by 2-3-year-old Brazilian children living in a fluoridated community. Comm Dent Oral Epidemiol

\section{Abstract}

Objectives: This study estimated the total daily fluoride intake by 2-3-year-old children from diet and dentifrice. The constituents of the diet were divided into solids, water and milk and other beverages, which were analyzed separately. Methods: Thirty-three children, living in a fluoridated area participated in the study. Fluoride intake from diet was monitored by the "duplicate plate" method, considering the different constituents of the diet. Fluoride ingested from dentifrice was determined by subtracting the amount of fluoride recovered after brushing from the amount originally placed onto the child's toothbrush. Fluoride was analyzed with the ion specific electrode, after hexamethyldisiloxane-facilitated diffusion. Results: Mean ( $\pm S D$ ) fluoride intake from diet and dentifrice was $0.025 \pm 0.013$ and $0.106 \pm 0.085 \mathrm{mg} / \mathrm{Kg}$ body weight/day, respectively, totalizing $0.130 \mathrm{mg} / \mathrm{Kg}$ body weight/day. A strong positive correlation $(r=0.971$, $p<0.0001)$ was seen between the amount of dentifrice loaded onto the brush $(0.488 \pm 0.303 \mathrm{~g})$ and the amount of fluoride ingested during toothbrushing $(0.591 \pm 0.445 \mathrm{mg})$. Among the constituents of the diet, water and milk had a significantly higher contribution to the fluoride intake $(0.184 \pm 0.108 \mathrm{mg} /$ day, $p<0.0001)$, when compared to solids $(0.072 \pm 0.045 \mathrm{mg} / \mathrm{day})$ and other beverages $(0.066 \pm 0.043 \mathrm{mg} /$ day $)$. Conclusions: Most of the children are exposed to a daily fluoride intake above the suggested threshold for dental fluorosis. The dentifrice alone is responsible for $80 \%$ of the daily fluoride intake, while among the constituents of the diet, water and milk are the most important contributors.

Key words: Fluoride; Dental Fluorosis; Dentifrice; Diet

Offprints request: Marília Afonso Rabelo Buzalaf

Faculdade de Odontologia de Bauru - Universidade de São Paulo

Al. Octávio Pinheiro Brisolla, 9-75 Bauru - SP Brazil 17012-901

mbuzalaf@fob.usp.br 


\section{INTRODUCTION}

The prevalence and severity of dental fluorosis has increased in both optimally fluoridated and nonfluoridated areas in many countries, as well as in Brazil $(1,2)$. More recent data show a prevalence of dental fluorosis of $8.56 \%$ in 12-year-old Brazilian children (3).

Dental fluorosis is regarded as a systemic effect secondary to the total fluoride intake and its absorption. It depends on the quantity of fluoride and duration of exposure, the stage of tooth development at the time of exposure, and individual variation in susceptibility. Evans and Darvell (4) showed that the maxillary central incisor appears most at risk to fluorosis from dietary fluoride between age fifteen and twenty-four months for males and between twenty-one and thirty months for females. Data is unavailable for the normal levels of plasma fluoride that avoid dental fluorosis development (5). A fluoride intake of $0.05-0.07 \mathrm{mg} / \mathrm{Kg}$ body weight per day is usually regarded as optimum, despite established empirically (6). However, even though these values are the most frequently employed as the limit dose, investigations conducted in Kenya have found dental fluorosis with a mean fluoride intake as low as $0.04 \mathrm{mg} / \mathrm{kg}$ of body weight/day (7). In addition, the analytical results from the studies made by Bawden et al. $(8,9)$, Bawden and Crenshanw (10), Speirs (11) and Aoba and Moreno (12) support the concept that fluoride levels in developing enamel are directly related to plasma fluoride levels. Thus, as it would be expected that plasma levels would show small peaks, according to the normal daily patterns of fluoride exposure from eating, drinking, brushing the teeth, etc (13), any increase in plasma fluoride levels due to the ingestion of elevated dietary fluoride levels or fluoride intake from dentifrice should be prevented for the children during the critical period of fluoride exposure for the fluorosis development.

When assessing the safety of various levels of fluoride intake it is important to consider the fluoride intake from all potential sources. These sources might include drinking water, fluoride oral care products and the environment as well as food and beverages $(1,6)$. The trio of diet, dentifrice and supplementation could exceed the optimal levels of fluoride intake. Some 
studies have been conducted to evaluate fluoride intake from diet and dentifrice $(5,14-17)$. Nevertheless, these studies analyze the total diet.

The increase in the prevalence of dental fluorosis has intensified the search for biomarkers of exposure to fluoride that are easy to collect and analyze (18). Nail sampling is simple and non-invasive, and there are many reports suggesting the use of nails as biomarkers for fluoride exposure in humans (19-27)

The aim of this study was to estimate the total daily fluoride intake by 2-3-year-old Brazilian children from diet and dentifrice. In addition, fingernails samples were collected in order to evaluate the correlation between fluoride concentrations in nails and the total daily fluoride intake by children.

\section{MATERIAL AND METHODS}

\section{Study population}

Thirty-three 2-3-year-old children that attended 9 public full-time daycare centers from Bauru, state of São Paulo, participated in the study. This age group was chosen considering the critical period for the development of dental fluorosis in permanent central maxillary incisors. Children who participated in this study were not randomly chosen; they were children for whom parental permission had been granted. Bauru has optimally adjusted fluoridated water $(0.6$ to $0.8 \mathrm{ppm}$ ). The protocol for the study was reviewed and approved by the IRB of the Bauru Dental School, University of São Paulo. The nature and purposes of the study were explained verbally and in writing to the subjects and their parents who signed an IRB-approved informed consent document.

\section{Estimation of fluoride intake from diet and dentifrice}

In order to estimate the total fluoride intake of the children, fluoride intake from diet was monitored by the "duplicate plate" method, as described by Guha-Chowdhurry and associates 
(5), and fluoride ingested from dentifrice was determined by subtracting the amount of fluoride recovered after brushing from the amount originally placed on the children's toothbrush.

Duplicate-plate approach

Duplicate portions of all foods and drinks consumed by each children over $24 \mathrm{~h}$ were collected in two seasons (winter and summer) on two separate days over a 1-week period, once during the week and again in a weekend day. The constituents of the diet were divided into solids, water and milk, and other beverages (28) and were collected at three different plastic vials. Samples were collected by teachers and parents at the daycare centers and at home, respectively. They were instructed to keep the usual diet habits of the children and to duplicate the diet as precisely as possible by observing the amounts that the children had really eaten and drunk. They were requested to remove parts of foods not normally eaten, such as seeds, cores, skin, and bones, before including the food in the container.

Solid samples were homogenized using deionized water and the total volume was measured. An aliquot sample of $50 \mathrm{~mL}$ of the homogenized solid foods, water and milk, and the other beverages was taken individually and frozen $\left(-20^{\circ} \mathrm{C}\right)$ until analysis.

\section{Simulated toothbrushing test}

The estimation of fluoride intake from the dentifrice was made at the daycare centers. Attempts were made to simulate real conditions by replicating whether the teacher (or parent) or the children performed the brushing, the size of the toothbrush used, how much dentifrice was spread on the brush, whether the adults or the children applied the dentifrice to the brush, whether the children expectorated after brushing and the length of time spent brushing. The toothbrush was weighed $( \pm 0.01 \mathrm{~g})$. The adults or children spread dentifrice onto the toothbrush, and the weight of the toothbrush plus dentifrice was recorded. This provided information on the amount of $\mathrm{F}$ loaded onto the brush. Brushing was performed by the children with or without the assistance and under the observation of the examiner. Depending on their habits, the children 
were allowed to expectorate or not and to rinse or not. The expectorant was collected in a weighed, plastic, wide-mouth vessel and analyzed for $\mathrm{F}$. The toothbrush was thoroughly rinsed in $50 \mathrm{~mL}$ of deionized water, and the rinse was analyzed for $\mathrm{F}$ to determine the amount of $\mathrm{F}$ left on the toothbrush. The amount of $\mathrm{F}$ left on the toothbrush and the amount expelled were added, to give the total amount of $F$ expelled and not swallowed. The amount of $F$ ingested was then indirectly derived, by subtracting the amount of $F$ expelled from the amount initially loaded onto the toothbrush. Information on frequency of brushing (in daycare centers and at home) was obtained and used to calculate the daily fluoride intake from dentifrice for each child. These procedures were done for 2 subsequent days.

In addition, samples of the usual dentifrice used by children were collected in order to analyze their fluoride concentration.

\section{Tap Water collections}

Since fluctuations in public water fluoride levels have been described in Bauru (29), two samples of tap water were collected at the houses of the children, at the same day of diet collection. Water samples, collected in $50 \mathrm{~mL}$ plastic vials, were frozen $\left(-20^{\circ} \mathrm{C}\right)$ until fluoride analysis.

\section{Nail sampling}

Fingernails were clipped and collected three times. Two of them were done at the same day of the diet collection and the other one in an intermediate day, between the diet collections. Fluoride analysis

Fluoride analysis in water samples was made by the directed method using an ionspecific electrode (Model 9609: Orion Research, Cambridge, MA, USA), after sample buffering with an equal volume of TISAB (Total Ionic Strength Adjustment Buffer). Standards were prepared by serial dilution of a $100 \mathrm{ppm} \mathrm{NaF}$ stock solution (Orion). The standard curve had a coefficient correlation $\geq 0.99$. The mean repeatability of duplicate samples was $96.2 \%$. In 
addition, fluoride analyses in $10 \%$ of samples were repeated, giving a mean reproducibility of $95.3 \%$.

Diet, dentifrice and fingernail samples were analyzed for fluoride after overnight hexamethyldisiloxane (HMDS)-facilitated diffusion (30) as modified by Whitford (13), using the fluoride ion-specific electrode and a miniature calomel reference electrode (Accumet, \#13-62079), coupled to a potentiometer (Orion Research, model EA 940). During the diffusion process, which was conducted at room temperature, the solutions in the non-wettable Petri dishes (Falcon, No. 1007) were gently swirled on a rotatory shaker. Fluoride standards $(0.0095,0.019$, $0.095,0.190$ and $0.950 \mu \mathrm{g}$ - for nails; $0.019,0.095,0.190,0.950,1.900,4.750$ and $7.500 \mu \mathrm{g} \mathrm{F}$ - for diet; $0.950,1.900,4.750$ and $7.500 \mu \mathrm{g} \mathrm{F}$ - for toothbrushing and dentifrice) were prepared by serial dilution of a stock solution of $0.1 \mathrm{M}$ fluoride (Orion 940906) in triplicate and diffused in the same manner as the samples. Comparison with identical nondiffused fluoride standards showed that recovery after diffusion was $>99 \%$. The standard curve had a correlation coefficient $\geq 0.99$. All samples were analyzed in duplicate. The mean repeatability of duplicate samples was $94.4 \%$. In addition, fluoride analysis in $10 \%$ of samples was repeated, giving a mean reproducibility of $95.9 \%$.

Statistical analysis

Repeated measures ANOVA was used to detect differences among the three groups of diet. It was complemented by Tukey-Kramer test for multiple comparisons. The same tests were used to detect differences among fluoride concentration in fingernails, at the different collections times.

Pearson's coefficient was used to assess the correlation between the total fluoride intake and mean fingernails fluoride concentration, as well as between the amount of dentifrice loaded onto the toothbrush and the amount of fluoride ingested from each toothbrushing. 
Difference between fluoride ingested from diet and dentifrice, was evaluated through paired Student's $t$ test. The same test was used to evaluate differences between the amount of fluoride intake on the two days of collection and on the two seasons (winter and summer) of collection, as well as differences between fluoride concentrations in water collected in two periods.

The significance level was set at $5 \%$.

\section{RESULTS}

Table 1 shows the mean, SD, minimum - maximum and $95 \% \mathrm{Cl}$ of the fluoride intake (mg F/kg body weight/day) from diet, dentifrice and the total (diet + dentifrice), by children $(n=33)$. The fluoride intake from dentifrice was statistically higher than fluoride intake from diet $(p<0.0001)$. Dentifrice was responsible for $80 \%$ of total fluoride intake by the children $(n=33)$.

Table 2 shows the mean, SD, minimum - maximum and $95 \% \mathrm{Cl}$ of the fluoride intake (mg F/day) from solids, water and milk, and other beverages, by children $(n=33)$. The fluoride intake from water and milk was statistically higher than fluoride ingested from solids and other beverages $(p<0.0001)$.

Table 3 shows the mean, SD, minimum - maximum and $95 \% \mathrm{Cl}$ of the fluoride intake (mg F/day) from solids, water and milk, other beverages and the total diet by children $(n=33)$, during the two periods (winter and summer) of collection. There was no statistically significant difference among the parameters analyzed ( $p>0.05)$.

Mean $( \pm S D)$ fluoride intake from diet in the weekday and in the weekend day was $0.341 \pm 0.131$ and $0.287 \pm 0.198 \mathrm{mg} F /$ day, respectively and this difference was not statistically significant $(p>0.05)$.

Mean $( \pm S D$ ) fingernails fluoride concentration in the three dates of collection was 3.111 $\pm 1.136,2.220 \pm 1.465$ and $3.526 \pm 1.397 \mu \mathrm{g} \mathrm{F/g}$. Mean fingernails fluoride concentration for 
samples collected in the second period was statistically lower than for the first and third collects $(p<0.05)$.

For children that ingested a dose above $0.07 \mathrm{mg} \mathrm{F} / \mathrm{kg}$ body weight/day $(\mathrm{n}=24)$, there was no correlation between fingernails fluoride concentration and total fluoride intake $(r=-0.052$, $\mathrm{p}=0.810)$.

Mean $( \pm \mathrm{SD}$ ) fluoride concentration in water collected in two periods was $0.761 \pm 0.278$ and $0.570 \pm 0.282 \mu \mathrm{g} \mathrm{F} / \mathrm{mL}$ and this difference was statistically significant $(p<0.01)$. There was no correlation between fluoride concentration in water and fingernails fluoride concentration $(r=0.2520, p=0.2349)$

Table 4 shows the mean, SD, minimum - maximum and $95 \% \mathrm{Cl}$ of the amount of dentifrice used $(\mathrm{g})$, total fluoride $(\mathrm{mg})$ and ingested fluoride $(\mathrm{mg})$, for each tooth brushing. Figure 1 shows the strong significant correlation between the amount of dentifrice loaded onto the toothbrush and fluoride ingested for each toothbrushing $(r=0.971 ; p<0.0001)$.

\section{DISCUSSION}

Fluoride intake by children at the age of risk for dental fluorosis has been subject of concern, since it has been reported a tendency of increase in the prevalence of dental fluorosis all over the world. (31-35). There are some studies regarding the fluoride intake of Brazilian children by diet and dentifrice. Nevertheless, these studies analyze the total diet. $(16,17,36)$. In this study, diet was analyzed separately, in order to evaluate the individual contribution of each constituent of children diet. Diet was separated and analyzed in three distinct groups: solids, water and milk and other beverages. This separation was based on the study of Clovis, Hargreaves (28), in which water and milk were the most consumed beverages by Canadian children at the same age as children in the present study. In the study of Rojas-Sanchez et al. (14), diet was divided into two groups, separating foods and beverages. 
Mean \pm SD $(\mathrm{Cl})$ of fluoride intake from diet was $0.025 \pm 0.013(0.003-0.700) \mathrm{mg} \mathrm{F} / \mathrm{body}$ weight/day. These results are similar to the findings of Levy et al. (27), who showed a mean fluoride intake from diet of $0.029 \mathrm{mg} \mathrm{F} / \mathrm{Kg}$ body weight/day, by 2-6-year-old Brazilian children, living in Bauru. Among the diet constituents, the group of water and milk contributed significantly more to the fluoride intake from diet compared the other groups. Fluoride intake from foods and beverages ingested by 16-40-month-old children, resident in the fluoridated Indianapolis was $146 \pm 17$ and $396 \pm 52 \mu \mathrm{g}$ F/day, respectively (14). Although the children's age and the dose of fluoride intake are different in both studies, the contribution of the beverages to the fluoride intake from diet was quite similar (73\% in the study by Rojas-Sanchez (14) and $77 \%$ in the present study). According to Rojas-Sanchez et al. (14) fluoride intake from beverages is directly related to the fluoride level in the drinking water. In Brazil, the study of Levy et al. (27), shows a fluoride intake from diet of $0.55 \pm 0.61$ and $0.09 \pm 0.06 \mathrm{mg}$ F/day for 2-6-year-old children, resident in a fluoridated and in a non fluoridated community, respectively. These findings confirm the important role of water for fluoride intake from the diet. Regarding the fluoride concentration in the water samples collected in this study, it was observed a statistically significant difference between the mean of fluoride concentration found in the first and second collections. In addition, the fluoride concentrations found spanned a wide range. These findings are in agreement with previous reports showing the occurrence of fluctuations in the water fluoride levels in Bauru $(29,37)$.

Table 3 shows that fluoride intake from diet during the winter was not different from summer. The same was observed for each individual component of the diet. There are some controversies in literature about this subject. Our results are in disagreement with those observed by Lima; Cury, (38). These authors related that fluoride intake during summer and spring was statistically higher than the dose ingested during winter and fall. However, the authors had to make some calculations to get to this result, because the fluoride concentration 
of the water during the winter and fall was statistically higher than that observed during the other seasons. In Bauru, as mentioned above, fluctuations in the public water fluoride levels are common $(29,37)$, but a recent study (unpublished data) has showed no differences in water fluoride levels among the four different seasons of the year.

Also, it was not observed a statistically significant difference between fluoride intake from the diet collected in a weekday and that collected in a weekend day. These results are in agreement with the findings of Guha-Chowdhury et al., (5), who collected samples of duplicate diet during 1 year. On the other hand, Rojas-Sanchez (14) found significant differences when collected duplicate diets in 2 or 3 days over a week, being one of the days during the weekend. The authors recommended that collections should be made for 3 days over one week. However, this procedure demands more expenses and increases the chance of drop-outs of the participants along the study. Another relevant fact is that, in this study, diet contributed to only $20 \%$ of total daily fluoride intake by the children. Thus, taking into account all these factors, a single duplicate-plate collection seems to be enough when the estimation of total fluoride intake needs to be done for this age group. In addition, collecting only one duplicate plate sample is more ethical, especially for non-established market economy countries, where the dilemma of collecting duplicate diets of populations that many times starve is always arisen.

In most of the studies that estimate the total daily fluoride intake from diet and dentifrice, this is the main contributor to total fluoride intake. Our findings showed a dose of $0.106 \pm 0.085$ $\mathrm{mg} \mathrm{F} / \mathrm{Kg}$ body weight/day, which, alone, is above the recommended limit of $0.07 \mathrm{mg} \mathrm{F} / \mathrm{Kg}$ body weight/day and corresponds to $80 \%$ of the total fluoride intake by the children. According to Lima; Cury (36), this percentage was $55 \%$ and to Paiva (39), $64 \%$. One fact that may have contributed to the high amount of fluoride intake from dentifrice in the present study is the high fluoride concentration found in some dentifrices used by the children (data not shown). Values up to $1,787 \mathrm{ppm}$ were found, despite the label displayed only $1,500 \mathrm{ppm}$ fluoride. However, the 
data of fluoride intake from dentifrice may be overestimated. A recent report from Pessan et al (40), who monitored the urinary fluoride excretion of 4-7-year-old children using placebo or fluoridated dentifrices, speculated that this overestimation may be around $50 \%$, and could be explained by a conjunction of factors: differences in absorption of NaF compared to MFP (4145) reduced bioavailability if $F$ is swallowed soon after eating $(46,47)$; overestimation of brushing frequency and amount of dentifrice loaded onto the brush by mothers; loss of dentifrice from the mouth.

Figure 1 shows the strong positive correlation between the amount of dentifrice loaded onto the toothbrush and the amount of fluoride ingested during toothbrushing. Children ingested $77 \%$ of the total amount of dentifrice loaded onto the toothbrush. These results are in agreement with those found by Paiva et al. (16), where this percentage was $64.6 \%$ in a fluoridated community. Even considering that these data may be overestimated, this high fluoride intake from dentifrice is subject of concern. In addition, the cariostatic efficacy of the dentifrice is related to its topic effect and ingestion is not necessary. Considering that dentifrice is the main source of fluoride ingestion for 2-3-year-old children, which are the most susceptible for the occurrence of dental fluorosis in the permanent central maxillary incisors, it is evident the importance to instruct parents and teachers about the need to use small amounts of dentifrice during toothbrushing, since the amount of ingested dentifrice is directly related to the amount loaded onto the tooth brush. This is an important measure, but we cannot forget that nowadays in most families both parents work and people who take care of the children not always follow parents' instructions. In addition, the flavor of most children dentifrices encourages ingestion. Because of this, it has been proposed that dentifrices with lower fluoride concentrations should be developed and marketed for use by young children, as has been done in many countries, including Brazil $(47,48)$. Therefore, the ideal lower fluoride dentifrice should not only reduce 
fluoride ingestion, but also be equally effective in caries prevention as currently marketed formulations of 1,000-1,100 ppm fluoride.

Some studies have been developed in order to evaluate the efficacy of dentifrices with low fluoride concentration. Reed (49), Mitropoulos et al. (50) and Koch et al. (51) concluded that dentifrices with low fluoride concentration might be less effective than dentifrices with 1,000 ppm. The only study that evaluated the efficacy of a dentifrice with $500-550 \mathrm{ppm} F$ with kindergarten children was done by Winter et al. (52). This "double-blind" study was developed for three years and compared the effectiveness of 500-550 ppm F dentifrices in 2-year-old children, through the increment in dmft index. The group that used the 500-550 ppm F dentifrice presented an increment on caries a little higher (10\%) after 3 years, but the difference was not statistically significant. The authors concluded that dentifrices with low fluoride concentration presented an anti-caries activity similar to control dentifrice and, so, could be recommended to young children. However, this conclusion was based only on one study and additional longitudinal randomized clinical trials should be made on this topic.

In order to predict the risk of dental fluorosis, before its occurrence, the possible use of biomarkers of fluoride exposure, as fingernails, has been studied (21-27).

In a recent study (26), 2-3-year-old Brazilian children used a placebo dentifrice for a period, followed by a period using fluoridated dentifrice (1500 ppm). It was observed a 3-fold increase in nails fluoride concentrations after the use of fluoridated dentifrice. However, the authors did not estimate the dose of fluoride intake from diet and dentifrice. The results of the present study, showing a contribution of $80 \%$ of fluoridated dentifrice for the total fluoride intake, could help to explain the increase in nails fluoride concentrations reported by Rodrigues et al. (26).

There are some reports in the literature showing that nails can be used as biomarkers to differentiate children exposed to different levels of fluoride from water $(25,27,53,54)$. However, 
in our study, there was no correlation between the daily dose of fluoride intake and fingernails fluoride concentration. However, in this study all the children were exposed to the same conditions, although there were individual variations on the amount of daily fluoride intake. Thus, the question of sensibility and specificity arises when it is intended to use nails as biomarkers of fluoride exposure and predictors for dental fluorosis. It is possible that nails could only be used to differ levels of fluoride exposure, when they are very discrepant. In fact, Sampaio et al. (55), attempting to validate fingernails fluoride concentration as a biomarker of fluoride exposure, examined to dental fluorosis children resident at the State of Paraíba, Brazil, where the natural levels of fluoride in the drinking water are $0.1,1.6$ and $2.3 \mathrm{mg} \mathrm{F} / \mathrm{mL}$. These children had been previous examined with regard to fluoride concentration of fingernails (25). The mean fluoride concentration of fingernails of children that presented TF 0 was statistically different of mean fluoride concentration of fingernails of children that presented TF 5. Nevertheless, this statistical difference was not observed in children with TF 1, 2, 3 and 4. Our results seems to be in agreement to the findings of Sampaio et al. (55), denoting that small variations on the daily dose of fluoride intake cannot be detected in fingernails.

Another important factor is a possible genetic susceptibility to dental fluorosis, already demonstrated in different mice strains by Everett et al. (56). Despite this has not been demonstrated in humans so far, there are some reports on the occurrence of dental fluorosis with lower levels of fluoride intake (0.02 mg F/body weight/day) (7), which could indicate that this individual susceptibility to fluoride also occurs in humans.

A finding of this study that seems difficult to be explained is the reduction in fingernails fluoride concentrations in the second collection. In the report by Levy et al. (27), these differences among samples collected in different dates were not observed, although the smaller sample number $(n=15)$. One fact that may have contributed to this reduction was that after the first estimation of fluoride intake, parents received instructions regarding the use of fluoridated 
dentifrices. This may have had an immediate impact on fluoride intake from dentifrice, causing a reduction in fingernail fluoride concentration. The fluctuations in public water fluoride levels reported in Bauru $(29,37)$ can partially help to explain this difference. However, this is limited, since the diet has a low contribution to the total fluoride intake. Thus, more studies should be made in order to evaluate the viability of fingernails use as biomarkers of chronic fluoride exposure, as well as the sensitivity and specificity of this method as a predictor of dental fluorosis.

In conclusion, the mean dose of total fluoride intake $(0.13 \pm 0.087 \mathrm{mg} \mathrm{F} / \mathrm{Kg}$ body weight/day) was a little higher than the dose found by Arsati (53) $(0.084 \pm 0.032 \mathrm{mg} \mathrm{F} / \mathrm{Kg}$ body weight/day) and by Paiva et al. (16) (0.88 \pm 0.049 and $0.090 \pm 0.022 \mathrm{mg} \mathrm{F} / \mathrm{Kg}$ body weight/day) for Brazilian children of the same age. Rojas-Sanchez (14), related a mean fluoride intake of $0.070 \pm 0.007 \mathrm{mg} \mathrm{F} / \mathrm{Kg}$ body weight/day, by American 16-40-month-old children, resident in a fluoridated community. In another study, with Japanese 3-5-year-old children (15), the mean dose of fluoride intake was much smaller $(0.021 \pm 0.012 \mathrm{mg} \mathrm{F} / \mathrm{Kg}$ body weight/day) than the one observed in this study. Considering $0.05-0.07 \mathrm{mg} \mathrm{F} / \mathrm{Kg}$ body weight/day (6) as the safe limit of fluoride intake in terms of dental fluorosis, 24 out of 33 children of the present study are at risk for dental fluorosis. Considering that most of the dentifrices used by the children contained $1,500 \mathrm{ppm} \mathrm{F}$, the use of dentifrice with $500 \mathrm{ppm} F$ would decrease the dose of fluoride intake from dentifrice to $0.035 \mathrm{mg} \mathrm{F} / \mathrm{Kg}$ body weight/day. Adding this dose to the dose of fluoride intake from diet of $0.025 \mathrm{mg} \mathrm{F} / \mathrm{Kg}$ body weight/day, would result in a dose of $0.060 \mathrm{mg} \mathrm{F} / \mathrm{Kg}$ body weight/day, which is acceptable according to the threshold of $0.05-0.07 \mathrm{mg} \mathrm{F} / \mathrm{Kg}$ body weight/day (6). Considering the possibility of overestimation of the data of fluoride intake from dentifrice, the total amount of fluoride intake could be even lower.

\section{ACKNOWLEDGEMENTS}


This study was partially supported by FAPESP. We thank all participants, children's parents and staff of the daycare centers for their help during the study.

\section{REFERENCES}

1. Buzalaf MAR, Cury JA, Whitford GM. F exposures and dental fluorosis: a literature review. Rev. Fac. Odont. Bauru 2001; 9 (1/2): 1-10.

2. Cangussu MC, Castellanos RA, Pinheiro MF, de Albuquerque SR, Pinho C. Dental caries in 12- and 15-year-old schoolchildren from public and private schools in Salvador, Bahia, Brazil, in 2001 Pesqui Odontol Bras, 2002;16(4):379-84.

3. Brasil, Health Bureau of State. Project SB Brasil 2003. Oral health conditions of Brazilian people 2002-2003. Brasília - DF. 52p.(in Portuguese)

4. Evans RW, Darvell BW. Refining the estimate of the critical period for susceptibility to enamel fluorosis in human maxillary central incisors. J. Publ. Hlth. Dent 1995; 55 (4): 238-49.

5. Guha-Chowdhury N, Drummond BK, Smillie AC. Total F intake in children aged 3 to 4 years - a longitudinal study. J. dent. Res 1996; 75 (7): 1451-7.

6. Burt BA. The changing patterns of systemic F intake. J. dent. Res 1992; 71 (5): 122837.

7. Baelum V, Ferjeskov O, Manji F, Larsen MJ. Dose of $F$ and dental fluorosis. Tandlaegebladet 1987; 91 (10): 452-6. 
8. Bawden JW, Deaton TG, Crenshaw MA. Role of the enamel organ in limiting fluoride uptake during the maturation phase of enamel development. J Dent Res, 1982; 61(3):506-9.

9. Bawden JW, Deaton TG, Crenshaw MA. Diffusion of fluoride through the rat enamel organ in vitro. J Dent Res, 1987; 66(8):1360-3.

10. Bawden JW, Crenshaw MA. Effect of inhibition of net calcium uptake on net fluoride uptake in developing rat molars. J Dent Res, 1984; 63(5):642-5.

11. Speirs RL. The relationship between fluoride concentrations in serum and in mineralized tissues in the rat. Arch Oral Biol, 1986;31(6):373-81.

12. Aoba T, Moreno EC. The enamel fluid in the early secretory stage of porcine amelogenesis: chemical composition and saturation with respect to enamel mineral. Calcif Tissue Int, 1987; 41(2):86-94.

13. Whitford GM. The metabolism and toxicity of fluoride. 2.ed. Basel: Karger, 1996.

14. Rojas-Sanchez F, Kelly SA, Drake KM, Eckert GJ, Stookey GK, Dunipace AJ. Fluoride intake from foods, beverages and dentifrice by young children in communities with negligible and optimally fluoridated water: a pilot study. Community Dent Oral Epidemiol, 1999; 27 (4): 288-97.

15. Murakami T, Narita N, Nakagaki H, Shibata T, Robinson C. Fluoride intake in Japanese children aged 3-5 years 93.by the duplicate-diet technique. Caries Res, 2002; 36 (6): 386-90.

16. Paiva SM, Lima YBO, Cury JA. Fluoride intake by Brazilian children from two communities with fluoridated water. Community Dent Oral Epidemiol, 2003; 31 (3): 18491. 
17. Pessan JP, Silva SMB, Buzalaf MAR. Evaluation of the total fluoride intake of 4-7-yearold children from diet and dentifrice. J Appl Oral Science Bauru, 2003; 11 (2): 150-156.

18. Clarkson, JJ. International collaborative research on fluoride. J Dent Res, 2000; 79 (4):893-904.

19. Schamschula RG, Sugar E, Un PS, Toth K, Barmes DE, Adkins BL. Physiological indicators of fluoride exposure and utilization: an epidemiological study. Community Dent Oral Epidemiol, 1985; 13 (2):104-7.

20. Macchoy, Z. Effects of environment upon fluoride in nails in children. Fluoride, 1989; 22 (4): 169-73.

21. Czarnowski W, Krechniak J. Fluoride in the urine, hair, and nails of phosphate fertilizer workers. Brit J Ind Med, 1990; 47:349-51.

22. Schmidt CW, Leuschke W. Fluoride content in finger nails of individuals with and without chronic fluoride exposure. Fluoride, 1990; 23:79-82.

23. Spate VL, Morris JS, Baskett CK, Mason MM, Reams CL, Hunter D et al. Determination of fluoride in human nails via cyclic instrumental neutron activation analysis. $J$ Radioanalyt Nucl Chem, 1994; 170:27-33.

24. Czarnowski W, Stolarska K, Brzezinska B, Krechniak J. Fluoride in drinking water an human urine in northern and central Poland. Sci Total Environ, 1996; 191 (1/2): 177-84.

25. Whitford GM, Sampaio FC, Arneberg P, von de Fehr FR. Fingernail fluoride: a method for monitoring fluoride exposure. Caries Res, 1999; 33:462-7.

26. Rodrigues MHC, Bastos JRM, Buzalaf MAR. Fingernails and toenails as biomarkers of subchronic exposure to fluoride from dentifrice in 2- to 3-year-old children. Caries Res, 2004; 38 (2): 109-14.

27. Levy FM, Bastos JRM, Buzalaf MAR. Nails as biomarkers of chronic exposure to fluoride from the diets of children in negligibly and optimally fluoridated communities. $J$ Dent Children, 2004; 71 (2): 121-5. 
28. Clovis J, Hargreaves JA. F intake from beverage comsumption. Community Dent. oral Epidem 1988; 16 (1):11-5.

29. Buzalaf MAR, Granjeiro JM, Damante CA, Ornelas F. Fluctuations in public water F level in Bauru. Brazil. J. Publ. HIth. Dent 2002; 62 (3): 173-6.

30. Taves DR. Separation of F by rapid diffusion using hexamethyldisiloxane. Talanta 1968; 15: 969-74,

31. Jackson RD, Kelly SA, Katz B, Brizendine E, Stookey GK. Dental fluorosis in children residing in communities with different water fluoride levels: 33-month follow-up. Pediatr Dent, 1999; 21 (4): 248-54.

32. Leverett $\mathrm{DH}$. Prevalence of dental fluorosis in fluoridated and in non-fluoridated communities-a preliminary investigation. J Public Health Dent, 1986; 46:184-7.

33. Tabari ED, Ellwood R, Rugg-Gunn AJ, Evans DJ, Davies RM. Dental fluorosis in permanent incisor teeth in relation to water fluoridation, social deprivation and toothpaste use in infancy. Br Dent J, 2000; 189 (4): 216-20.

34. Tsutsui A, Yagi M, Horowitz AM. The prevalence of dental caries and fluorosis in japanese communities with up to $1.4 \mathrm{ppm}$ of naturally occurring fluoride. J Public Health Dent, 2000; 60 (3): 147-53.

35. Pereira AC, Cunha FL, Meneghim MC, Werner CW. Dental caries and fluorosis prevalence study in a nonfluoridated Brazilian community: trend analysis and toothpaste association. ASDC J Dent Child, 2000; 67 (2): 132-5.

36. Lima Y B O, Cury JA. Ingestão de flúor por crianças pela água e dentifrício. Rev Saúde Pública, 2001; 35 (6): 576-81.

37. Buzalaf MA, Levy FM, Rodrigues MH, Bastos JR. Effect of domestic water filters on water fluoride content and level of the public water supply in Bauru, Brazil. J Dent Child (Chic). 2003; 70(3):226-30. 
38. Lima YBO, Cury JA. Seasonal variation of fluoride intake by children in a subtropical region. Caries Res, 2003; 37 (5): 335-8.

39. Paiva SM. Ingestão total de flúor através da dieta e de dentifrícios: determinação da dose em relação ao risco de fluorose dental. São Paulo, 1999. 59p. Tese (Doutorado) - Universidade de São Paulo, Faculdade de Odontologia.

40. Pessan JP, Pin MLG, Martinhon CCR, Silva SMB, Granjeiro JM, Buzalaf MAR. Analysis of fingernails and urine as biomarkers of fluoride exposure from dentifrice and varnish in 4-7-year-old children. Caries Res 2004 (in press).

41. Trautner K, Einwag J. Influence of milk and food on fluoride bioavailability from $\mathrm{NaF}$ and $\mathrm{Na}_{2} \mathrm{FPO}_{3}$ in man. J Dent Res 1989; 68:72-77.

42. Ekstrand J, Ehrnebo M. Absorption of fluoride from fluoride dentifrices. Caries Res 1980; 14:96-102.

43. Forsman B, Ericsson Y. Fluoride absorption from swallowed fluoride toothpaste. Community Dent Oral Epidemiol 1973; 1:115-120.

44. Drummond BK, Curzon MEJ. Urinary excretion of fluoride following ingestion of MFP toothpastes by infants aged two to six years. J Dent Res $1985 ; 64: 1145-1148$.

45. Drummond BK, Curzon MEJ, Strong M. Estimation of fluoride absorption from swallowed fluoride toothpastes. Caries Res 1990; 24:211-215.

46. Trautner K, Siebert G. An experimental study of bioavailability of fluoride from dietary sources in man. Arch Oral Biol 1986; 31:223-228.

47. Beltran ED, Szpunar SM. Fluoride in toothpastes for children: suggestions for change. Pediatr. Dent., 1988; 10:185-8.

48. Horowitz HS. The need for toothpastes with lower than conventional fluoride concentrations for preschool-aged children. J. Public Health Dent., 1992; 52:216-21. 
49. Reed MW. Clinical evaluation of three concentrations of sodium fluoride in dentifrices. $J$ Am Dent Ass, 1973; 87 (7): 1401-5.

50. Mitropoulos CM, Holloway PJ, Davies TGH, Worthington HV. Relative efficacy of dentifrices containing 250 or 1000 ppm F in preventing dental caries - report of a 32month clinical trial. Community Dent Health, 1984; 1: 193-200.

51. Koch G. Caries preventive effect of fluoride dentifrices with and without anticalculus agents: a three-year control clinical trial. Caries Res, 1990; 24: 72-9.

52. Winter GB, Holt RD, Williams B. Clinical trial of a low-fluoride toothpaste for young children. Int Dent J, 1989; 39 (4): 227-35.

53. Arsati YBOL. A unha como indicador biológico de exposição a fluoreto para prever risco de fluorose dental. Piracicaba, 2003. 75p. Tese (Doutorado) - Faculdade de Odontologia de Piracicaba, Universidade de Campinas.

54. Fukushima R, Sampaio FC, Buzalaf, MAR. Unha como biomarcador de exposição crônica ao flúor através da água. Braz Oral Res, 2004; 18:170, Supll (21 ${ }^{\text {st }}$ Annual SBPqO Meeting)/ abstract n. Pb106/

55. Sampaio FC, Whitford GM, Arneberg P, von der Fehr FR. Validation of fingernail fluoride as a biomarker for dental fluorosis. Caries Res, 2003; 37:291-2, IAbstract n. 72/

56. Everett ET, McHenry MA, Reynolds N, Eggertsson H, Sullivan J, Kantmann C, et al. Dental fluorosis: variability among different inbred mouse strains. J Dent Res, 2002; 81 (11): 794-8. 
Table 1: Mean, SD, minimum, maximum and $95 \% \mathrm{Cl}$ of the fluoride intake by children $(\mathrm{mg} \mathrm{F} / \mathrm{kg}$ body weight/day, $n=33$ ) from diet, dentifrice and the total (diet + dentifrice)

\begin{tabular}{lccc}
\hline Ingested F & Diet & Dentifrice & Total \\
\hline Mean & $0.025^{\mathrm{a}}$ & $0.106^{\mathrm{b}}$ & 0.130 \\
$\mathrm{SD}$ & 0.013 & 0.085 & 0.087 \\
Minimum & 0.003 & 0.004 & 0.027 \\
Maximum & 0.070 & 0.401 & 0.413 \\
95\% Cl & $0.021-0.029$ & $0.076-0.137$ & $0.104-0.165$ \\
\hline${ }^{*}$ Means followed by different letters are statistically significant $(\mathrm{p}<0.0001)$.
\end{tabular}


Table 2: Mean, SD, minimum, maximum and $95 \% \mathrm{Cl}$ of the fluoride intake (mg F/day) by children $(n=33)$ from solids, water and milk, and other beverages.

\begin{tabular}{llc}
\hline Components of diet & & Ingested F $(\mathbf{m g}$ F/dia) \\
\hline Solids & Mean & $0.072^{\mathrm{a}}$ \\
& SD & 0.045 \\
& Minimum & 0.013 \\
& Maximum & 0.185 \\
& $95 \% \mathrm{Cl}$ & $0.056-0.088$ \\
\hline Water and milk & Mean & $0.184^{\mathrm{b}}$ \\
& SD & 0.108 \\
& Minimum & 0.002 \\
& Maximum & 0.485 \\
& $95 \% \mathrm{Cl}$ & $0.146-0.222$ \\
\hline Other beverages & Mean & $0.066^{\mathrm{a}}$ \\
& SD & 0.043 \\
& Minimum & 0.002 \\
& Maximum & 0.171 \\
& $95 \% \mathrm{Cl}$ & $0.050-0.081$ \\
\hline
\end{tabular}

${ }^{*}$ Means followed by different letters are statistically significant $(p<0.0001)$. 
Table 3: Mean, standard deviation, minimum, maximum and $95 \% \mathrm{Cl}$ of the fluoride intake by children (mg F/day, $n=33$ ) from solids ( $S$ ), water and milk (WM), other beverages (B) and the total diet (D), during the two periods of collection: winter (1) and summer (2).

\begin{tabular}{|c|c|c|c|c|c|c|c|c|}
\hline $\begin{array}{c}\text { Ingested } \\
\text { F }\end{array}$ & S1 & S2 & WM1 & WM2 & B1 & B2 & D1 & D2 \\
\hline Mean & 0.071 & 0.082 & 0.199 & 0.171 & 0.065 & 0.067 & 0.318 & 0.296 \\
\hline SD & 0.058 & 0.062 & 0.157 & 0.091 & 0.052 & 0.054 & 0.208 & 0.142 \\
\hline Minimum & 0.004 & 0.008 & 0.002 & 0.025 & 0.002 & 0.003 & 0.006 & 0.075 \\
\hline Maximum & 0.219 & 0.291 & 0.627 & 0.379 & 0.236 & 0.251 & 0.714 & 0.720 \\
\hline $95 \% \mathrm{Cl}$ & $\begin{array}{c}0.050- \\
0.091\end{array}$ & $\begin{array}{c}0.060- \\
0.104\end{array}$ & $\begin{array}{c}0.142- \\
0.253\end{array}$ & $\begin{array}{c}0.138- \\
0.203\end{array}$ & $\begin{array}{c}0.047- \\
0.084\end{array}$ & $\begin{array}{c}0.048- \\
0.087\end{array}$ & $\begin{array}{c}0.240- \\
0.396\end{array}$ & $\begin{array}{c}0.243- \\
0.349\end{array}$ \\
\hline
\end{tabular}


Table 4: Mean, SD, minimum, maximum and $95 \% \mathrm{Cl}$ of the amount of dentifrice used $(\mathrm{g})$, total fluoride (mg) and ingested fluoride (mg), for each tooth brushing.

\begin{tabular}{lccc}
\hline & Dentifrice & Total F & ingested F \\
\hline Mean & 0.488 & 0.763 & 0.591 \\
SD & 0.303 & 0.502 & 0.445 \\
Minimum & 0.040 & 0.044 & 0.011 \\
Maximum & 1.320 & 0.656 & 1.759 \\
$\mathbf{9 5 \%}$ Cl & $0.418-0.559$ & $0.647-0.879$ & $0.488-0.694$ \\
\hline
\end{tabular}




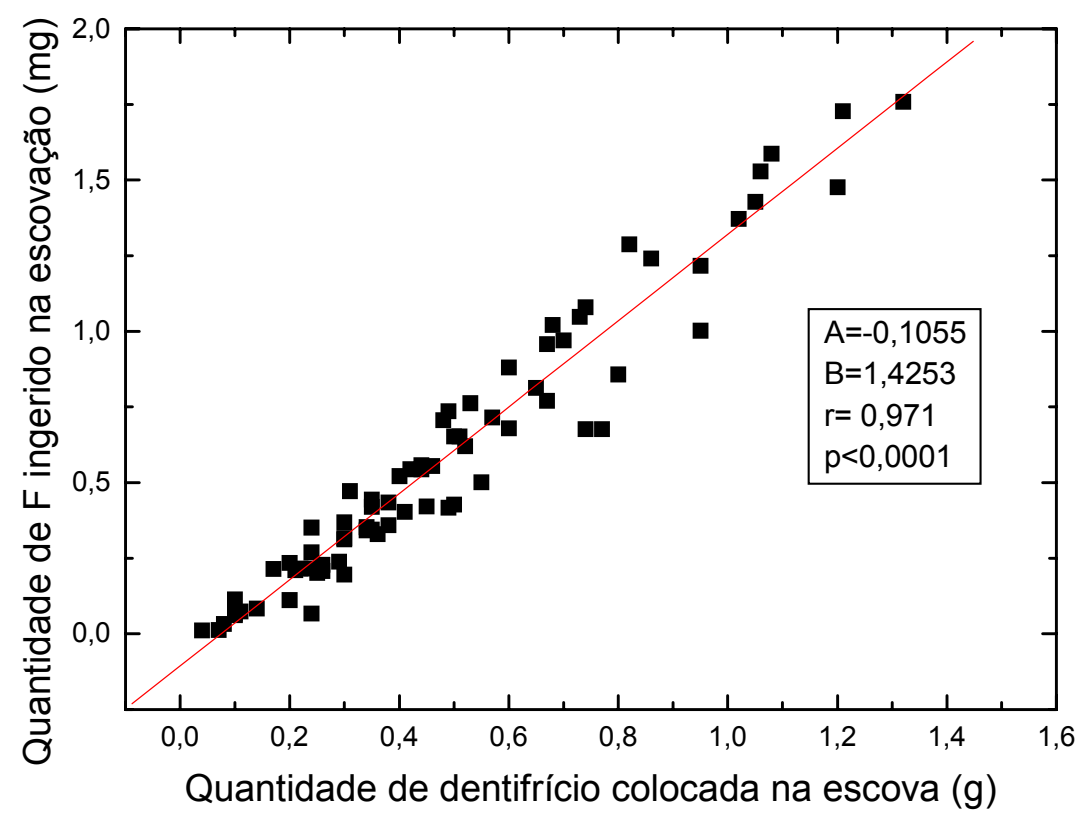

Figure 1: Correlation between the amount of dentifrice loaded onto the toothbrush $(\mathrm{g})$ and the amount of fluoride ingested $(\mathrm{mg})$ for each toothbrushing. 